Engineer Research and

Development Center

Navigation Systems Research Program

\title{
Assessing Corrosion Damage and Corrosion Progression in Multistrand Anchor Systems in Use at Corps Projects
}

Robert M. Ebeling, Ralph W. Strom, John E. Hite Jr., July 2013

Richard W. Haskins, and James A. Evans

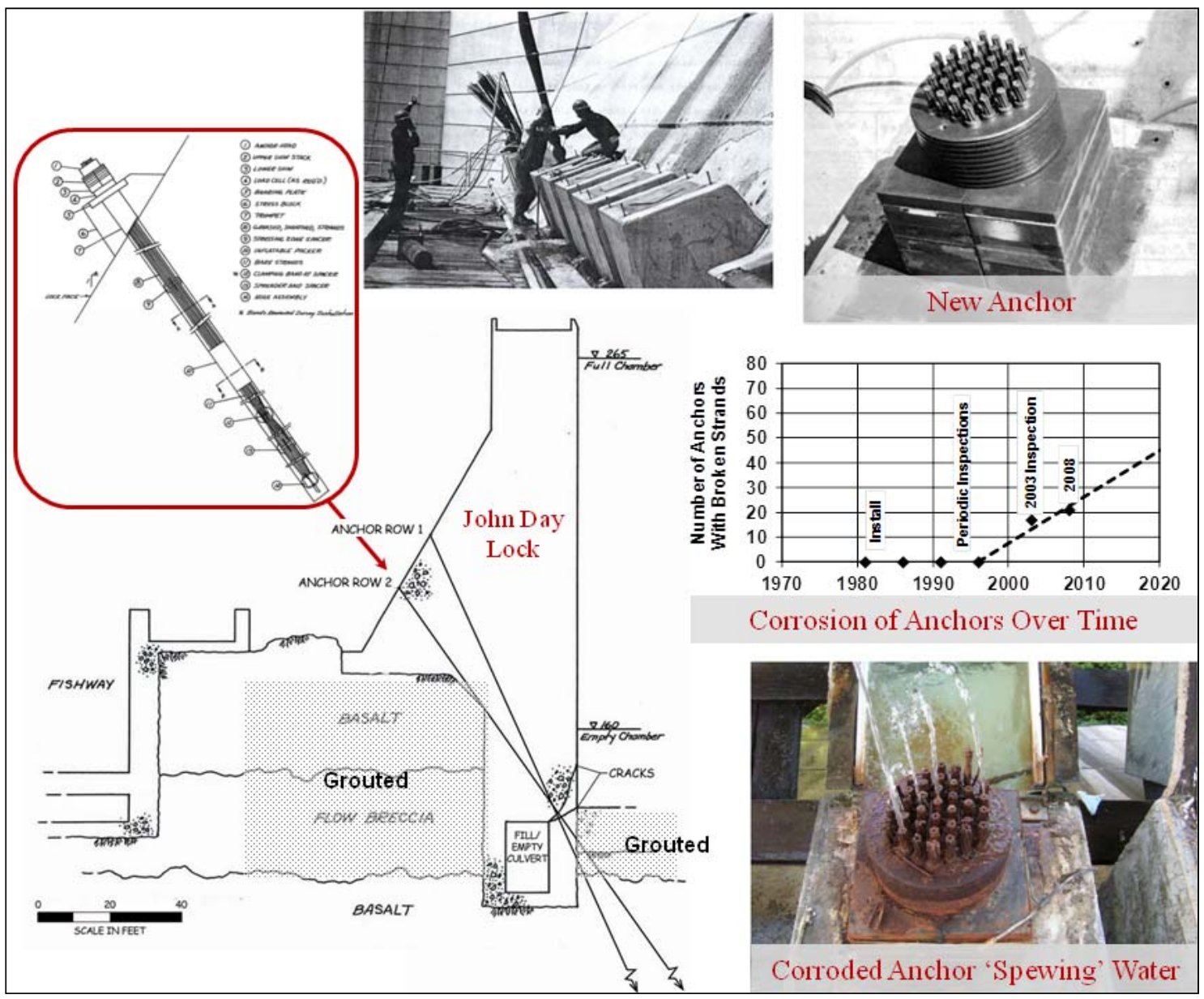


The US Army Engineer Research and Development Center (ERDC) solves the nation's toughest engineering and environmental challenges. ERDC develops innovative solutions in civil and military engineering, geospatial sciences, water resources, and environmental sciences for the Army, the Department of Defense, civilian agencies, and our nation's public good. Find out more at www.erdc.usace.army.mil.

To search for other technical reports published by ERDC, visit the ERDC online library at http://acwc.sdp.sirsi.net/client/default. 


\section{Assessing Corrosion Damage and Corrosion Progression in Multistrand Anchor Systems in Use at Corps Projects}

Robert M. Ebeling, Richard W. Haskins, and James A. Evans

Information Technology Laboratory

US Army Engineer Research and Development Center

3909 Halls Ferry Road

Vicksburg, MS 39180-6199

John E. Hite Jr.

Coastal and Hydraulics Laboratory

US Army Engineer Research and Development Center

3909 Halls Ferry Road

Vicksburg, MS 39180-6199

Ralph W. Strom

9474 S.E. Canaby Way

Happy Valley, OR 97086

Final report

Approved for public release; distribution is unlimited.

Prepared for Headquarters, US Army Corps of Engineers

441 G. Street, NW

Washington, DC 20314-1000

Under Work Unit 7J048B 


\section{Abstract}

Stressed steel tendons have been used to strengthen hydraulic structures and to improve their serviceability and stability. Over the past three decades, the US Army Corps of Engineers has worked to upgrade its projects by installing high-capacity, post-tensioned foundation anchors. The goal has been to achieve structural stability for Corps hydraulic concrete structures and/or to remediate cracked concrete monoliths. Substantial improvements to protect multistrand anchor systems from corrosion have been made since they were first used at Corps projects more the 50 years ago. Corrosion of older multistrand units is of concern.

Researchers at the US Army Engineer Research and Development Center (ERDC) are looking to develop engineering procedures to estimate the current state of load-carrying capacity of the ground anchorage, to estimate remaining life of the tendon, and to establish the deterioration of anchorage capacity (with time) so costly replacement of ground anchorage can be delayed until absolutely needed. Analytical, laboratory, and field-testing efforts will be used to develop a methodology and analytical models. Probabilistic procedures will be used to quantify uncertainties for the primary variables and will be carried into the analytical model. Procedures to extend the life of deteriorating multistrand tendons also will be investigated.

A review of Corps projects using multistrand anchors and a literature review of corrosion of the anchors are summarized in this report. Also included are the history and performance of the multistrand anchors at the John Day Navigation Lock (Columbia River, Portland District), along with postinstallation lift-off test results. A summary of a review of nondestructive testing (NDT) to identify defects in the anchors is part of this report, too.

DISCLAIMER: The contents of this report are not to be used for advertising, publication, or promotional purposes. Citation of trade names does not constitute an official endorsement or approval of the use of such commercial products. All product names and trademarks cited are the property of their respective owners. The findings of this report are not to be construed as an official Department of the Army position unless so designated by other authorized documents. 


\section{Contents}

Abstract................................................................................................................................... ii

Figures and Tables............................................................................................................vi

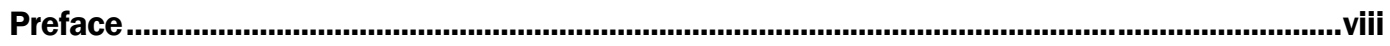

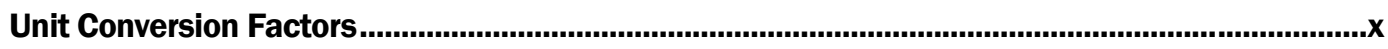

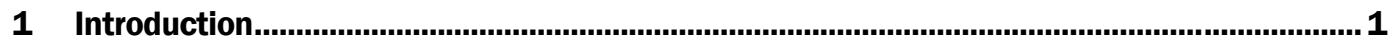

1.1 Statement 0

1.2 Technical objectives ......................................................................................... 2

1.3 Plan for achieving technical objectives ............................................................. 3

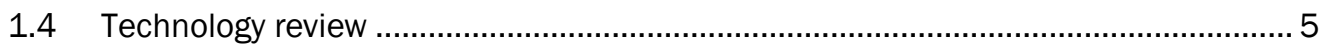

2 Post-Tensioning Systems' Use at Corps Projects .................................................................... 7

2.1 The Dalles Dam training wall ...................................................................... 7

2.2 Bluestone Dam ................................................................................................... 8

2.3 Miller's Ferry Lock, Holt Lock, and Snell and Eisenhower Locks............................... 8

2.4 John Day Navigation Lock .............................................................................. 10

3 Unbonded vs. Fully Bonded Anchor Systems ..............................................................12

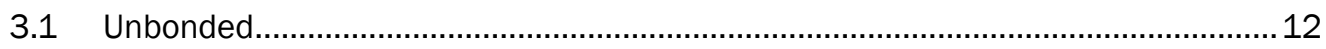

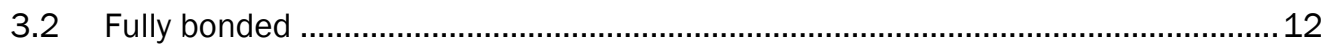

4 Types of Tendon Corrosion ..................................................................................................13

4.1 Uniform corrosion .................................................................................. 13

4.2 Localized corrosion and pitting corrosion ................................................... 13

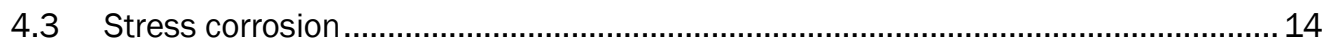

4.4 Hydrogen embrittlement .................................................................................. 14

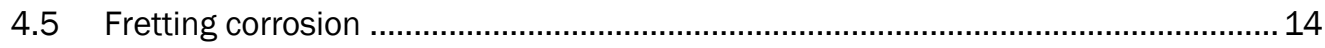

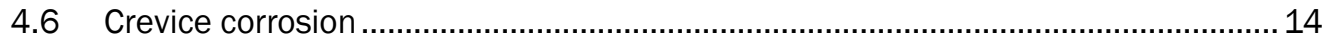

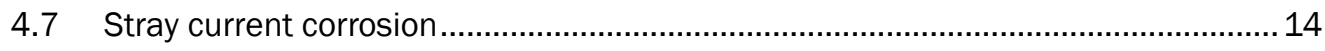

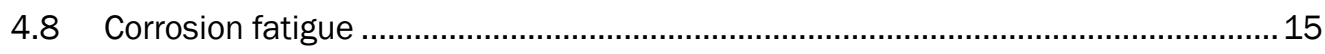

5 Historical Perspective: Post-Tensioned Corrosion Protection.............................................16

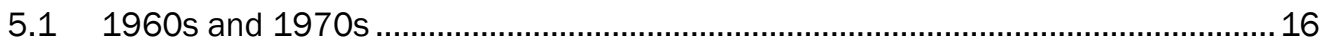

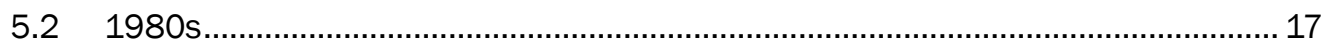

5.3 Current methodologies....................................................................................... 17

5.4 Delaware Lake Spillway anchor corrosion testing ................................................20

5.5 Effect of pitting corrosion on capacity of prestressing wires ...................................22

6 Lessons from John Day Navigation Lock Post-Tensioned Corrosion .................................23

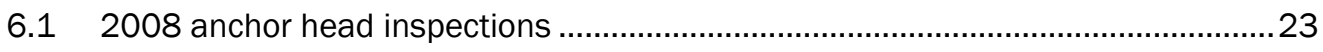

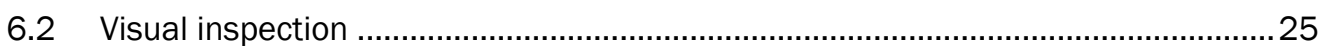


6.3 Conclusions from Cornforth Consultants (2009) ……..........................................26

6.4 Latest condition of John Day anchor .............................................................. 27

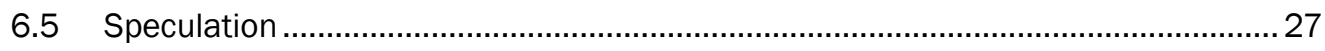

6.5.1 Water penetration along tendons ..................................................................2

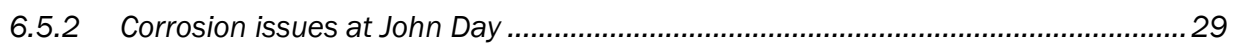

6.5.3 Center strand corrosion failures..........................................................................29

6.6 ERDC-recommended field tests for John Day multistrand anchors........................... 31

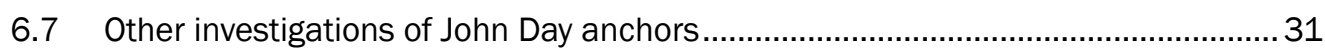

6.8 Initial results of John Day anchor head disassemblies ...........................................33

7 Nondestructive Testing (NDT) Methods to Detect Anchor System Defects ..........................39

7.1 1999 National Cooperative Highway Research Program NDT technology

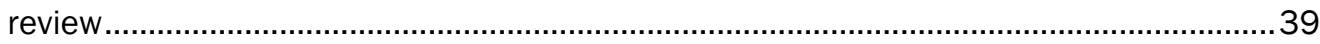

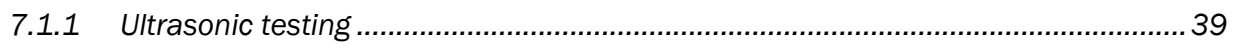

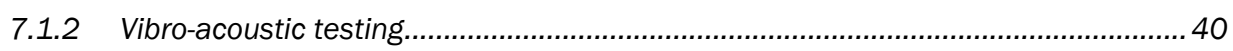

7.1.3 Acoustic emission testing................................................................................... 40

7.1.4 Guided Ultrasonic Waves (GUWs) ................................................................... 40

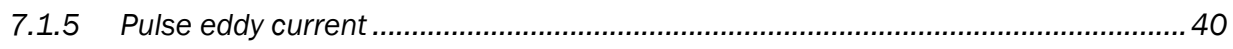

7.1.6 Electrical time domain reflectometry (ETDR) ……….......................................40

7.1.7 Magnetostrictive sensors ......................................................................... 41

7.1.8 Magnetic flux leakage................................................................................. 41

7.1.9 Power-focusing, ground-penetrating radar........................................................ 41

7.21999 NCHRP technical review conclusions............................................................... 41

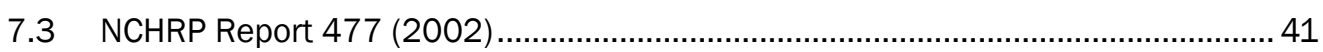

7.4 Other relevant NDT publications..................................................................... 42

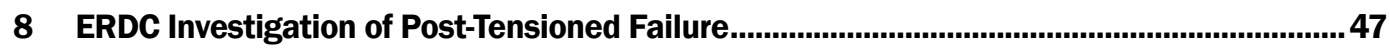

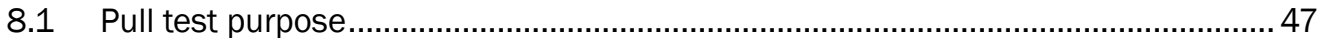

8.2 Overview of post-tensioning corrosion and defects ................................................. 47

8.3 Blunt defects such as lab saw cuts and stress concentration factors ......................49

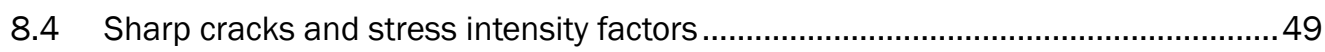

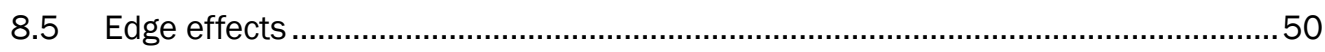

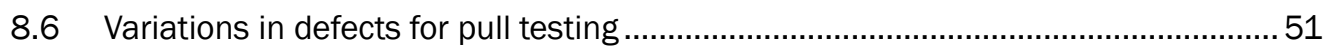

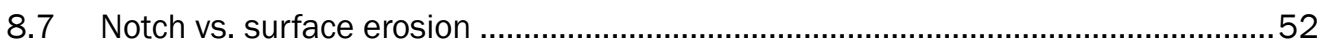

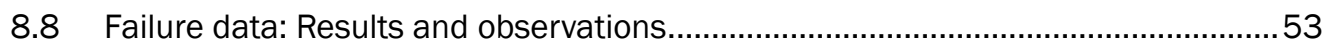

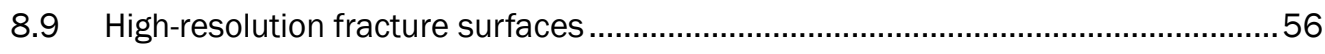

8.10 Correlation of laboratory and field observations of exposed ends...........................5 57

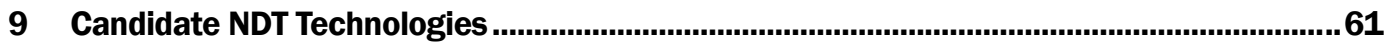

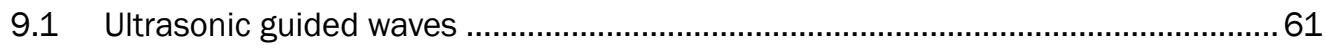

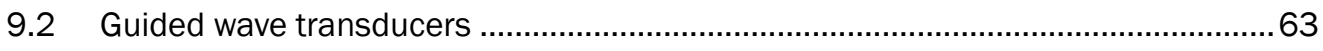

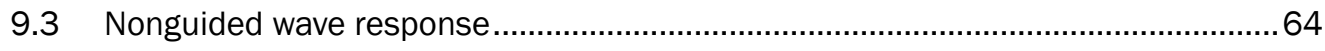

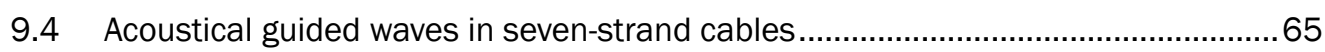

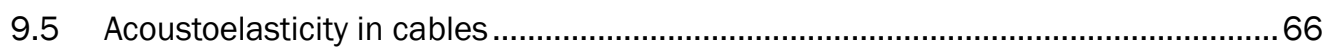

9.6 Notch frequency and other waveguide effects .....................................................6

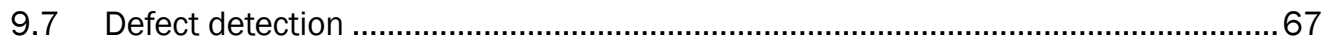

9.8 Preliminary ERDC measurements of seven-strand cable .......................................70 


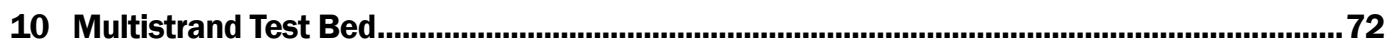

References............................................................................................................................... 75

Appendix A: Pull Test Data................................................................................................................82

Appendix B: Literature Search of Methods Suitable for Use in Predicting Corrosion

Damage and Progression.

Report Documentation Page 


\section{Figures and Tables}

\section{Figures}

Figure 2-1. The Dalles training wall remediation with vertical anchors. ............................................ 7

Figure 2-2. Bluestone anchor repair to prevent sliding. ................................................................... 8

Figure 2-3. Remediation for locks with cracks initiating at an internal culvert. ................................. 9

Figure 2-4. Remediation of John Day culvert cracks. ……............................................................ 10

Figure 4-1. Electrolytic corrosion of anchor wire. ..................................................................... 13

Figure 5-1. Class I Protection for dead end anchor zone. .............................................................. 17

Figure 5-2. Examples of corrosion protection for Class I and Class II strand tendons ..................... 18

Figure 5-3. Examples of corrosion protection for Class I and Class II bar tendons............................19

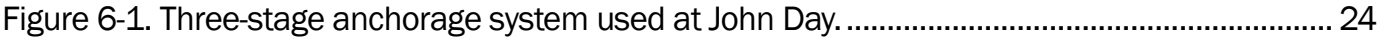

Figure 6-2. Examples of configuration, placement, and current testing techniques........................ 24

Figure 6-3. Performance of anchors during lift-off tests and evidence of corrosion. .........................2 25

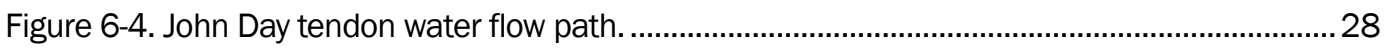

Figure 6-5. Covered anchor head at John Day. …………..........................................................

Figure 6-6. Anchor head before removing shim stack................................................................. 34

Figure 6-7. Wet grease with rust and possibly mildew contamination (top) and the voided

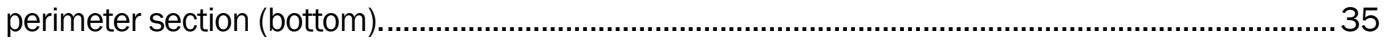

Figure 6-8. Anchor head removed for shipment to ERDC-Vicksburg................................................36

Figure 6-9. Water flowing up yellow tubes during lockages ...............................................................36

Figure 6-10. Water exits anchor heads through wedges and missing king wires............................... 37

Figure 6-11. Grease with lower contamination. ........................................................................... 37

Figure 6-12. Cable sheaths with no signs of deterioration .................................................................38

Figure 6-13. No grout detected in anchor heads that were disassembled......................................38

Figure 7-1. Half-cell potential measurement. ................................................................................... 44

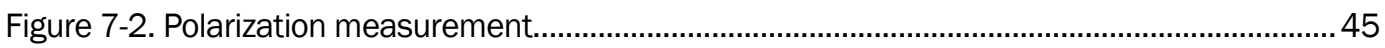

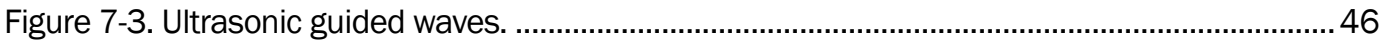

Figure 8-1. Machine used for cable pull test. ................................................................................ 48

Figure 8-2. Common perimeter wire failure at wedge tip............................................................52

Figure 8-3. One-sided notch area vs. circumference loss. ...............................................................53

Figure 8-4. Typical seven-strand load-vs.-displacement curve for swk (Test 10). .............................54

Figure 8-5. Stress for swk (Test 10) determined by changing cross-sectional area as

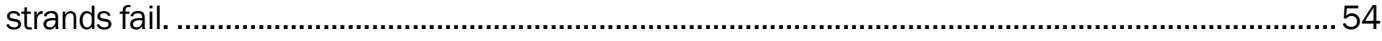

Figure 8-6. Tensile strength from a notch at various locations, depth, and wires. ...........................55

Figure 8-7. Images of (a) cup failure and (b) cone failure with (c) high resolution........................... 57

Figure 8-8. Images of shear failure: (a) section view, (b) side view, and (c) high-resolution view............. 58

Figure 8-9. Failure images from a notched sample: (a) section view, (b) side view, and (c) high-resolution view. 
Figure 8-10. Displacement past the wedge seen in pull testing. .................................................. 60

Figure 8-11. Cable unwinding due to energy release after failure. .................................................60

Figure 9-1. (a) Coiled cable with transmitter and receiver on each end; (b) measurement's first peak is through transmission and the second is through echo............................................... 71

Figure 10-1a. Side view of framing for test bed. ………………………………………....... 72

Figure 10-1b. End view of test bed with reinforcement rebar............................................................ 72

Figure 10-2. Test bed design with strand support hardware shown............................................... 73

Figure 10-3. Stressing tool similar to the multistrand one............................................................

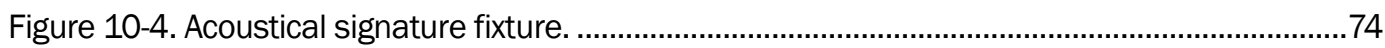

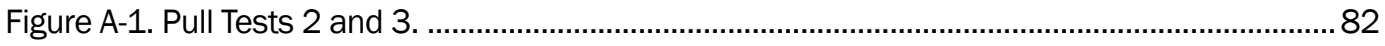

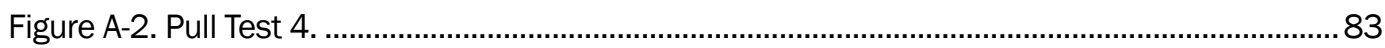

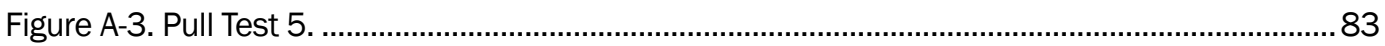

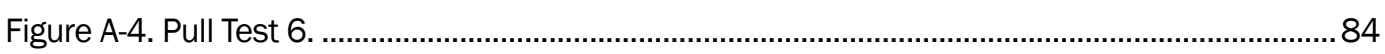

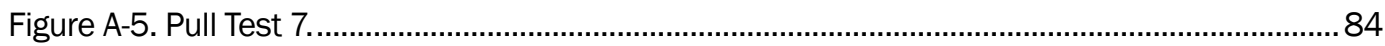

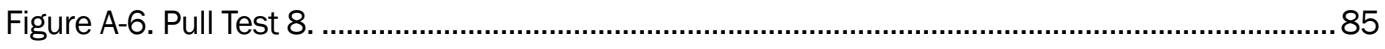

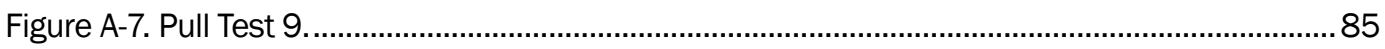

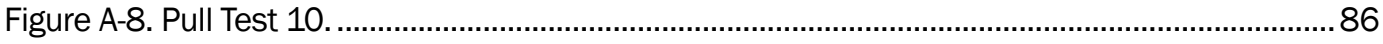

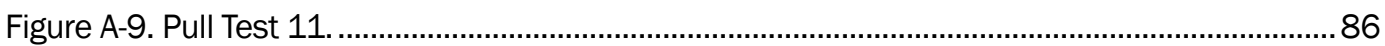

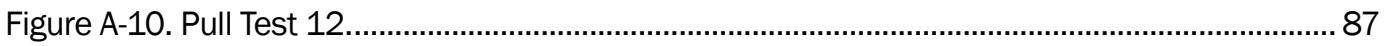

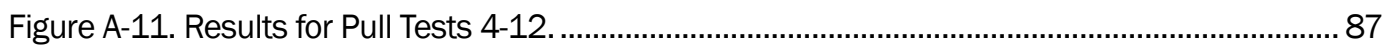

Figure A-12. Pressure vs. deflection pull test results to first wire break (Tests 2-12) . ..................... 88

Figure A-13. Pressure vs. deflection pull test results to second wire break (Tests 4-12). ................ 89

Figure A-14. Pressure vs. deflection pull test results (Tests 4-12). ............................................... 90

Figure A-15. Pressure vs. deflection pull test results to first wire break (Tests 4-12). .................... 91

Figure A-16. Pressure VS. deflection pull test results to second wire break (Tests 4-12)................92

\section{Tables}

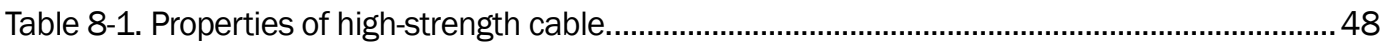

Table 8-2. Defect variations and ultimate strength of the first and maximum breaks......................52

Table 9-1. Guided wave transducer types and characteristics........................................................64 


\section{Preface}

This technical report describes initial research to assess corrosion damage and progression in multistrand anchor systems in use at US Army Corps of Engineers projects.

The investigation reported herein was authorized by Headquarters, US Army Corps of Engineers (HQUSACE), and was performed from July 2011 to September 2012 under the Navigation Systems Research Program, Work Unit "Probabilistic Assessment of the Reduced Capacity of Multistrand Post-Tensioned Ground Anchorage Due to Tendon Corrosion.” Jim Walker was the HQUSACE Navigation Business Line Manager.

The Program Manager for the Navigation Systems Research Program was Charles E. Wiggins, Coastal and Hydraulics Laboratory (CHL), US Army Engineer Research and Development Center (ERDC). Dr. John E. Hite Jr., CHL, was the Inland Focus Area Leader. W. Jeff Lillycrop was the Technical Director for Navigation, CHL. The investigation was led by Dr. Robert M. Ebeling, Information Technology Laboratory (ITL), who was Principal Investigator of Work Unit 7Jo48B.

This report was authored by Dr. Ebeling; Ralph W. Strom, consultant; Dr. Hite; and Richard W. Haskins and James A. Evans, both of the Sensors Measurement and Instrumentation Branch (SMIB), Computational Science and Engineering Division (CSED), ITL.

Portland District personnel who assisted in the field studies were Patrick Hunter at the John Day Lock and Dam project site and Jeremy Britton and David Scoffield in the district office. Special thanks to Scoffield for helping plan and coordinate the field work with the fisheries groups and the Portland District Contracting office. Gerry Heslin of Cornforth Consultants was instrumental in the demanding operation of accessing, removing, and recovering two large anchor heads at John Day. Observation of the exposed anchorages during lockages provided revolutionary new insight of the exact water migration path in these failed anchor heads. 
Dr. Robert Moser, Concrete and Materials Branch (CMB), Geotechnical and Structures Laboratory (GSL), ERDC, and Robert McCullough, intern, University of Alabama, performed high-resolution imaging and analysis.

At the time of the research was conducted, at ITL, Dr. Reed L. Mosher was Director; Dr. Deborah F. Dent was Deputy Director; and Dr. Robert M. Wallace was Chief, CSED. At CHL, Dr. William D. Martin was Director; Jose E. Sanchez was Deputy Director; and Dr. Rose M. Kress was Chief, Navigation Division.

At the time of publication, COL Kevin J. Wilson was Commander, ERDC, and Dr. Jeffery P. Holland was Director. 


\section{Unit Conversion Factors}

\begin{tabular}{|l|l|l|}
\hline Multiply & By & To Obtain \\
\hline feet & 0.3048 & meters \\
\hline inches & 0.0254 & meters \\
\hline knots & 0.5144444 & meters per second \\
\hline miles (nautical) & 1,852 & meters \\
\hline miles (US statute) & $1,609.347$ & meters \\
\hline miles per hour & 0.44704 & meters per second \\
\hline pounds (force) & 4.448222 & newtons \\
\hline pounds (mass) & 0.45359237 & kilograms \\
\hline slugs & 14.59390 & kilograms \\
\hline tons (force) & $8,896.443$ & newtons \\
\hline tons (force) per square foot & 95.76052 & kilopascals \\
\hline tons (long) per cubic yard & $1,328.939$ & $\begin{array}{l}\text { kilograms per cubic } \\
\text { meter }\end{array}$ \\
\hline tons (2,000 Ib, mass) & & kilograms \\
\hline tons (2,000 Ib, mass) per square foot & $9,764.856$ & $\begin{array}{l}\text { kilograms per square } \\
\text { meter }\end{array}$ \\
\hline tons (force) & 2 & kips \\
\hline kips & 1,000 & pounds \\
\hline
\end{tabular}




\section{Introduction}

Stressed steel tendons have been used to strengthen hydraulic structures and improve their serviceability and stability. Since they were first used at US Army Corps of Engineers projects more than 50 years ago, there have been substantial efforts to protect multistrand anchor systems from corrosion. Corrosion of older multistrand units is of concern.

\subsection{Statement of need}

In an effort to achieve structural stability of hydraulic concrete structures and/or to remediate cracked concrete monoliths, the Corps over the past three decades has installed at many of its projects high-capacity, posttensioned foundation anchors. Projects with changing hydrologic conditions sometimes need to pass higher discharges than they were designed for, and the anchors have been considered to ensure structural stability under conditions more stringent than those of the original design. These anchors typically are embedded in the monolith, meaning only the top anchor head can be inspected. Corps districts report that several of the early installed anchors have inadequate corrosion protection and do not meet current standards. Some of the older anchors are showing deterioration and corrosion. Reports indicate that some even have broken strands. The current load-carrying capacity and the remaining life of the anchors are both unknown. Consequently, structural engineers are unable to make accurate stability assessments of concrete monoliths with these damaged or corroded ground anchorages.

Some Corps engineers have proposed using lift-off tests to help determine the condition of aged and deteriorated anchors. These tests are expensive and potentially dangerous. Also, they cannot be performed on all types of anchorages, such as those that are grouted for corrosion protection (a Corps requirement for new ground anchorage, HQUSACE 2005). In the past, testing deteriorated anchors has been avoided because of the greater danger of breaking these older anchors. Lift-off testing usually is conducted on good anchors. Testing the good anchors exclusively provides only a capacity value (current time) that is biased toward the high end.

Load testing of newly installed anchorage in the field never will involve loading to failure. Post-tensioned anchors used as ground anchors for the 
support of excavations, slopes, landslide stabilization, and tie-downs are proof tested at the time of anchorage installation. These proof tests take the form of either (1) short-term performance testing or (2) short-term proof testing, and possibly (3) extended creep testing. A description of the various testing methods used for foundation-type anchors can be found in Strom and Ebeling (2002). Tests are conducted on either new production anchors (that will be for permanent use within the hydraulic structure) or on new sacrificial anchors used as part of a preconstruction anchorage testing program. The measured anchor loads are used to verify or establish anchorage performance during the design phase of the permanent ground anchorage. In either case, loading applied to the new ground anchorage is not sufficient to fail the tendon or the bonded (grouted) zone of the anchorage. Another factor for deteriorated anchorages being considered for lift-off tests is that the current ultimate capacity at the time of testing will not be determined from a pull-out or creep test. The applied load will not be sufficient to cause failure of the tendon nor pull-out the bonded zone, whichever is weaker. Thus, pull-out or creep tests conducted in the field on existing deteriorated anchorage will not establish the ultimate capacity of the deteriorated anchorage(s) in question at the time of its testing.

\subsection{Technical objectives}

The primary objective of this research is to develop engineering procedures to (1) estimate the rate of corrosion and the current state of load-carrying capacity of the ground anchorage, (2) estimate remaining life of the tendon, and (3) establish the deterioration of anchorage capacity (with time) so costly replacement of ground anchorage can be delayed until absolutely needed. Analytical, laboratory, and field-testing efforts all will be used in the development of this engineering methodology and resulting analytical models. Probabilistic procedures will be used to quantify uncertainties for the primary variables and will carried into the analytical model. Lastly, procedures to extend the life of deteriorating multistrand tendons will be investigated.

The Corps has no deterministic or probabilistic-based methodology in place to assess corrosion damage or progression and its impact. Therefore, the Corps cannot determine in stability assessments the current reserve capacity of hydraulic concrete structural monoliths with deteriorated ground anchorage nor can it establish when deteriorated ground anchorage will need to be replaced. 


\subsection{Plan for achieving technical objectives}

Suggested are these steps:

1. Locate and review documents, discuss the issues with Portland District engineers, and interpret the anchorage capacity deterioration problem at John Day Lock (Columbia River). The lock is suffering from multistrand corrosion, broken strands, broken wedges in the anchor heads, and the loss of anchorage capacity of the multistrand tendons.

2. Conduct a literature review on (a) corrosion deterioration and (b) loss of anchorage capacity of the post-tensioned ground anchorage. This includes a search for measurement(s) used to characterize tendon deterioration as well as possible nondestructive testing (NDT). NDT is a wide group of analysis techniques used by engineers and scientists to evaluate the properties of a material, component, or system without causing damage. In this report, the technology is used to evaluate the seven-strand wires in a posttensioned anchorage system. The terms nondestructive examination, nondestructive evaluation (both NDE), and nondestructive inspection (NDI) are interchangeable. NDT will be used in this report. Because NDT does not permanently alter the seven-strand wires of the post-tensioned anchorage system being inspected, it is a highly valuable tool that is expected to save time and money during an in-situ (in-the-field) evaluation and during the laboratory research effort being conducted at the US Army Engineer Research and Development Center (ERDC). During the review of technical literature that is part of this report, special emphasis will be placed on research and development conducted on lessons learned from aging and deterioration of tensioned, multistrand steel tendons in bridges.

3. Design and build a test bed at ERDC for corrosion deterioration of multistrand wire, strands in anchor heads, anchor heads, and for NDT of (reduced) multistrand wire groups in an anchorage system configuration in the laboratory.

4. Develop in the laboratory a correlation between a measurement of corrosion (i.e., deterioration) and the stretch and ultimate capacity (i.e., at failure) for a multistrand tendon. The laboratory testing program either will create corroded tendons or a damaged tendon that mimics the characteristics of a corroded tendon. The laboratory testing program to be developed will consist of three parts: (a) a procedure to measure the level of corrosion (i.e., deterioration) that has occurred in the multistrand tendon anchorage system, (b) the development of a procedure for creating corroded (i.e., damaged) multistrand tendons that represent specified levels of deterioration, and (c) pull testing to failure of that deteriorated 
tendon with stretch measurements made during the course of loading. Application or development of NDT methods to relate NDT measurements to the corrosion of the laboratory specimens will be part of this effort.

5. Perform a forensic investigation of corroded anchorage and anchor heads at John Day Lock. The field visit involves gaining access through the top of the anchor head. This involves removing the anchor head for inspection of the upper trumpet region and gripping wedges, investigation of the sevenstrand wires for the corrosion pattern, and gathering details on wire failures at this anchor head zone. An attempt will be made to recover the anchor head, gripping wedges, and seven-strand wires at the anchor head.

6. Develop a probabilistic analytical model correlating NDT and laboratorymeasured parameters of deterioration with the reduced tendon capacity and increased stretch characteristics.

7. Conduct NDT of corrosion on corroded anchor head tendons in the ERDC Test Bed.

8. Using the corroded anchor head test bed results, expand the laboratorybased statistical model for the prediction of reduced tendon anchorage capacity.

9. Formulate a time-dependent analytical model that includes the application of statistical procedures to account for uncertainties in (a) the laboratory corrosion (i.e., deterioration) measurements, (b) the ultimate tendon capacity measurements, and (c) the NDT corrosion measurements for use on full-scale anchorage features in the field.

10. Implement this probabilistic anchorage model within a GDLAD_Foundation software framework. GDLAD_Foundation is an ERDC PC-based software developed by Dr. Robert M. Ebeling, one of the authors of this report and Principal Investigator (PI) of this research effort, and used to construct fragility curves (i.e., system response curves) for a non-overflow gravity dam cross section embedded within a rock foundation that is subjected to a hydraulic hazard and stabilized using ground anchorage. An expansion of GDLAD_Foundation to cover navigation structural geometry will be required to accommodate this new probabilistic model.

11. Investigate procedures to extend the life of deteriorating multistrand tendons.

Predictions related to the corrosion of post-tensioning systems will be by probabilistic methods. Dependable NDT techniques are required if probabilistic methods are to be meaningful. NDT is needed to detect (1) gaps and voids in strand-corrosion protection, (2) pitting in strands due to 
corrosion, and (3) strands fractured by corrosion. The search for a dependable NDT procedure applicable to Corps hydraulic structures will be challenging. To date, there is little evidence that a dependable one to determine the degrees of corrosion exists. Destructive local probing at locations where corrosion is anticipated (usually at anchor heads) is often unproductive. It takes only a single area of corrosion pitting to cause failure in an unbonded system.

Some of the unbonded post-tensioned anchorages that were used to improve the serviceability of deteriorating navigation lock monoliths at John Day have failed due to corrosion, and others are in the process of failing. The intention, with respect to Step 5 of the 11-step process described earlier, is to:

1. Remove as many of the tendons as possible from one of the John Day navigation lock monoliths;

2. Transport the tendon (or tendons) intact to ERDC for physical examination and testing;

3. Remove sheathing and conduct a metallurgical evaluation of the specimens.

Assuming data collected from NDT at the ERDC Test Bed are reliable, it is envisioned that, upon development of the software tool identified in Step 10 of the 11-step process, probabilistic analyses then can be used to assess the likelihood and consequences of failure, the remaining life of the various post-tensioned systems, and to assess the need for program funds for rehabilitation using the systems with Class I corrosion protection. This observation would be made along with in-situ NDT of the post-tensioned anchorage system being evaluated, especially the older (prior to 1985) ones used at Corps projects.

\subsection{Technology review}

Searches were made to identify promising NDT technologies, with application to the types of post-tensioning used at Corps projects, to improve serviceability and strength of concrete hydraulic structures. Papers on the subject were reviewed. A complete listing is in the references section of this report. Two papers published by the National Cooperative Highway Research Program (NCHRP) were the primary sources of information for this report. NCHRP (1999) provided a basis for characterizing available NDT technologies. NCHRP (2002) provided useful information on NDT 
systems applicable to ground anchors that have strand embedment characteristics similar to those found at Corps concrete hydraulic structures. The first NCHRP document listed promising NDT systems, while the second pinpointed four NDT systems that could be applied to strand-type, posttensioning systems found at Corps projects.

During the literature search on this general topic, these three research efforts were found cited on the Centre for Energy Advancement through Technological Innovation (CEATI) web site:

1. Non-Destructive Testing of Bar or Cable Anchors Embedded in Concrete Dams, CEATI Publication To52700 0208;

2. Non-Destructive Testing of Bar or Cable Anchors Embedded in Concrete Dams, Proof of Concept Testing, CEATI Publication To52700 0208F;

3. SSTDR, Testing of Anchors at Loch Alva and Log Falls Dams, CEATI Publication To62700 0208E.

CEATI attempted to use magnetostrictive sensor and cylindrically guided wave techniques to detect corrosion damage in a seven-strand wire embedded in concrete. CEATI, however, felt these NDT methods failed to meet its corrosion detection objectives and, therefore, did not offer the reports for purchase. This underscores the difficulties in finding NDT methods for assessing corrosion damage in post-tensioning steel embedded in concrete.

Many of the NDT procedures in NCHRP (1999) that show promise with respect to the corrosion of units in post-tensioned bridge decks and posttensioned concrete supporting members are for one reason or another unsuitable for units in Corps hydraulic structures. NDT methods are described further in Chapter 7. 


\section{Post-Tensioning Systems' Use at Corps Projects}

Post-tensioning systems have been used at Corps projects to provide strength and stability to concrete hydraulic structures, to improve the stability of concrete dams, and to restore strength and serviceability to concrete hydraulic structures that have deteriorated due to cracking. Examples of site-specific applications at a few Corps projects are presented next.

\subsection{The Dalles Dam training wall}

The Dalles Lock and Dam is a multipurpose project on the Columbia River, in the Portland District. The Dalles Dam training wall (Figure 2-1) is $10 \mathrm{ft}$ wide, $35 \mathrm{ft}$ high (in the stilling basin), and $850 \mathrm{ft}$ long, and is an example of a multistrand post-tensioning anchorage system used to provide strength and serviceability to a hydraulic structure. The training wall directs spillway flows in a manner that will improve juvenile fish survivability at The Dalles project. The training wall, to match the existing spillway pier thickness, required a small footprint to avoid blocking flow from adjacent spillway bays. Post-tensioning for wall stability, therefore, was required.

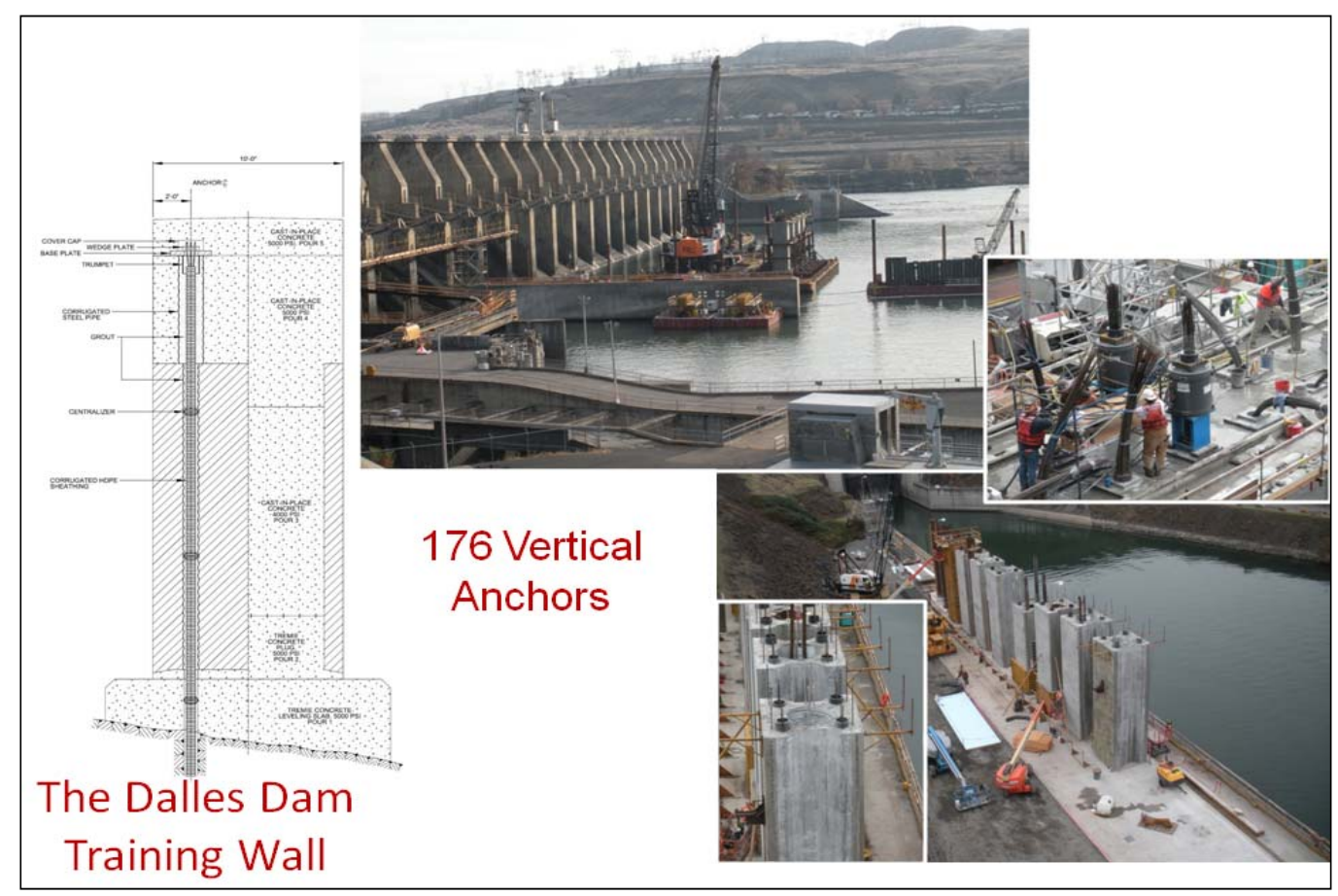

Figure 2-1. The Dalles training wall remediation with vertical anchors. 


\subsection{Bluestone Dam}

An example of a multistrand, post-tensioning anchorage system used to stabilize an existing dam is Bluestone Dam (Figure 2-2), a flood control project on the New River in the Huntington District. The Corps determined that the dam should be raised $8 \mathrm{ft}$ and that anchors needed to be installed to secure its base to bedrock. Structural analyses indicated that the bedrock securing the dam might not be as strong as assumed when the dam was constructed and that adding anchors was of critical importance. Phase $2 \mathrm{~b}$ of the overall dam safety assurance plan consisted of installing multistrand anchors in strategic locations to provide additional strength for the dam.

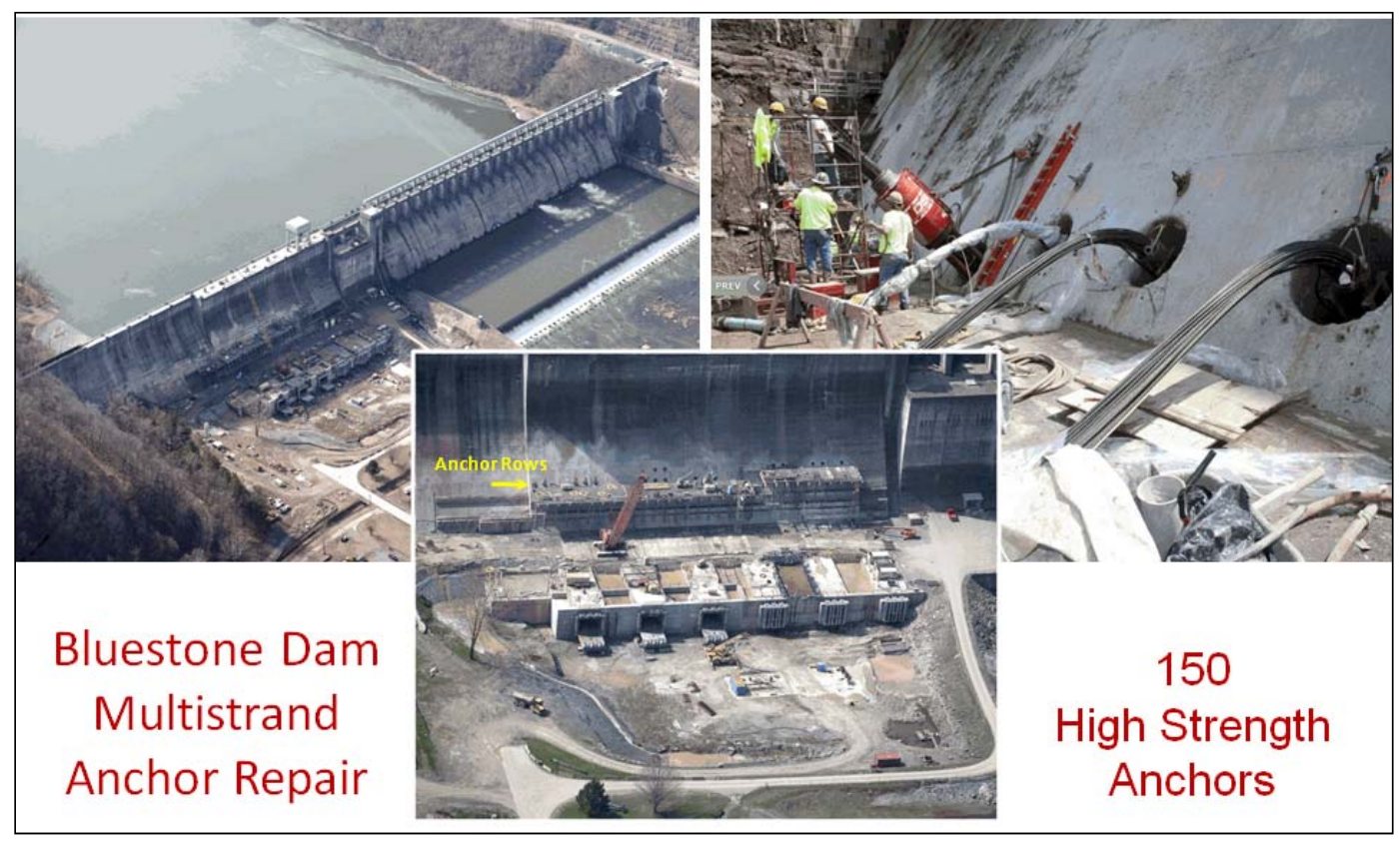

Figure 2-2. Bluestone anchor repair to prevent sliding.

\subsection{Miller's Ferry Lock, Holt Lock, and Snell and Eisenhower Locks}

Other examples of multistrand post-tensioning used to restore strength and serviceability to deteriorated concrete hydraulic structures are Miller's Ferry Lock (Alabama River, Mobile District), Holt Lock (Black Warrior River, Mobile District), and Snell and Eisenhower Locks (St. Lawrence Seaway) (Figure 2-3). The case histories of these locks and their remediations are discussed in Ebeling et al. (1996). These locks developed cracks in the landward-ceiling corner of the filling/empting culverts. It is common for cracks to occur in the re-entrant corners of concrete structures (ACI 2007a). Cracking likely started at the corner of the filling/emptying culvert due to restraint and volume change effects. 


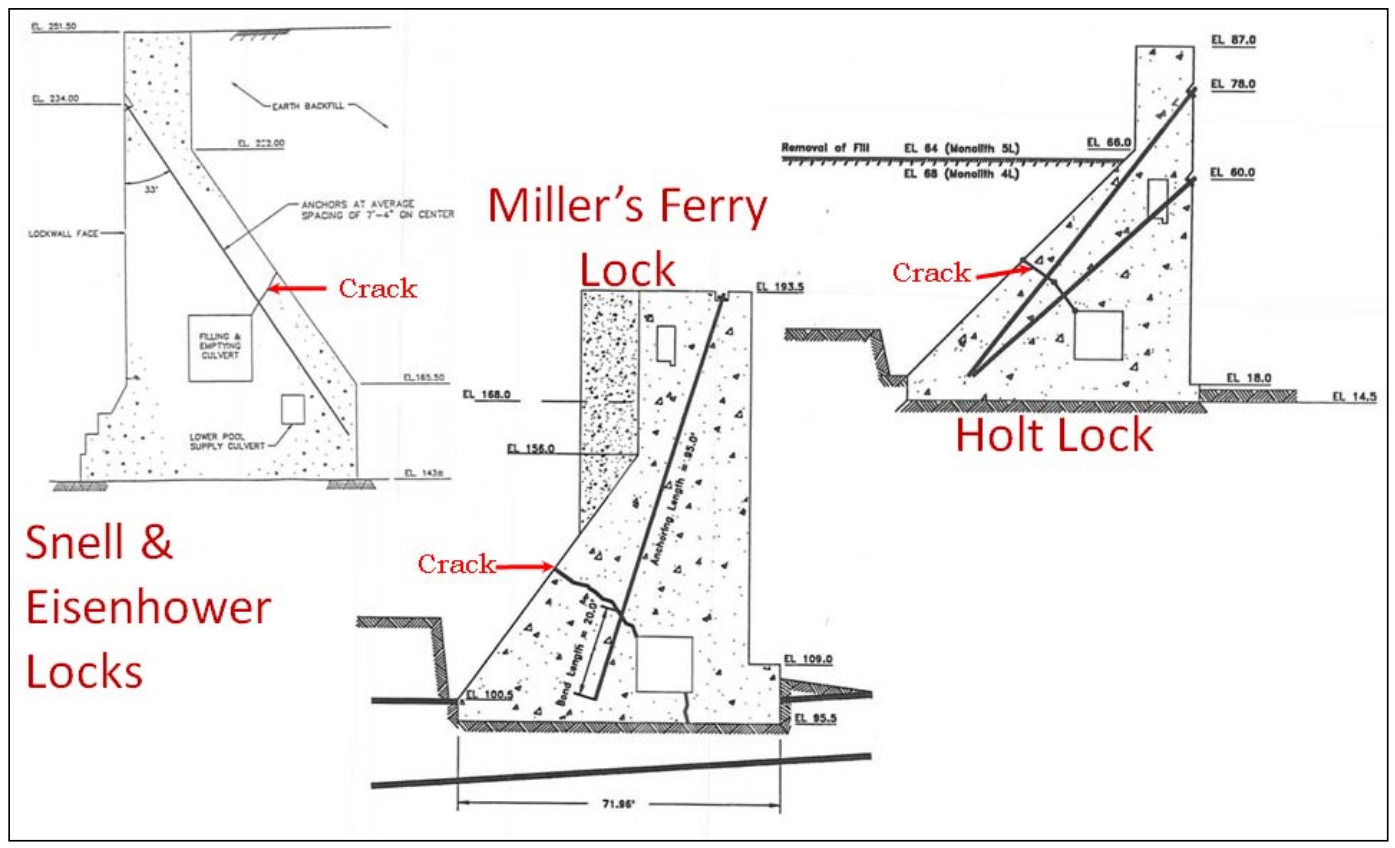

Figure 2-3. Remediation for locks with cracks initiating at an internal culvert.

Restrained volume change could be a major contributing factor with respect to crack formation and propagation (ACI 2007b). Since high stresses are always present at the tip of a crack, the additional strain energy required to propagate the crack is small (much less than that required to initiate the crack). Cracking will follow the path of least resistance, which for these locks would be the region between the landward-ceiling corner of the culverts and the back earth retaining side of the lock monolith. Eventually, the cracks propagated to the backfill. Earth pressures and changing water tables contributed to the internal stresses of the locks, which initiated the cracking and subsequent propagation that needed to be fixed with posttensioned anchors (Ebeling et al. 1996 and 2001).

The rehabilitation consisted of placing high-capacity, post-tensioned anchors across the crack (Figure 2-3). The post-tensioned anchors introduced compressive stress in a region once in tension. In 1989, the anchors at Eisenhower Lock might have sustained corrosion due to water leaking through the culvert cracks (Mosher et al. 1991). Examined were two anchors, in close proximity to cracks, producing the greatest amount of leakage. Results of the anchor investigation showed the grout was intact and surrounded the anchor strands. The anchor strands were as shiny as new, with no evidence of surface or pitting corrosion. 


\subsection{John Day Navigation Lock}

Another example of multistrand post-tensioning used to restore strength and serviceability to a deteriorated concrete hydraulic structure is the John Day Navigation Lock (Figure 2-4). A general section through the John Day wall also is illustrated in Figure 2-4. As with the Miller's Ferry, Holt, and Snell and Eisenhower lock projects, it is common for cracks to occur in the re-entrant corners of concrete structures. Cracking will follow the path of least resistance, which in the case of John Day is the region between the lock-side ceiling corner of the culverts and the lock-side face of the monolith. Eventually, the cracks propagated into the lock chamber. The cracks might have propagated during lock filling, when the pressure in the crack exceeds the pressure of the water in the lock chamber. Pressure differential between the water in the crack and the lock chamber is suspected to have caused the failures observed at John Day.

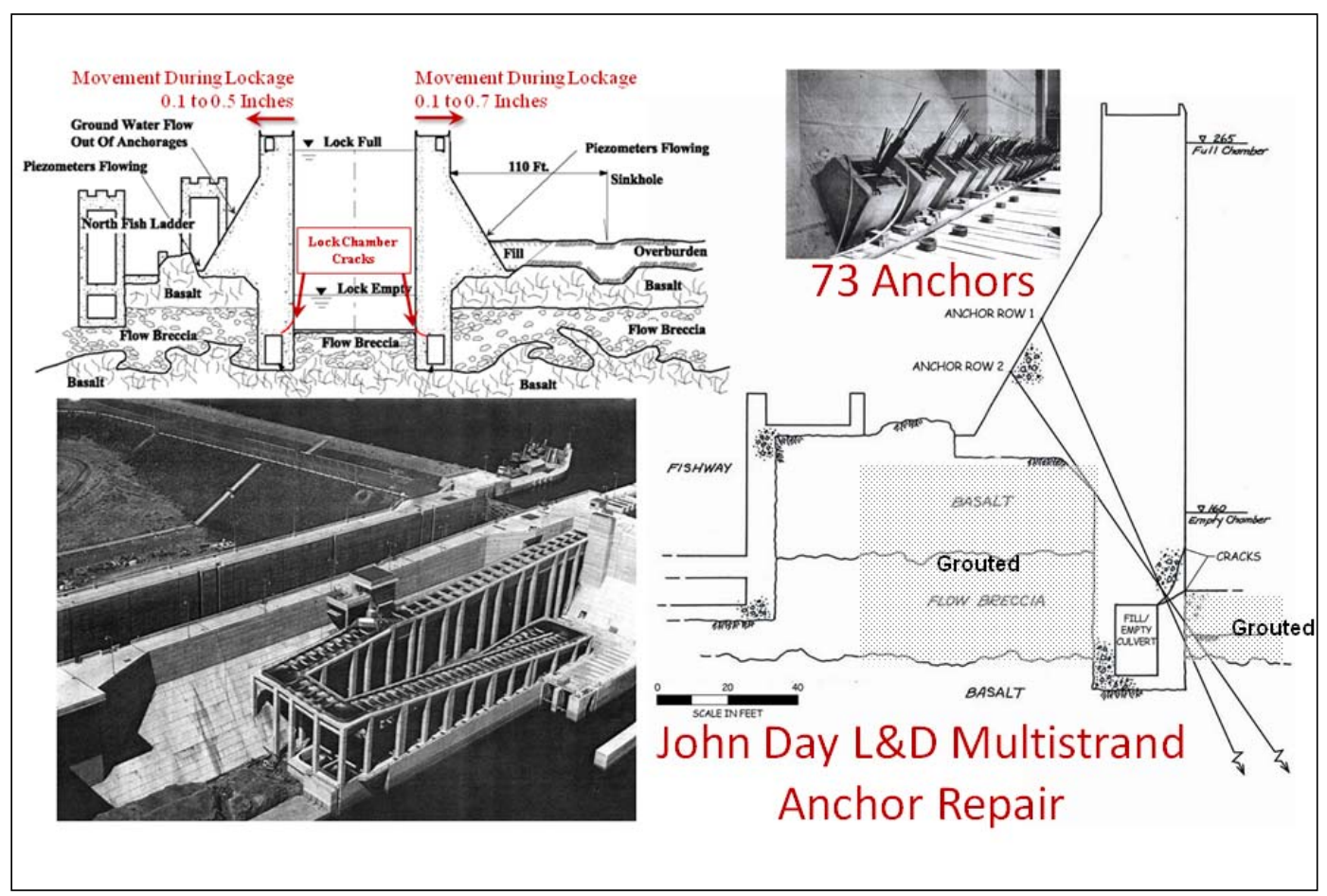

Figure 2-4. Remediation of John Day culvert cracks.

Cracking could have started at an early age, due to restrained volume change effects resulting from a gradual loss of the heat generated by the hydrating cement. Propagation and widening of the crack might have resulted from: 
1. Hydrodynamic pressure heads (water hammer effects) that occurred in the filling/emptying culverts during initial filling operations. Hydrodynamic pressure heads ultimately were reduced to acceptable levels by slowing the rate at which the tainter valves opened and closed;

2. Hydrostatic pressure due to differential head between the filling culvert and lock chamber;

3. High compressibility of the flow breccia layer under the gravity section of the monolith;

4. Poor tensile stress/strain capacity of the concrete.

Remediation consisted of:

1. Using cement to grout the foundation material (flow breccia). This was done to increase the stiffness of the foundation and, thereby, reduce the rocking action observed with the various navigation lock monoliths;

2. Drilling in and installing large high-capacity, post-tensioned anchors (unbonded anchors) to close the cracks and place the region between the lock-side ceiling corner of the culverts and the lock-side face of the monolith into compression. The anchors also tied the monoliths to the underling basalt layer.

Corrosion of the unbonded tendons and other details for the John Day multistrand anchors are discussed in Chapter 6. 


\section{Unbonded vs. Fully Bonded Anchor Systems}

\subsection{Unbonded}

According to PTI (1996), "unbonded anchors are anchors in which the free stressing length remains permanently unbounded.” The free-stressing length is the designed length of the tendon that is not bonded by grout, during or after stressing, to the surrounding concrete or surrounding ground, in the case of rock and soil anchors. With unbonded tendons, the prestressing steel is permanently free to move relative to the structure. Therefore, unbonded tendons are the only post-tensioning system that can accommodate re-stressing and lift-off testing after completion. In unbounded tendons, anchor head corrosion eventually leads to a loss of prestress and possible structural failure.

\subsection{Fully bonded}

A fully bonded anchor is one for which the free-stressing length is bonded by grout to the surrounding structure. Fully bonded anchors have the potential to keep the system in a state of prestress, should corrosion damage occur at the anchor head. 


\section{Types of Tendon Corrosion}

Podolny (1992) discusses types of tendon corrosion. Corrosion is a galvanic cell-type mechanism involving an anode, cathode, and electrolyte. For corrosion to occur, the anode and the cathode must be connected by an electrolyte (Figure 4-1). At the anode, metal atoms give up free electrons in a reaction with the corroding medium. The free electrons are consumed at the cathode by oxygen reduction.

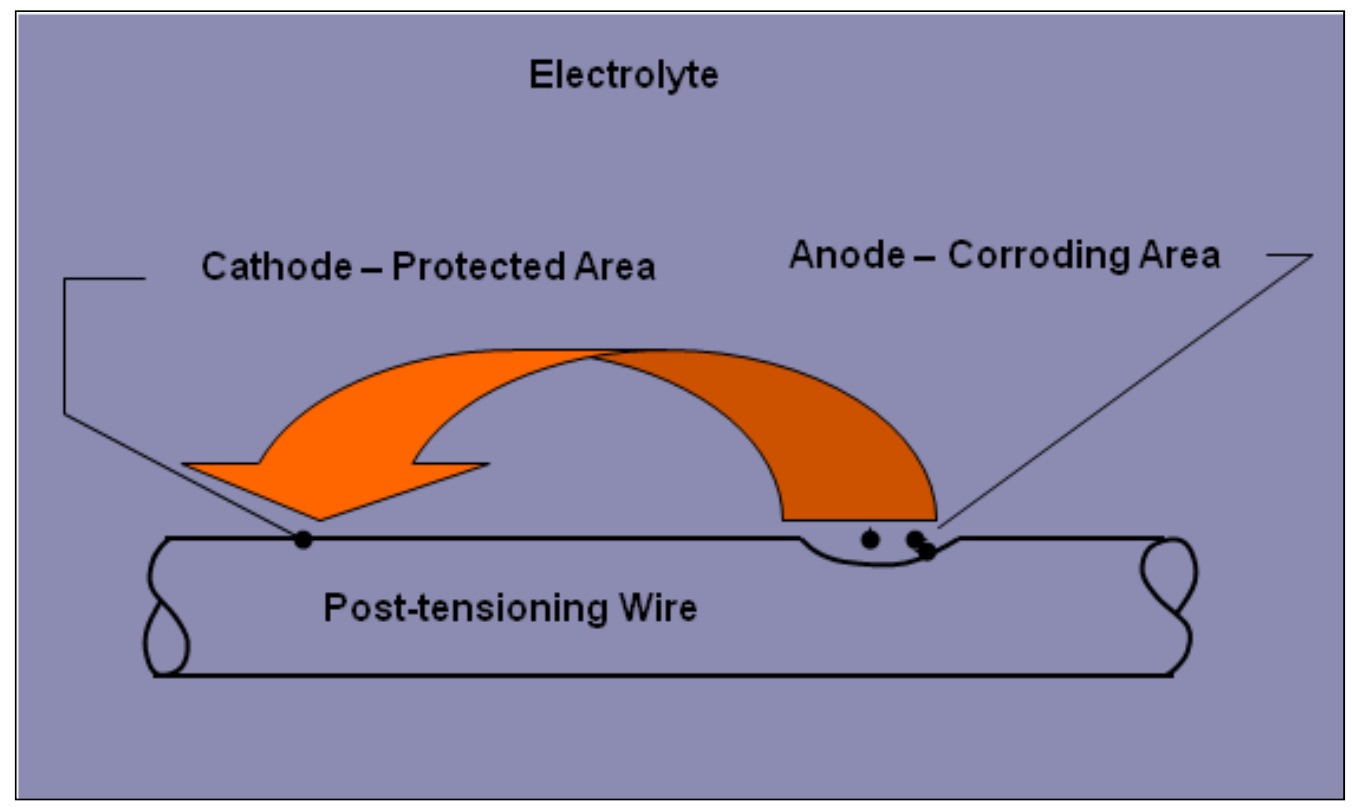

Figure 4-1. Electrolytic corrosion of anchor wire.

\subsection{Uniform corrosion}

This type of corrosion occurs when unprotected post-tensioned wires are exposed to the environment during shipping and handling or during storage. When corrosion is uniform a rust barrier will form, preventing further corrosion. For this reason, uniform corrosion is not of concern.

\subsection{Localized corrosion and pitting corrosion}

In these forms of corrosion, discrete anodic and cathodic electrochemical cells form, causing localized or pitting corrosion. Pitting corrosion has been known to cause stress concentrations and brittle failure after a negligible loss of metal. The rate of pitting corrosion is generally high, with the time to failure generally short. Pitting is the most devastating form of corrosion. 


\subsection{Stress corrosion}

The combination of high-tensile stress and corrosion can lead to accelerated stress corrosion and corrosion cracking in post-tensioned wires. When evaluating the performance of strands in the anchor zone, where the wedges introduce notches and biaxial stresses beyond the elastic limit, stress corrosion is rarely observed (Schupack 1991).

\subsection{Hydrogen embrittlement}

Hydrogen embrittlement cracking of post-tensioned wires under tensile stress occurs when atomic hydrogen has an opportunity to penetrate the wires and recombine with hydrogen molecules, producing internal pressures in the metal due to the much greater volume associated with molecular hydrogen (Podolny 1992). Hydrogen embrittlement generally occurs in a corrosive environment, where the steel is coupled to a more anodic metal such as zinc coating. It also can occur when contaminants such as sulfides are present.

\subsection{Fretting corrosion}

Relative movement between the post-tensioned strands and their encasement can cause fretting. The movement required to produce fretting is small. Localized cracks in the post-tensioned wires can result from fretting and lead to strand failure.

\subsection{Crevice corrosion}

Crevices can occur on the surface of post-tensioned wires that are in contact with another impervious material. Crevices can lead to a brittle failure of the tendon, something that occurs without warning.

\subsection{Stray current corrosion}

Stray electrical currents can pass through the post-tensioned wires, producing a potential difference between the concrete and steel and leading to corrosion of the steel by the creation of electrochemical corrosion cells (Podolny 1992). Power-generating and transmission plants are particularly vulnerable. 


\subsection{Corrosion fatigue}

Fatigue that takes place in a corrosive environment can reduce the number of cycles generally considered acceptable before fatigue and fatigue-related failure occur. 


\section{Historical Perspective: Post-Tensioned Corrosion Protection}

Surveys have been conducted over the years to assess the corrosion problem as it relates to pre-stressing steels first introduced to the engineering practice in the 1950s. Initially, it was felt that the corrosion-inhibiting characteristics of Portland cement concrete and grout would protect prestressing steels, especially in pre- and post-tensioned structures that would be free of the cracks usually found in conventional reinforced concrete structures. A 1978 survey covering a time interval from 1950 to 1977 cited 28 structures worldwide with known corrosion incidents (Podolny 1992). In a 1982 report covering the time interval from 1978 to 1982, 50 structures in the United States were found to have tendon corrosion, an average of 10 per year. Of the 50, 10 cases of probable brittle failure were related to stress corrosion or hydrogen embrittlement. It was estimated in 1988, in the United States and Canada, the number of reported corrosion incidents was in the hundreds (Podolny 1992).

\section{$5.11960 s$ and 1970s}

Post-tensioned systems first were used by the Corps in the mid-1960s (Heslin et al. 2009). To date, there are 400 dams in North America with such systems. The majority of dams that incorporated post-tensioned systems in design or remediation took place after the mid-1980s. Before 1970, there was no guidance for corrosion protection and it was assumed the corrosion-inhibiting characteristics of Portland cement concrete and grout would provide suitable protection. In 1974, a Post-Tensioning Division of the Precast/Prestressed Concrete Institute (PCI) was created, and, in 1976, the Post Tensioning Institute (PTI). The initial purpose of the PTI was to encourage the use of post-tensioning and corrosion protection, which essentially was left to individual prestressing steel providers. However, in 1974, the PCI published Recommendations, a document requiring grout protection for tendons and the use of sheathing only as a bond breaker in the free-stressing length zone. Two-stage grouting, initial grouting for the dead end anchor zone, and secondary grouting for protection of the stressing length were the standard practices. 


\section{$5.21980 \mathrm{~s}$}

In the 1980 Recommendations, PTI recommended corrugated sheathing or epoxy-coated strand in the dead end anchor zone and greased and sheathed tendons in the free-stressing length zone. The latter sheathing was intended both as a bond breaker and for corrosion protection. Two-stage grouting remained the standard practice.

In the 1986 Recommendations, PTI emphasized chemical analysis for selecting the appropriate level of corrosion protection. Encapsulated tendons, although no details were provided, were required only for aggressive ground. One-stage grouting was relatively new.

\subsection{Current methodologies}

In the 1996 Recommendations, Class I Protection (sometimes called double corrosion protection) and Class II Protection (sometimes called single corrosion protection) were introduced. Provided by PTI were clear encapsulation details and a decision tree that allowed engineers to base the selection of Class I or Class II on factors such as ground aggressivity and consequences of failure. Single-stage grouting became the standard for post-tensioned ground anchors. Figure 5-1 shows a typical configuration for Class I Protection in the dead end anchor bond zone. Figures 5-2 and 5-3 show Class I and Class II protection for prestressed rock and soil anchors.

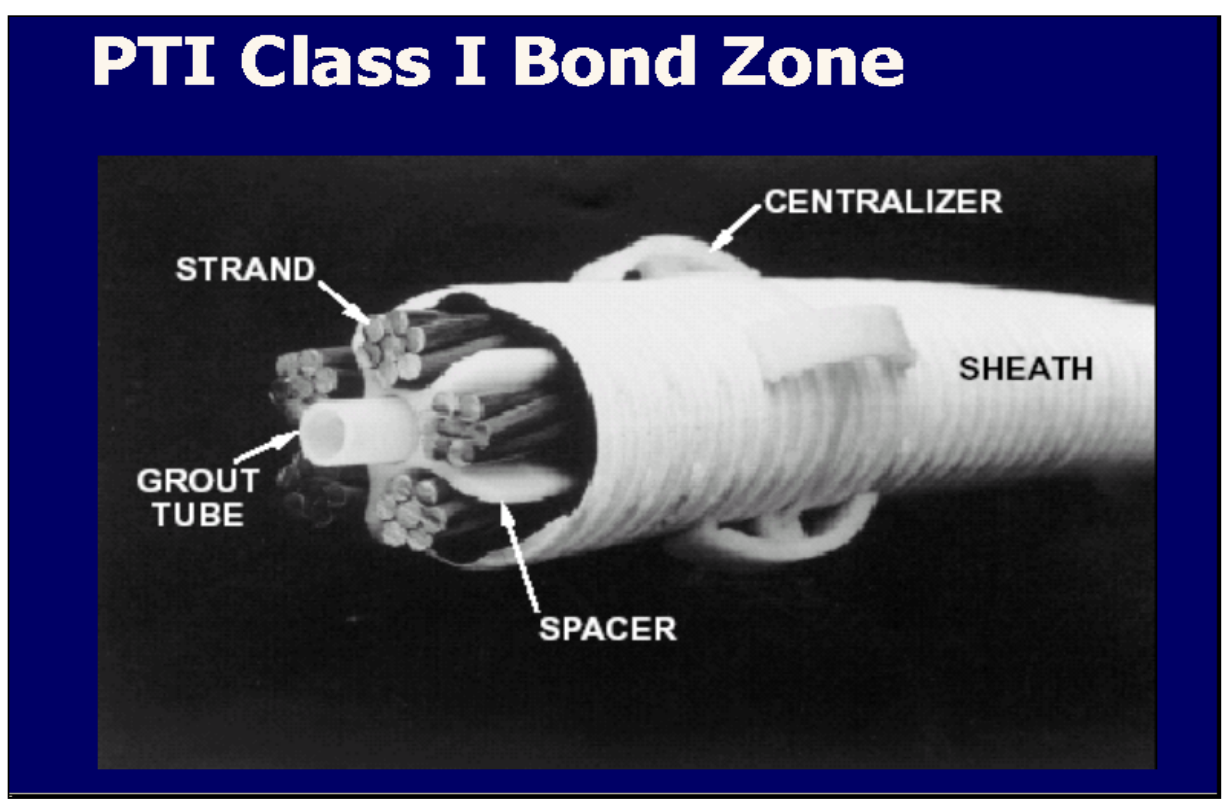

Figure 5-1. Class I Protection for dead end anchor zone. 

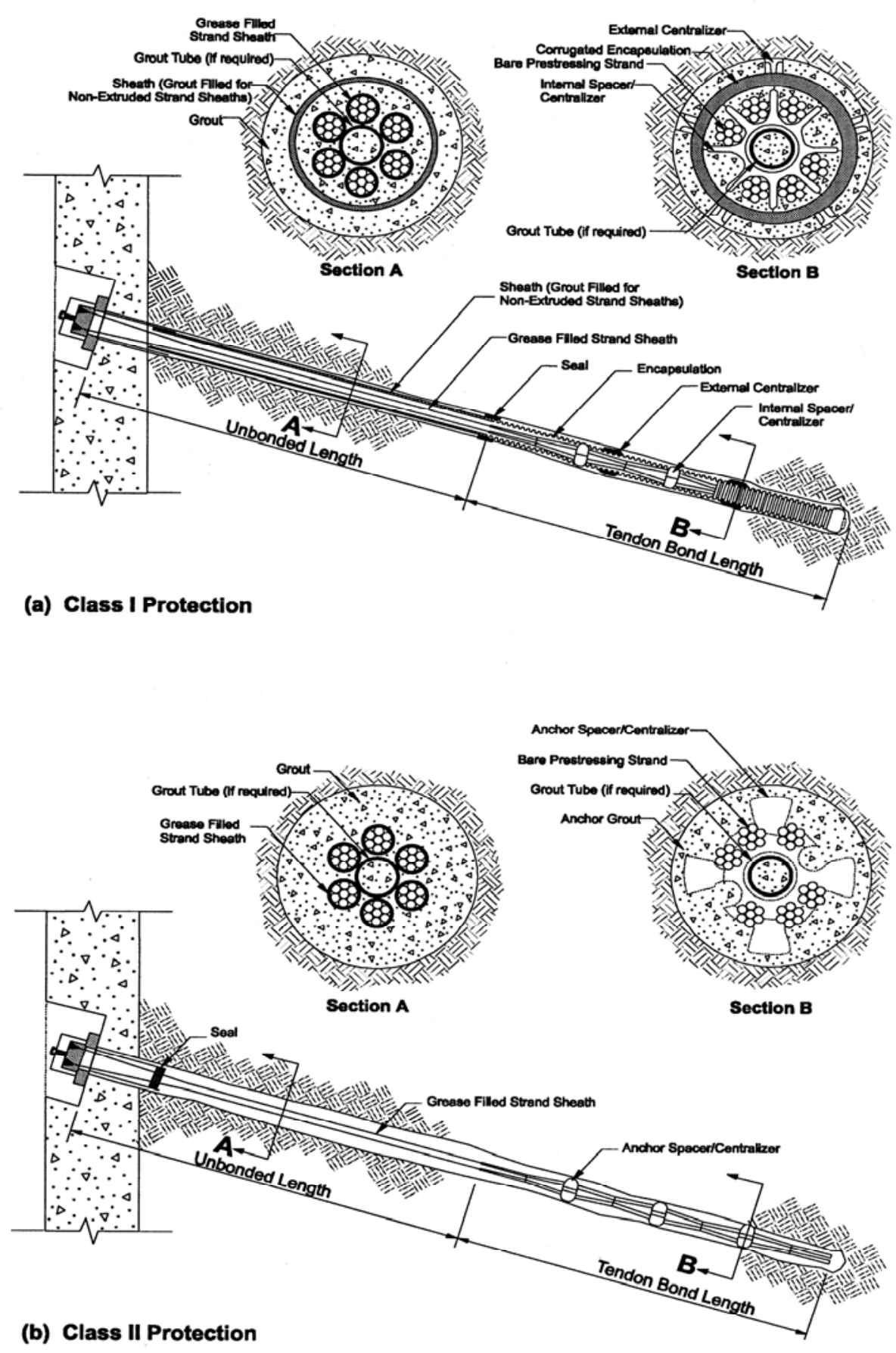

Figure 5-2. Examples of corrosion protection for Class I and Class II strand tendons (after Figure 61, Sabatini et al. 1999). 


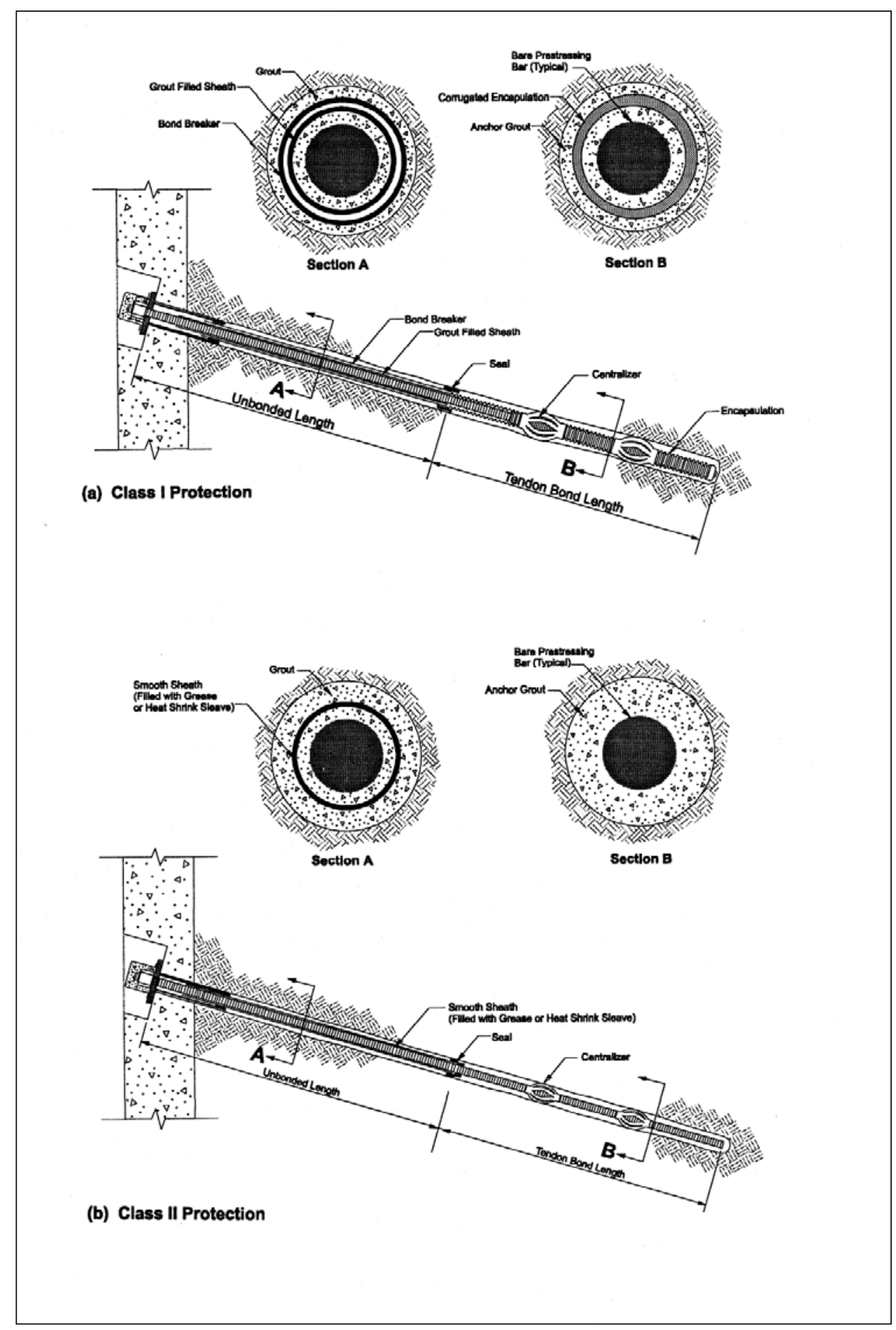

Figure 5-3. Examples of corrosion protection for Class I and Class II bar tendons (after Figure 61, Sabatini et al. 1999).

Nierlich and Bruce (1997) highlight the most significant changes and improvements made in PTI's 1996 guidance for prestressed rock and soil anchors. They point out that, in Chapter 5 on corrosion protection, more 
emphasis is put on the corrosion protection near the stressing end, where statistics show by far the highest frequency of corrosion failures.

\subsection{Delaware Lake Spillway anchor corrosion testing}

A contractor for ERDC's Construction Engineering Research Laboratory (CERL), performed corrosion testing of anchor tendons to provide corrosion data for the Delaware Lake (Huntington District) Spillway Anchoring Project (Weber 2010). Multistrand anchors were installed to provide the necessary structural stability. The laboratory corrosion tests were performed to try to bracket the corrosion rates anticipated at the project site. The purpose was to determine if the use of single corrosion (Class II) protection would provide longevity (years required to corrode away 50\% of the wire diameter) sufficient to assure Corps safety requirements will be met over the life of the spillway remediation.

Corrosion testing was done in a manner that would simulate the type of corrosion protection provided for the anchor length and free-stressing length of the tendons and the conditions encountered from emersion in the Delaware Lake reservoir environment. Bare steel, polypropylene/ grease-coated steel, tensioned steel encased in grout, and epoxy bonding agent-coated steel encased in concrete were immersed in a water bath. The bath was similar in chemistry to samples taken from core holes drilled in bedrock to the same depth as the anchor end of the tendon in an area downstream of the dam. The corrosion rate study consisted of Linear Polarization Resistance (LPR) measurements of the steel after the corrosion processes were stabilized. The corrosion current data was used to calculate the corrosion rate for the samples that had been submerged in the water bath for more than one month. This time allowed the corrosion processes to reach equilibrium. Run on each specimen were three specimens of each condition and three LPR measurements.

The corrosion rates for the laboratory samples are provided in Weber (2010). The Ultimate Tensile Strength (UTS) of the individual strands used in the field was 58,600 psi. The field tendons were stressed to 0.6 of the UTS, so the final tension was expected to be somewhat less than this amount. The anchor assemblies tested in the laboratory were loaded to 5, ooo psi. The report recommended a series of corrosion tests should be conducted on the anchors in the field. At least three anchors would need to be assessed and each of the anchors could be used as one of the three 
electrodes required to conduct the LPR tests. These field tests would give an accurate measurement of the corrosion rates for the anchors in service.

Although valuable insights were gained from the Weber (2010) study, concerns about the results are:

1. Corrosion resulting in a 50\% reduction of wire diameter was used as a basis for longevity without subsequent load testing to establish tendon capacity after corrosion;

2. Corrosion testing was conducted at prestress levels far less than that associated with in-place conditions (i.e., $60 \%$ of minimum specified tensile strength);

3. Conclusions cannot be made about other post-tensioning systems with different corrosion protection or with different corrosive environments.

ACI (1985) indicates the corrosion rate of steel embedded in concrete is influenced strongly by environmental factors and by corrosion protection measures. The importance of the corrosion protection aspect has been further substantiated by the Delaware Lake spillway anchor corrosion testing. Corrosion propagation for the Delaware project, as is generally the case, is modeled by assuming a relatively uniform loss of material thickness. Because pitting corrosion, due to its detrimental effect on the performance of structures, is the quantity of interest, a probabilistic approach that correlates pitting corrosion with the uniform corrosion process would be useful. Darmawan (2010) presents a probabilistic-based correlation between pitting corrosion and general corrosion.

The general corrosion rate for bare wires in the Delaware Lake testing was in the range of 1 to 2 mils/year. Corrosion rates for the protected strands were much lower. Per BRITE/EURAM (1995), general corrosion rates range from $0.04 \mathrm{mils} /$ year $(0.001 \mathrm{~mm} /$ year) in generally passive environments to 40 mils/year ( $1 \mathrm{~mm} /$ year) in aggressive environments. Corps structures, except those immersed in salt water, generally are exposed to a low-to-moderate corrosive environment with general corrosion rates of 0.4 mils/year (0.01 mm/year).

Information in Clear (1989) suggests the following interpretation of general corrosion rate data ${ }^{1}$ :

1 Conclusions regarding Clear (1989) data are based on information in Dickson et al. (1993). 
1. For general corrosion rates less than 0.1 mils/year: no corrosion damage expected;

2. For general corrosion rates between 0.1 and 0.5 mils/year: corrosion damage possible in the range of 10 to 15 years;

3. For general corrosion rates between 0.5 and 5 mils/year: corrosion damage possible in the range of 2 to 10 years.

\subsection{Effect of pitting corrosion on capacity of prestressing wires}

Darmawan and Stewart (2007) performed comprehensive corrosion testing for prestressed beams and slabs. The approach used was considered comprehensive because:

1. Varying corrosion rates were examined;

2. Pitting corrosion was examined visually and quantified with respect to corrosion rate;

3. Load testing was conducted to determine load capacity of strands undergoing various degrees of pitting corrosion;

4. Probabilistic models were developed from test data for use in predicting safety performance for strands subjected to various corrosion rates.

It has been thought that pitting corrosion, because of its notching effect and stress intensity at the notch location, would lead to sudden fracturetype failures. The testing by Darmawan and Stewart (2007) suggests this is not the case and failure is a ductile necking-down process somewhat similar to that occurring in non-corroded strands, although the ductility capacity (i.e., ability to reach high ultimate strain capacity) is significantly less.

It is assumed that evidence of corrosion of prestressing systems at Corps projects, such as rust staining, concrete cracking, and concrete spalling, will lead to a determination of the corrosion rate through field measurements. Once a corrosion rate has been established, a safety performance evaluation can be made and performance quantified over the remaining life of the project. 


\section{Lessons from John Day Navigation Lock Post-Tensioned Corrosion}

In 1981, the Corps completed remedial repairs at the John Day Dam Navigation Lock to mitigate monolith deflections observed during lockages and to repair a crack near the southern filling/emptying culvert. Mitigation measures included foundation grouting and 73 tie-down anchors in the southern navigation lock monoliths. Foundation grouting was intended to stiffen a layer of flow breccia underlying the heel of the navigation lock monoliths. The anchors each had 37 seven-wire strands and were locked off at approximately $1,518 \mathrm{kips}$, or $70 \%$ of the Specified Minimum Tensile Strength (SMTS). Figure 6-1 shows the three-stage anchor system used at John Day Lock, and Figure 6-2 shows the installation and configuration of the anchors. Immediately after installation, seepage was observed exiting from several anchor heads when the navigation lock was full. Notice, in the lower right portion of Figure 6-3, water flowing from the anchor head. In 2003, the anchor heads were inspected and photographed. Also that year, lift-off tests were conducted on selected anchors. Refer to Ebeling et al. (2012) for more on the John Day Lock multistrand anchors and associated corrosion.

\subsection{8 anchor head inspections}

Anchor head inspections were completed between October 20 and 27, 2008, by Cornforth Consultants. During the inspections, the anchor covers and protective grease were removed from the stressing head, the number of damaged strands and amount of corrosion were recorded, the stressing heads were re-greased, and the anchor covers were replaced. The conditions of the anchor heads were highly variable. Some showed almost no sign of damage or corrosion, while others exhibited severe corrosion, broken strands, and water seepage when the navigation lock was full. In Cornforth Consultants (2009), an unpublished letter report to the Portland District, a broken strand was any strand that was visibly damaged. This included strands with missing wedges, with one or more missing wires, and that had retracted below the top of the gripping wedges. It was observed that 70 of the 73 anchors exhibited grease discoloration adjacent to the stressing head. This suggested nearly all the anchor heads were experiencing some degree of seepage. 


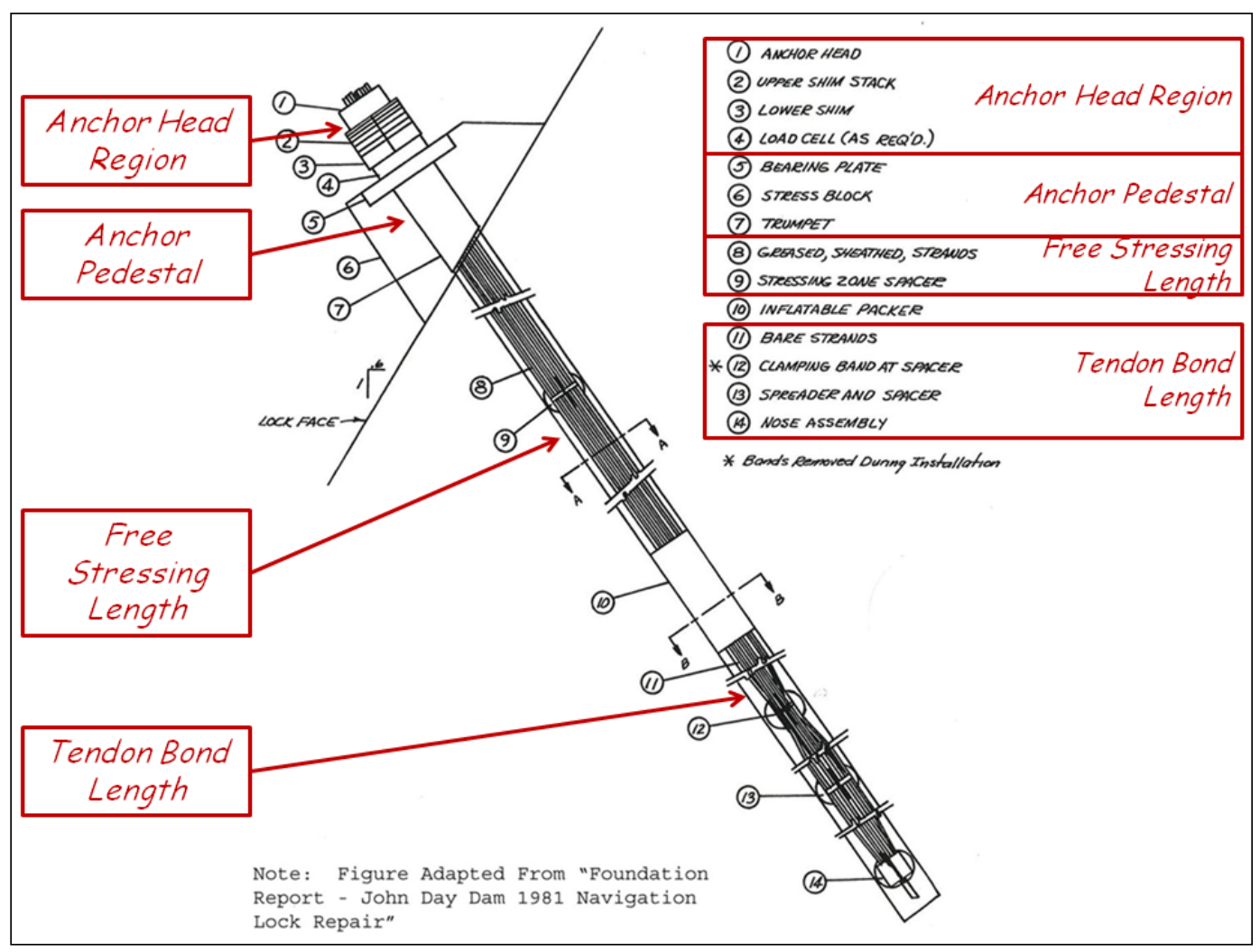

Figure 6-1. Three-stage anchorage system used at John Day.

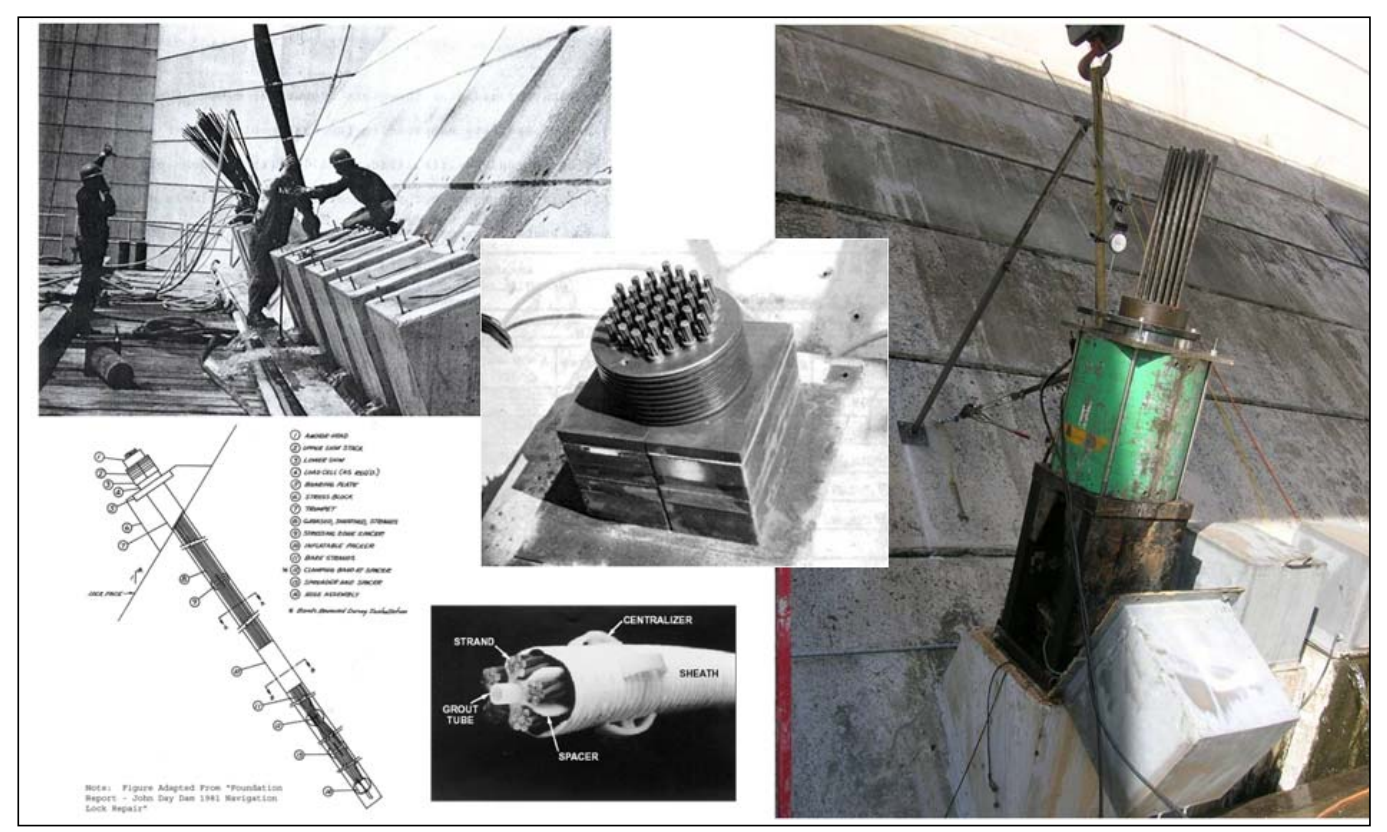

Figure 6-2. Examples of configuration, placement, and current testing techniques. 


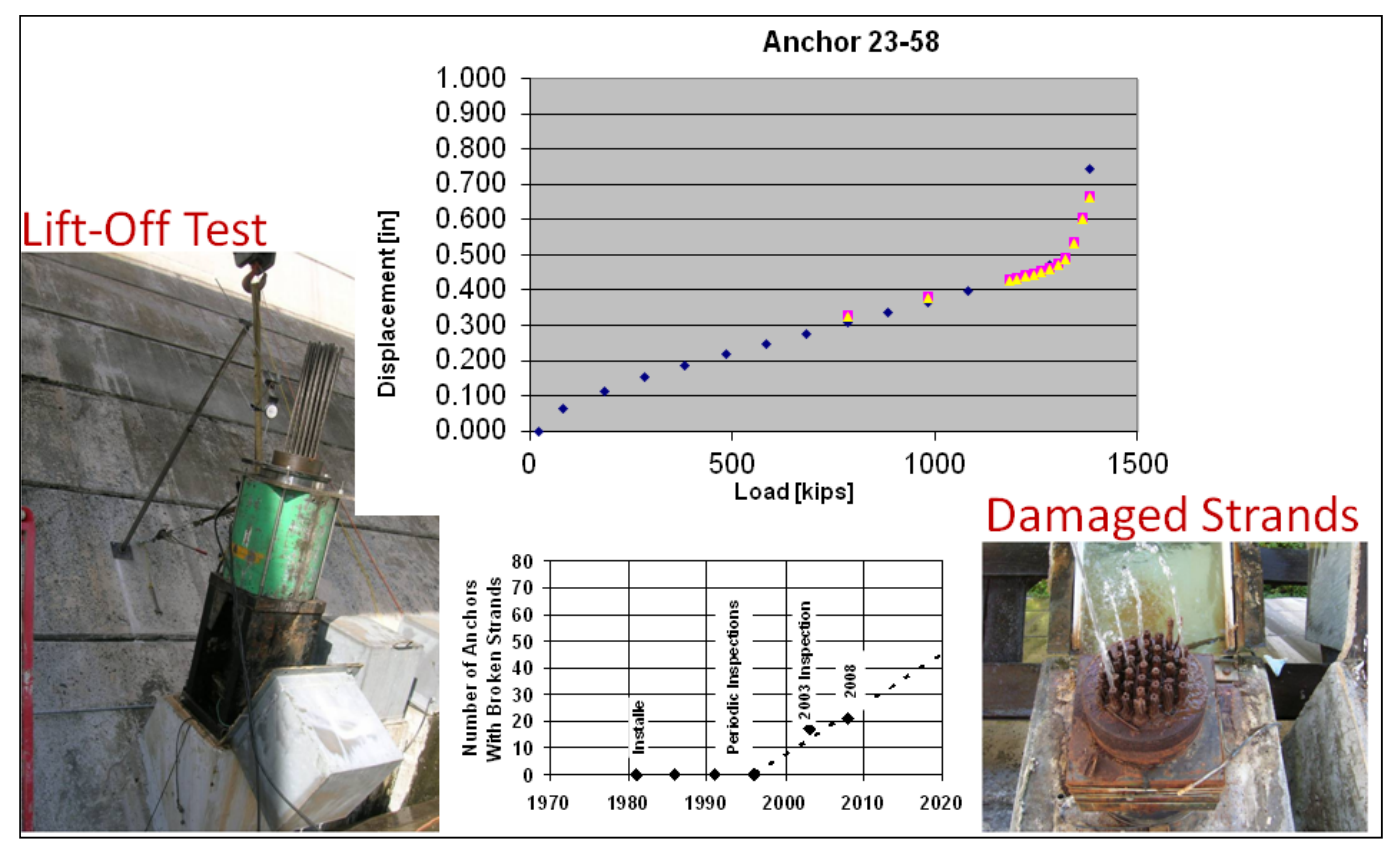

Figure 6-3. Performance of anchors during lift-off tests and evidence of corrosion.

\subsection{Visual inspection}

At the time of the 2008 observations, it was clear that the anchors had deteriorated since inspections in 2003. It appeared the primary cause of the anchor deterioration was corrosion caused by water flowing during lockages and exiting at the anchor head. Broken or displaced king wires are the most common visual clues of failed strands at the exposed anchor head. On occasion, perimeter wires also were displaced by small amounts.

For anchors with visually undamaged strands at the anchor head, the measured lift-off load is typically 85 to $90 \%$ of the original lock-off load. For steel tendons used in the early 1980 , a load loss of 10 to $15 \%$ due to stress relaxation is not uncommon. Although the stress relaxation properties of the tendons used at John Day were not documented in the project records, it is reasonable to assume that the primary source of the load loss in the visually undamaged anchors was stress relaxation.

For anchors with visibly damaged strands at the anchor head, lift-off load is proportional to the number of visually undamaged strands. However, lift-off load calculations indicate the actual number of damaged strands is greater than the number of damaged strands observed during visual inspections. This indicates that, while visual inspection is a valuable tool to monitor the rate of corrosion and anchor damage, the actual degree of damage is likely to be worse than can be observed at the anchor head surface. 
Installing a cathodic protection system to slow the corrosion rate of the anchors was considered. A cathodic protection system was feasible, but would be of limited value in areas where corrosion was already evident. The primary features that would limit the effectiveness of the system are the steel trumpet under the bearing plate and the individual strand sheaths in the tendon free length. Both of these would shield or partially shield the strand from the electrical current of the cathodic protection system. If the current does not reach the strand, there is no benefit. Also, anchor tendons are manufactured from high-strength steel. Cathodic protection systems for high-strength steel often cause hydrogen embrittlement of the steel they are designed to protect. High-strength steel also is susceptible to pronounced crevice corrosion. Hydrogen embrittlement of steel in the vicinity of crevice corrosion could cause tendons to rupture under cyclic loading experienced during lockages.

\subsection{Conclusions from Cornforth Consultants (2009)}

Based on visual inspection and data obtained from lift-off tests, Cornforth Consultants (2009) found:

1. Nearly all anchors showed signs of seepage exiting from the strands and/or anchor head. This seepage has caused and will continue to cause corrosion and subsequent strand damage.

2. Corrosion rate appeared to be highly dependent on location. The rate was expected to increase over time as an ever-decreasing steel tendon area is subjected to increasing seepage rates. Current data suggested each year would result in a 3 to $5 \%$ increase in the number of anchors with damaged strands. Similarly, annual loss of total load capacity (number of intact strands) could be between $1 / 4$ to $1 / 2 \%$.

3. Undamaged anchors were retaining 85 to $90 \%$ of the original lock-off load. The largest component of the load loss appeared to be the result of stress relaxation in the tendon. Stress relaxation moving forward was expected to be negligible because stress relaxation follows a log-linear relationship.

4. The number of effective strands in the anchors was fewer than the number of visually undamaged strands. This implied corrosion likely was occurring beneath the anchor head.

5. A cathodic protection system could be installed to slow the corrosion rate of anchor tendons. However, the system probably only would benefit the portion of the tendon in the anchor bond length. It appeared the unbonded length and area near the anchor head were experiencing the highest rates of corrosion. 


\subsection{Latest condition of John Day anchor}

Cornforth Consultants (2009), which incorporates feedback from consultant Donald Bruce as well as commentary on the 1982 placement and the 2003 and 2008 pull-off tests, covers numerous specifics vital to profiling the deterioration at John Day and its impact. Based on the 2003 and 2008 reports, the number of damaged anchors went from 13 to $22 \%$, respectively. This corresponds to roughly a $1.7 \%$ loss of total load capacity in those five years. The viewpoint is this rate will accelerate due to loss of material and expected results of an increase in water penetration. Cornforth Consultants (2009) goes on to estimate a widely varying margin of debond length (plastic grout region) from o to $15 \mathrm{ft}$. Also investigated is the value of a cathodic protection system. This approach is discounted largely due to a lack of an obvious ground path and a fear of hydrogen embrittlement of the high-strength steel. One idea is to utilize a failed strand as either a current path or access point to the cables below the anchor head. One benefit of a low-level cathodic system is it can be monitored for feedback on active corrosion levels. Another potential path for slowing deterioration due to corrosion would be to use a nitrogen gas to create higher head pressure at the anchors during lockages. This would impede water from flowing up through the cable and out the anchor head. A pressure of 12 to 15 psi would more than offset expected fluid head pressure. Such nitrogen systems are used in commercial products for filling car tires.

\subsection{Speculation}

In an August 30, 2011, meeting among the ERDC post-tensioning corrosion team members, Gerry Heslin of Cornforth Consultants, and David Scofield of the Portland District, speculations in several areas were made about the corrosion process and effects observed during the 2008 lift-off testing and presented in Cornforth Consultants (2009).

\subsubsection{Water penetration along tendons}

The lack of double corrosion (Class I) protection in the dead end anchor region allowed cracks (that formed as a result of strain penetration during tendon pre-stressing) to propagate to regions in the foundation rock that had jointing with direct access to the water within the lock chamber. This allowed water to follow components of the anchorage system to the live end anchor zone where oxygen was readily available and, thus, the corrosion process began (Figure 6-4). 


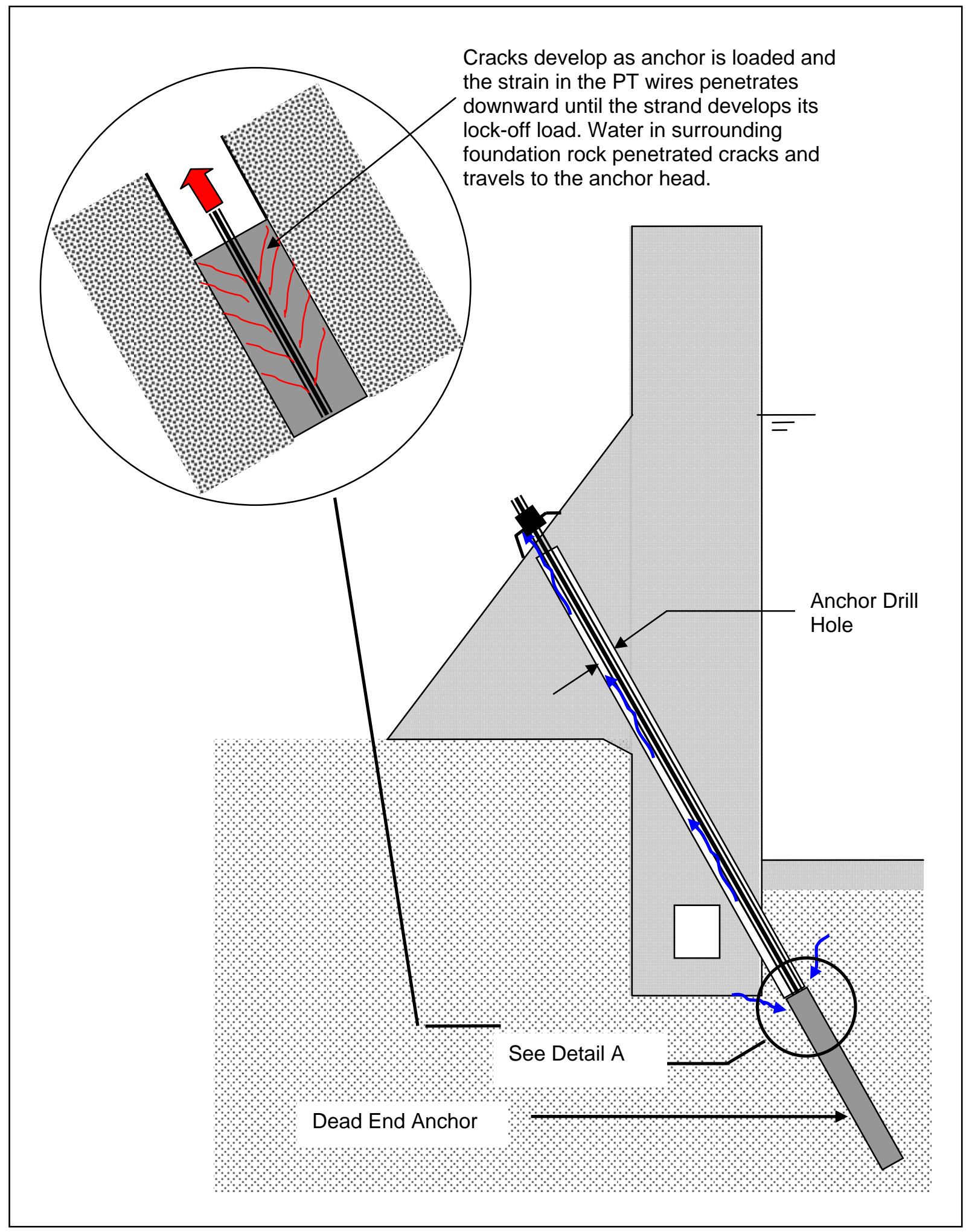

Figure 6-4. John Day tendon water flow path. 


\subsubsection{Corrosion issues at John Day}

Issues contributing to corrosion-induced deterioration of the posttensioned anchors at John Day are:

1. The bonded zone is situated below the base of the lock in the basalt and in proximity to the permeable flow breccia.

2. Piezometers located below the base of the culvert indicate the basalt in this zone is fractured, providing a conduit for water during lock operations.

3. In addition to Item 2, significant bond damage occurs as the tendon is prestressed and load is transferred to the grouted anchor zone and surrounding rock. The large tensile strains induced in the load transfer zone lead to crack formation in the surrounding grout and foundation rock.

4. The culvert was constructed using minimal reinforcing steel to accommodate tensile strain due to flexure in the culvert wall and volume change effects. The reinforcement provided was inadequate for crack control. Fracture of some reinforcing bars was observed during periodic inspections. Lock wall cracking in this region allows access to lock chamber water.

5. Quality assurance issues with the contractor resulted in large, rounded, river-run aggregate with high variability in concrete compaction and tensile strength. Bond between the aggregate and cement paste is a key to tensile stress-strain capacity, and large quantities of rounded river-run aggregate meant the tensile stress-strain capacity would be low.

6. Water on the Columbia River is characteristically soft, which further contributes to corrosiveness. It was noted that there are extreme seasonal temperatures and that the pedestals containing the anchor heads are exposed to these conditions.

\subsubsection{Center strand corrosion failures}

A seven-strand, post-tensioned tendon is made up of a straight center wire and six outer helical wires (Podolny 1992). At the anchor head (live end anchor), the wedges used to secure the tendons in the anchor head introduce notches and biaxial stresses that are beyond the elastic limit of the strands (Schupack 1991). These high stresses can lead to stress corrosion, a condition in which the corrosion process is accelerated. The notch effect will cause stress risers that can lead to brittle failure of the strand. However, Schupack (1991) indicates this is not necessarily the case. At John Day, a number of center strand failures at or near wedge locations have been observed. The center wire of a strand has a diameter slightly larger than the 
surrounding helical wires ( $5.5 \mathrm{~mm}$ vs. $5.2 \mathrm{~mm}$ ). This failed wire has been observed, either retracting into the seven-strand grouping or protruding outward and above the tops of the seven-strand wire groups. For those wires protruding, the length has been on the order of 6 to 8 in. This length likely corresponds to the distance between the tip of the gripping wedge and the top of the wire above the anchor head. Figure 6-3 shows the flow of water through the anchor from the lock operation and the loss of the center wires. Potential contributors to strand failure near the anchor head are:

1. Temperature;

2. Wetting and drying action;

3. Corrosion stress, stress concentration, or loss of cross section at the gripping wedge;

4. De-oxygenation of the water column toward the anchor head;

5. Increased corrosion potentials (electrical potentials).

Other observations and possible contributors:

1. If the king wire is straight, an argument can be made that the six surrounding wires will have less tension (will be longer) and will add a shearing force.

2. Water appeared to be moving up the length of cable. One fundamental question is the path the water is taking toward the anchor head (e.g., is the water moving up around the king wire, inside the sheath, or outside the sheath or through some other mechanism?). This question is the reason for removing an anchor head and recovering and inspecting the subsurface cable.

3. Where does the sheath terminate and does this contribute to corrosion issues occurring mostly toward the anchor head?

4. Recovery of a nonfunctional anchor head would allow for a detailed assessment of points of access for insertion of NDT/mitigation technologies.

The requirement that the center wire be larger than any outside wire is important. If this relationship is not maintained, the outer wires can form a pipe around the center wire without bearing on it, thereby permitting the center wire to slip and prevent it from carrying its share of the load. Normally, the outer wires, not the center wire, would be expected to fail due to stress risers caused by the anchor head wedges. The reason for center wire failure is unclear. 


\subsection{ERDC-recommended field tests for John Day multistrand anchors}

Field activities will benefit the investigation of the multistrand anchors by helping to determine more details for the corrosion, deterioration, and failure issues. Inspection and recovery of the top section of the anchor head for anchors that have experienced a loss of tension is desired. The results of the previous lift-off tests can be used to identify these anchors.

The proposed procedure to obtain an anchor:

1. Use a bottle hydraulic jack to elongate strands sufficiently, to free wedges.

2. Remove the wedges and shim plates.

3. Release tension in the strands.

4. Saw cut with wire saw at the base of the trumpet.

5. Photograph and recover the head, grip wedges, and cables.

Other field activities that could be conducted for assessment of baseline corrosion rates and catalysts are to install a datalogger to monitor four anchor heads. Temperature, pressure, and cathodic potentials data also could be collected. These details were being assessed.

\subsection{Other investigations of John Day anchors}

It was known in 1982, during the final construction phases of the anchor installations, that the corrosion measures put in place were not entirely successful. It was clear, from water observed percolating through the anchor heads during a lockage, that water was being pushed up through the anchor head and that future corrosion failures were possible if not probable. Two corrosion investigations were funded by the Portland District. Keep in mind, modern corrosion prevention has changed significantly since the installation at John Day. Today's post-tensioned cables often have an extruded outer jacket and an interstitial, wax-like filler. The state-of-the-art method in 1982 involved pressurized injection of epoxy into the cracked concrete and rock via the core hole, re-coring of the post-tensioned holes, utilization of grease-filled polyethylene sleeves around the individual cables, and tremie grouting around the cables with cement-based grouts. Cable failure at John Day was caused by failure of the waterproofing system. The system failed because, during lockages, water enters at or below the packer and travels under elevated head pressure to the anchor head. Details of this failure are discussed in the next section. 
There appears to be limitations in the investigations of the potential for post-tensioning failures due to corrosion. The Northern Pacific Division findings, in USACE (1982), studied short tensioned sections of cable under strong acidic attack. The objectives of the report were to determine (1) if a correlation with long-term corrosion could be made and (2) the effect of corrosion on tensile strength. The acid strength and applied tension were such that most of the samples failed quickly during the exposure phase before they could be quantified in a mechanical pull test. An effort was made to mechanically notch specimens to supplement the missing corrosion data points. Presented in the report are four data points of cables that were notched and three data points of cables that were exposed to acid. The data points show a general trend of reduced load capacity with reduced cross section. The cross-sectional loss from acid seems to be more damaging than the same apparent loss when a notch is made to the same depth. The poor agreement between the acid and notch samples most likely can be chalked up to non-quantified damage mechanisms such as hydrogen embrittlement. No correlation that could allow a prediction of the rate of long-term corrosion was found during the study. However, it was found that small area losses did have a significant impact on loaded strands tensile strength and that most strands seemed to fail in a brittle manner with little evidence of necking or pitting.

Segan et al. (1984) looked at an individual strand from the seven-strand cable under tension and chloride-accelerated corrosion. The investigation by CERL was designed to measure the time to fail under load due to stress corrosion cracking (SCC) and, from this information, determine the stress intensity factor. The result of single strand experimentation estimated a $K_{1 S C C}$ of 15 to $30 \mathrm{ksi} \sqrt{ }$ (in.). Segan et al. (1984) did not deal with any other failure mechanisms in detail, except to state that load reduction would contribute to an increase in corrosion fatigue (fatigue in a corrosive environment) during lock cycles. While much of the report provides general information, some specifics were given about the standard 0.2-in. wire diameter and crack progression. Specifically, an initiation depth of 0.01 in. was found to be necessary to start SCC, with rapid total failure occurring at an estimated 16 to $166 \mathrm{hr}$ (until the crack reaches $0.07 \mathrm{in}$.). These are sharp cracks, not saw cut depths, but this 0.01-in. threshold seems low. The report also estimated catastrophic failure of a tendon (anchor head) under lockage at John Day if 11 of the 37 strands failed. 


\subsection{Initial results of John Day anchor head disassemblies}

On of the authors of this report, Richard W. Haskins, traveled to John Day in September 2012 for the purpose of examining the condition of deteriorated post-tensioned anchor heads (13-21.5 and 15-21.5). Two heads were selected that were not contributing structuraly to the post-tensioning system, and plans were made to remove the top reaction block of the posttensioning system to examine the materials and conditions in the concrete pedestal/trumpet region shown in Figure 6-5. After removing the protective box cover, the anchor heads appeared as shown in Figure 6-6. The grease in this figure was reapplied in the 2008 pull-off testing effort. During that effort, the structural condition of the anchor heads were assessed by direct pull-off testing. The anchor heads were dissected by hammering out the shim stacks. The second anchor head (15 21.5) required some lateral force, with a small comealong, to release the shim stack.

Once the shim stacks were removed, both anchor heads looked similar. A feeler rod was used to locate the grout in the trumpet. In both cases, no grout was detected. The grease appeared highly contaminated. In the upper section, it was red from rust products and, in the lower section, water and possible mildew had turned it black. Figure 6-7 shows the

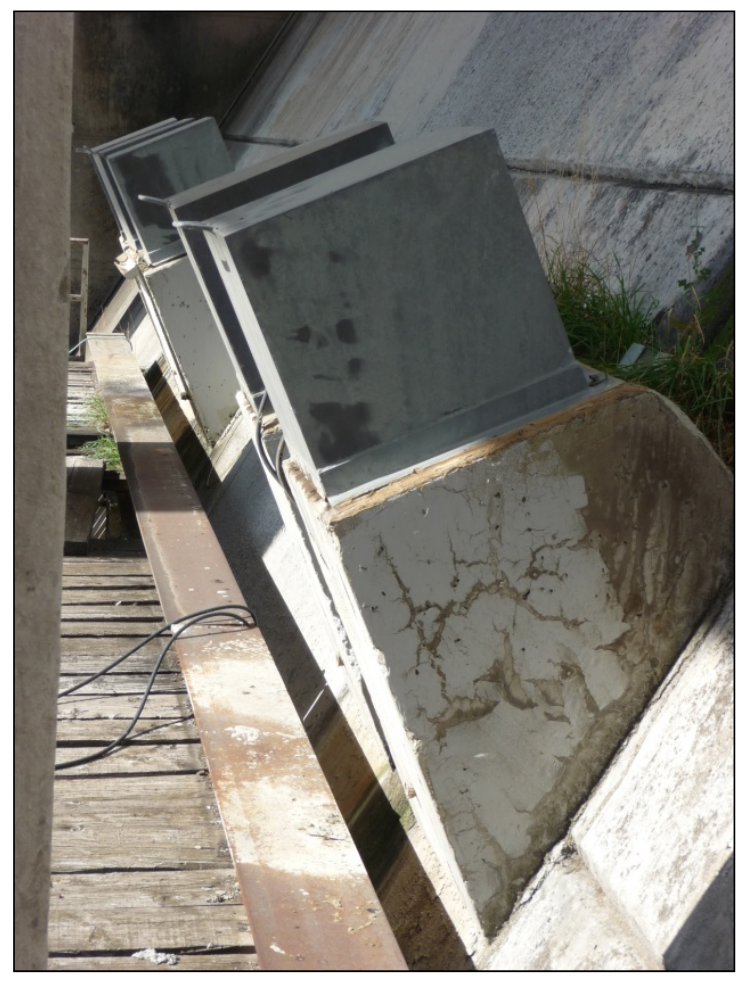

Figure 6-5. Covered anchor head at John Day. 


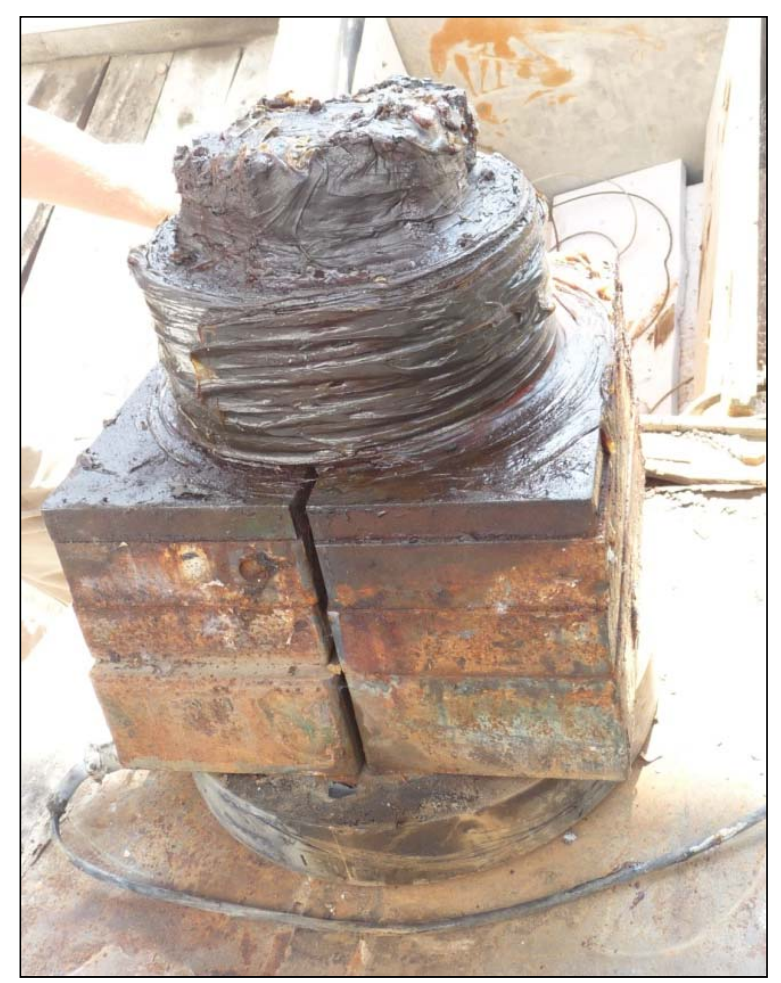

Figure 6-6. Anchor head before removing shim stack.

contaiminated grease. The grease with more rust product is stiffer and, as one moves down from the top of the anchor head, the grease is water saturated and softer.

Found in the anchor heads were tubes of different colors and materials. In Figure 6-8, the red packer air line is being cut. Also observed were rigid tubes that were yellow and blue. It is believed these are grout and possibly vent tubes. During lockages, it was observed in both anchor heads that the mass volume of water was traveling up the yellow tubes. This flow is indicated by the arrows in Figure 6-9. No other water seemed to be entering the trumpet, except from the path of these yellow tubes. This new information changes the perspective of the 1982 inspection report and the 2008 Cornforth report that the water was traveling up the strand itself. Figure 6-10 shows where the water flow through the top of the anchor head leakage had pushed grease away.

Found inside the tubes was some grease that appeared less contaminated. The red staining in the grease was obviously corrosion product (Figure 6-11). The black was believed to be mildew or some other growth contamination. Samples were to be analyzed for mechanical (acoustical) and chemical properties. 


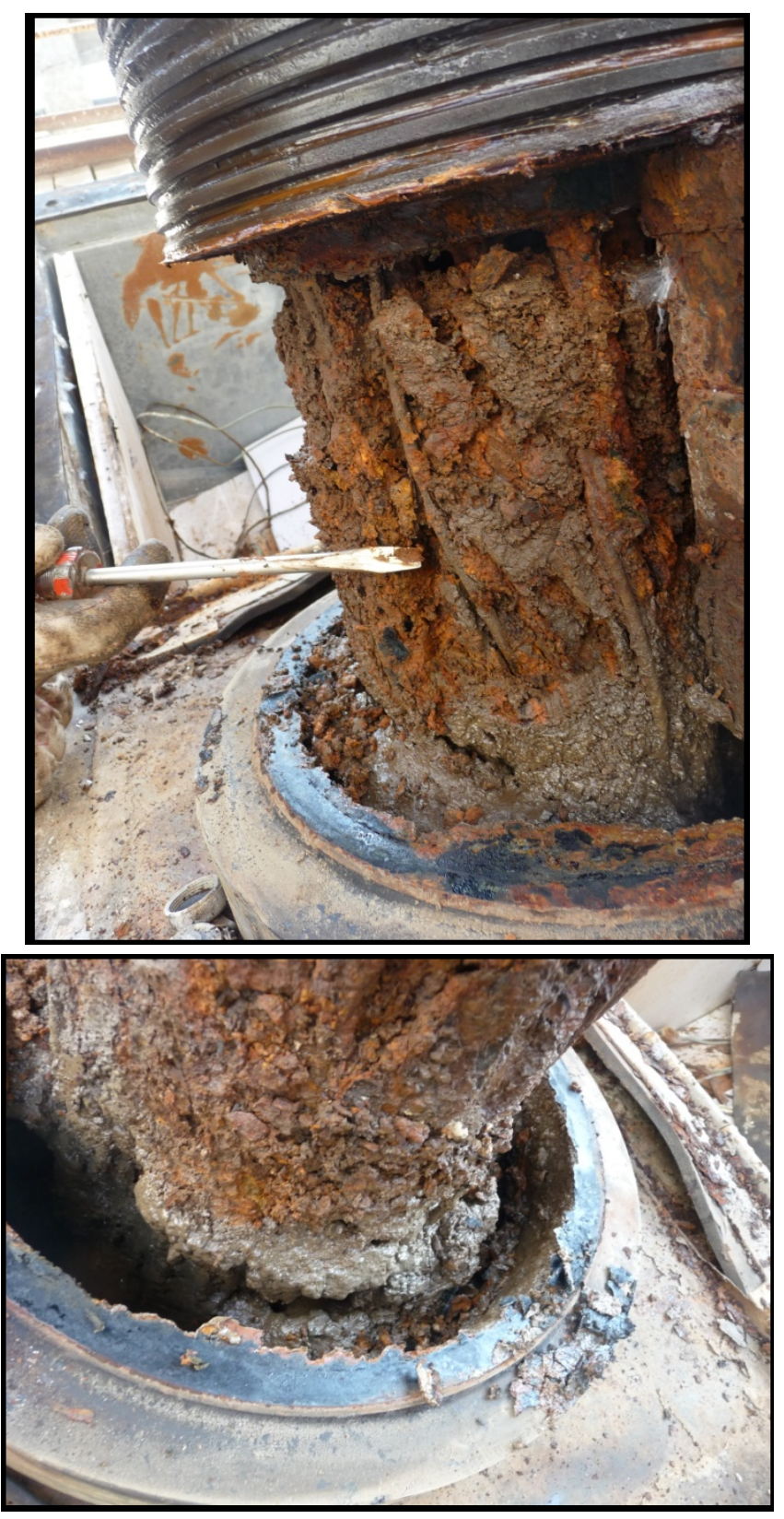

Figure 6-7. Wet grease with rust and possibly mildew contamination (top) and the voided perimeter section (bottom). 


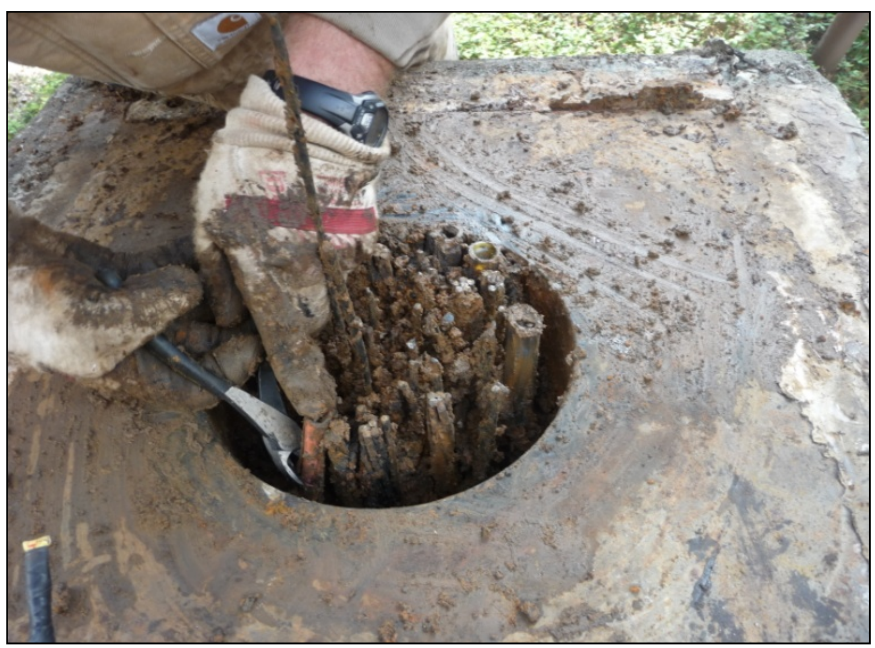

Figure 6-8. Anchor head removed for shipment to ERDCVicksburg.

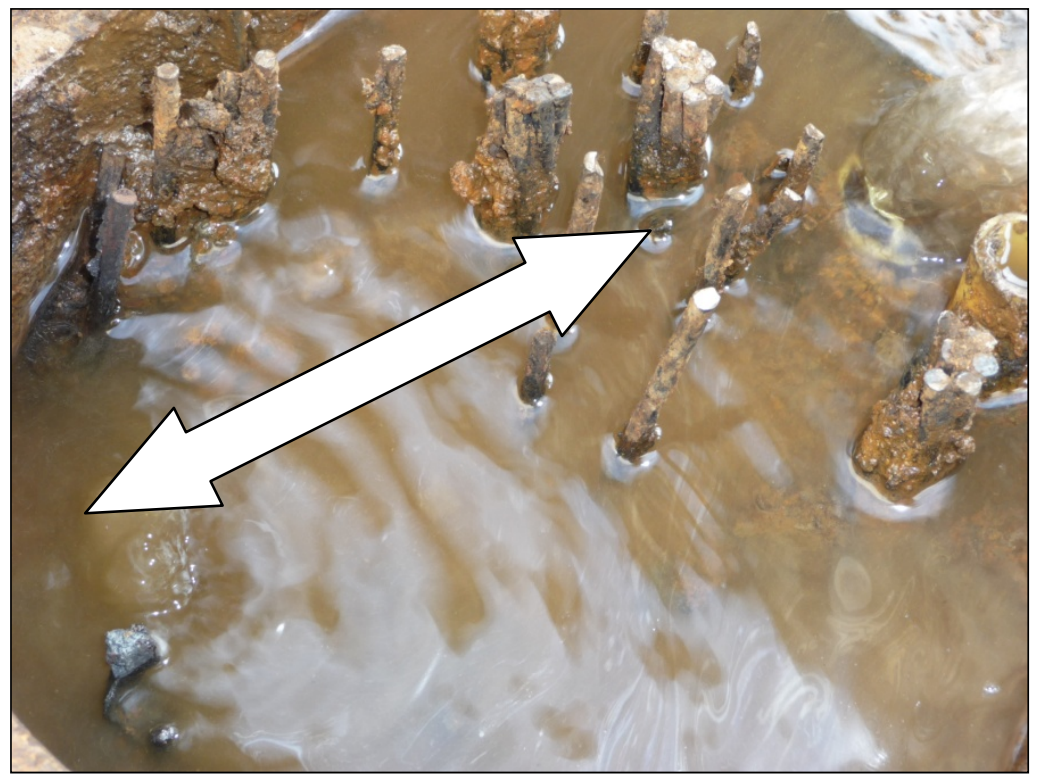

Figure 6-9. Water flowing up yellow tubes during lockages (observed at both heads). 


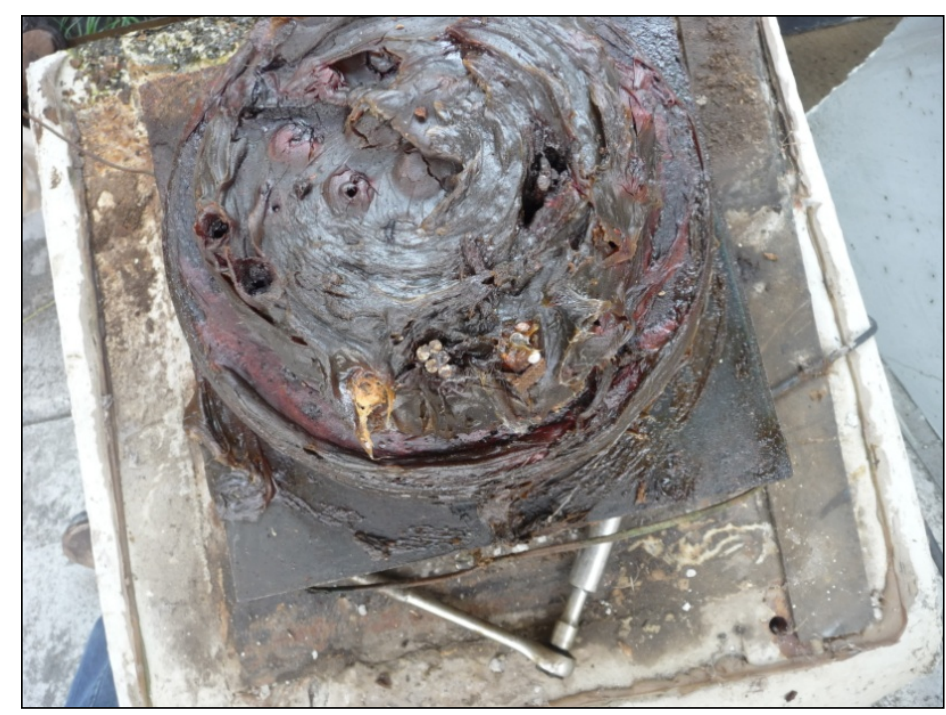

Figure 6-10. Water exits anchor heads through wedges and missing king wires.

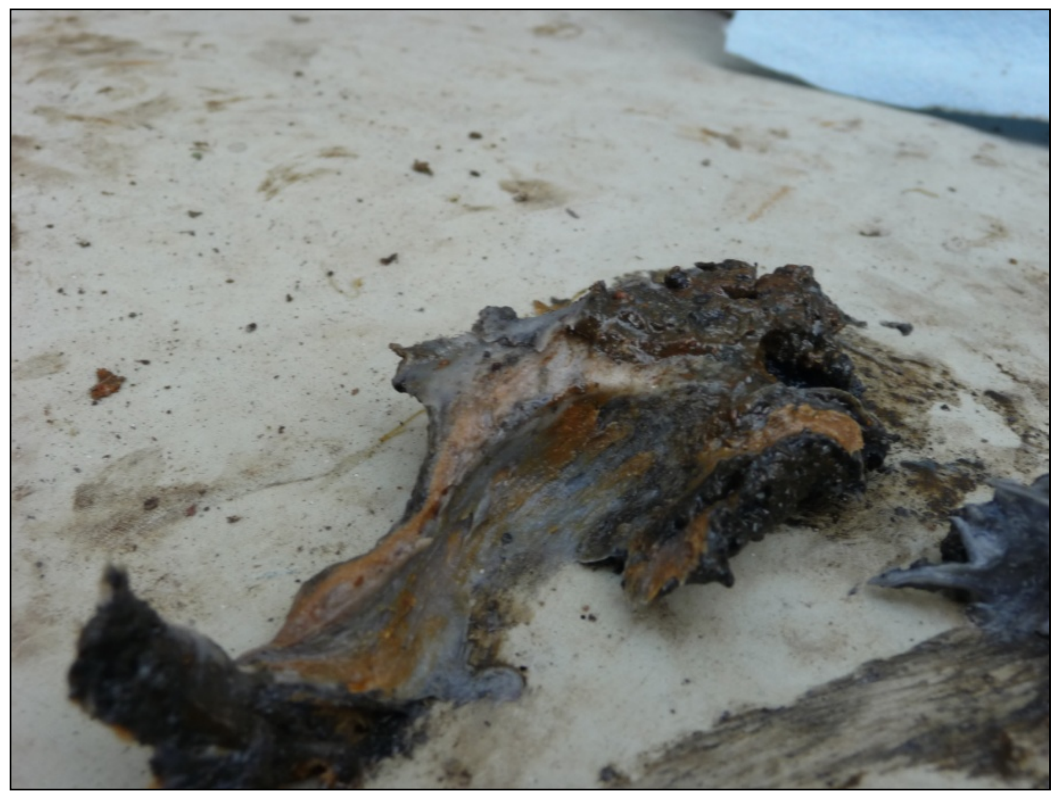

Figure 6-11. Grease with lower contamination (white, black, and red coloration).

Figure 6-12 shows cable sheaths, of which little had been known. They appeared in good condition, with no signs of deterioration. As shown in Figure 6-13, no grout was detected in the trumpet section. A 3 - $\mathrm{ft}$ feeler was used to verify that grout was not where it shouldn't be (at least 18 in. into the trumpet section). The removed anchor heads were being sent to ERDCVicksburg for further analysis. One speculated finding from this trip was the two analyzed anchor heads might have stopped taking grout during construction, explaining the absence of grout in the trumpet section. It also might 
explain the open grout-vent tubes (yellow) that should by any standard have ended up grouted. The two heads disassembled were the worst case in terms of leakage, load loss, and so forth. It was not clear if this ungrouted tube was the primary deterioration problem in all cases.

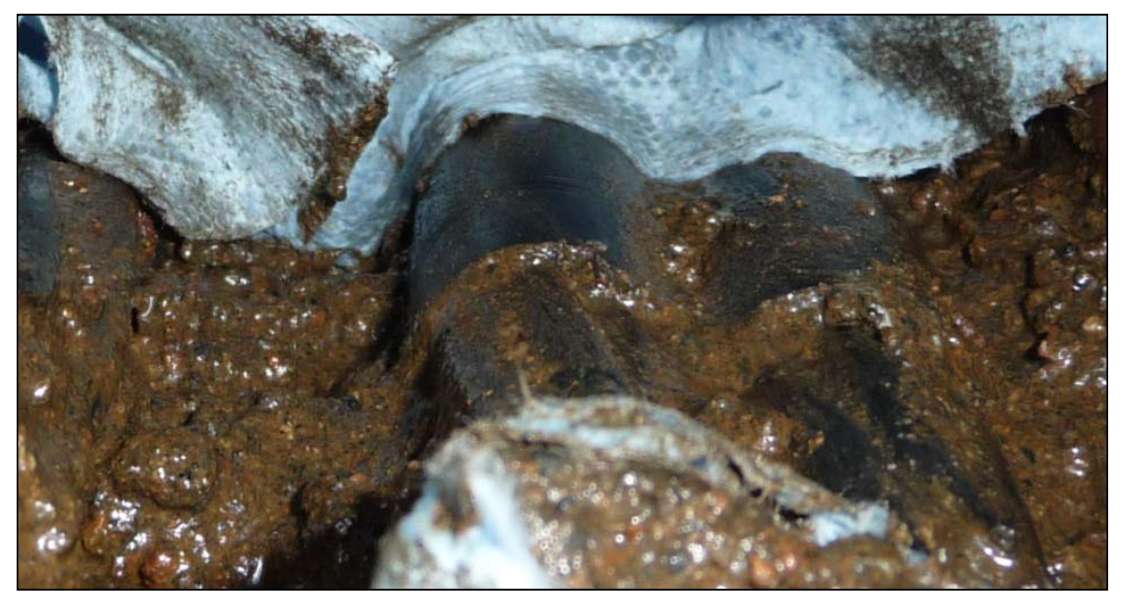

Figure 6-12. Cable sheaths with no signs of deterioration (3/4-in. diameter).

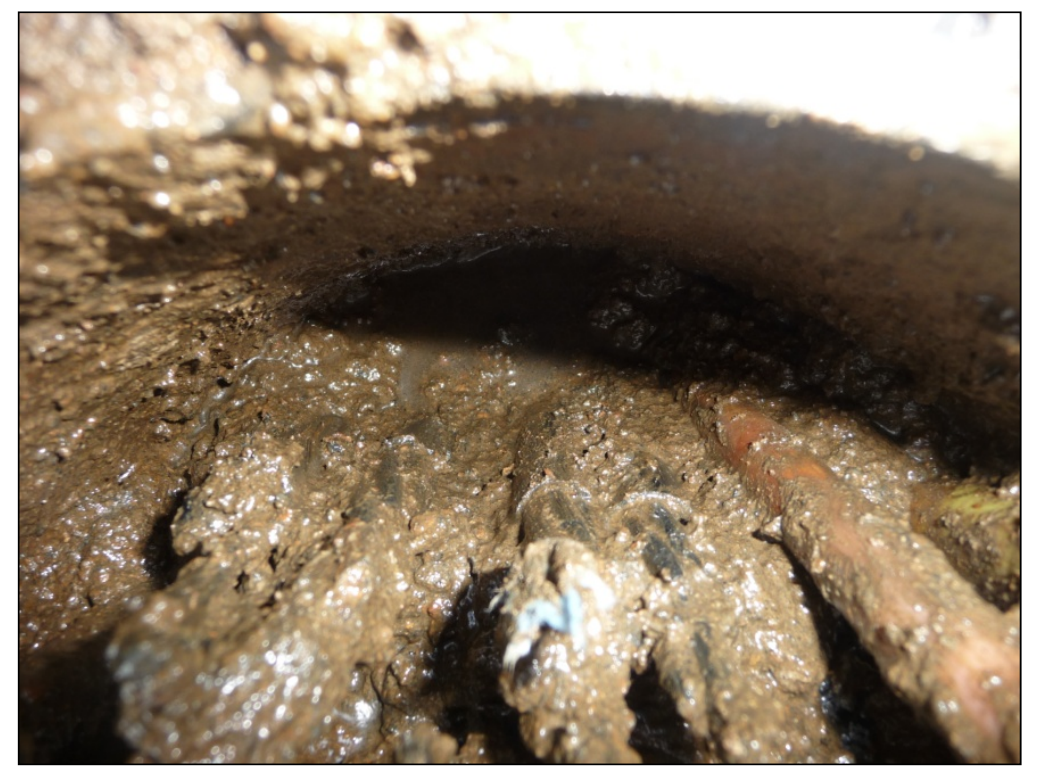

Figure 6-13. No grout detected in anchor heads that were disassembled. 


\section{Nondestructive Testing (NDT) Methods to Detect Anchor System Defects}

A review was performed to investigate previous methods of finding defects in multistrand anchor systems. An important source of information is the application of post-tensioning systems within bridges. Those findings that are relevant to Corps hydraulic structures are summarized in this chapter.

\subsection{National Cooperative Highway Research Program NDT technology review}

The most comprehensive effort related to the NDT of post-tensioning was found in NCHRP (1999).

The objective was to scan for anomalies all strands over their entire length (NCHRP 1999). Meeting this objective for bridge-type structures is extremely difficult and even more so for hydraulic structures where the concrete cover to the post-tensioning system is much greater than that for bridges. NCHRP (1999) considered the following NDT methods:

1. Ultrasonic testing;

2. Nonlinear vibro-acoustic method testing;

3. Pulsed eddy current testing;

4. Electrical time domain reflectometry (ETDR) testing;

5. Surface spectral resistivity method testing;

6. Magnetic sensor testing;

7. Magnetic flux leakage testing;

8. Power-focusing, ground-penetrating radar testing.

Descriptions and detailed evaluations can be found in NCHRP (1999). Problems with some of the methods and others are summarized next.

\subsubsection{Ultrasonic testing}

This is addressed in Chapter 9. 


\subsubsection{Vibro-acoustic testing}

Although this is believed to have potential for long-term success in providing information regarding condition and soundness of the concretesteel interface, it cannot provide a direct measure of loss of cross-sectional area or the presence of cracks or fractures in the strand. Furthermore, it is not applicable to grouted cables.

\subsubsection{Acoustic emission testing}

This has potential for the monitoring of deterioration in unbonded strands, but is ineffective for bonded strands because of severe attenuation of elastic waves due to the surrounding concrete or grout.

\subsubsection{Guided Ultrasonic Waves (GUWs)}

GUWs in post-tensioned cables are discussed in Chapter 9.

\subsubsection{Pulse eddy current}

This method has little potential because of significant problems with detecting flaws in seven-wire strands. Because the strands are ferromagnetic, the depth of inspection is limited to the wire surface.

\subsubsection{Electrical time domain reflectometry (ETDR)}

This shows promise for new post-tensioning installations in which a suitable ground wire can be installed parallel to the strand (sensing wire). Its application to existing bonded post-tensioning systems shows little promise. These logistical retrofit issues include the following. (1) As you go deeper in the post tension system the cables are typically touching or bundled together. (2) Empty tubes or available space would only allow sensing of nearby or adjacent cables. (3) In a retrofit scenario it would be difficult to maintain the sensing wire parallel to the post tension strand. However, for new construction with unbonded systems in which it is possible to install the ground wire in close proximity to the post-tensioned wires, detection of flaws by ETDR might be feasible. 


\subsubsection{Magnetostrictive sensors}

The application of this technology is limited for bonded tendons because of the significant attenuation of waves propagating along steel when embedded in concrete.

\subsubsection{Magnetic flux leakage}

This method has the highest potential for detecting flaws in posttensioning tendons. However, using this method for hydraulic structures might be impractical, considering the depth of concrete cover and environmental factors that will limit equipment access and complicate the interpretation of results. To be effective, the magnetic flux leakage sensors must be in close proximity (a few inches) to the post-tensioned wires. In general, this approach is only applicable for structures like beams and only then for the near surface cables. The permanent magnets used in the system are two large neodymium iron boron magnets. Each of the two magnets is a packed assembly of eight individual magnets, with the overall dimension of each assembly equal to $8.25 \times 4.25 \times 1.8$ in. For post-tensioned concrete hydraulic structures, the difficulty of drilling two large holes near the strands makes it impossible to use this method at Corps projects.

\subsubsection{Power-focusing, ground-penetrating radar}

The electromagnetic field generated by radar cannot penetrate and propagate through steel strands. Therefore, this method is unsuitable for detecting flaws in post-tensioning tendons.

\subsection{NCHRP technical review conclusions}

The review gives no evidence that the state-of-the-art methods in use at the time of the NCHRP report are compatible with NDT methods to reliably predict the extent of corrosion or forecast system failure as a result of corrosion.

\subsection{NCHRP Report 477 (2002)}

In 2002, NCHRP issued a report called Recommended Practice for Evaluation of Metal-Tensioned Systems in Geotechnical Applications. It addressed the corrosion of ground anchors, strands and bars, and other buried metallic systems used for ground slope stability. Ground anchor systems are, with respect to accessibility, more representative of the post- 
tensioning systems used for concrete hydraulic structures. NCHRP (2002) describes four NDT techniques:

1. Measurement of half-cell potential to determine if corrosion is present;

2. Measurement of polarization current to evaluate the level of protection afforded to the post-tensioning system;

3. Impact echo tests to evaluate the condition of the post-tensioning element;

4. Ultrasonic tests to evaluate the condition of the post-tensioning element.

The limitations of NDT, with respect to strand systems, are described in NCHRP (2002):

"The ability to test strand-type elements is limited. The impact test (impact echo) is not applicable because no method has been developed to monitor vibration (i.e., it is unfeasible to attach an accelerometer to the surface of the strand). Application of the ultrasonic test appears possible, but there is limited experience monitoring strand elements. According to observations documented so far, application of the ultrasonic test to strand elements is promising. High-strength quenched and tempered steels, which are sometimes used in the manufacture of strand-type elements, are particularly vulnerable to stress crack corrosion and hydrogen embrittlement. Brittle failure from stress crack corrosion and hydrogen embrittlement occurs suddenly, which is dangerous and aggravated by the fact that ground anchors may be subjected to high pre-stress. It is impossible to monitor these corrosion processes using any of the four tests described above."

NCHRP (2002) indicates the loss of cross section due to general corrosion can be detected, provided the loss is greater than $25 \%$. For the NDT methods recommended in the report, access to the end of the posttensioning element is required.

Figures 7-1 through 7-3 show half-cell potential measurement, polarization measurement, and ultrasonic guided wave testing for wire corrosion-related defects or breaks.

\subsection{Other relevant NDT publications}

ACI (1985) describes tools that can be used to identify corrosive environments, measure the extent of active corrosion, and recognize concrete deterioration that occurs as a result of corrosion. ACI (1985) deals with the 
general topic of corrosion of metals in concrete, and cites NDT methods that can be used, directly or indirectly, for detecting corrosion in mild steel reinforcement. ACI (2001) addresses the corrosion of high-strength, prestressing steels and methods that can be used to detect potential corrosion in pre-tensioned and post-tensioned concrete members. The methods described in the cited ACI documents deal with NDT methods used successfully in the field. Other NDT methods are in various stages of research and, although somewhat limited in application or unproven, they show great promise for field applications, leading to reliable methods for evaluating corrosion damage in high-strength wire. 


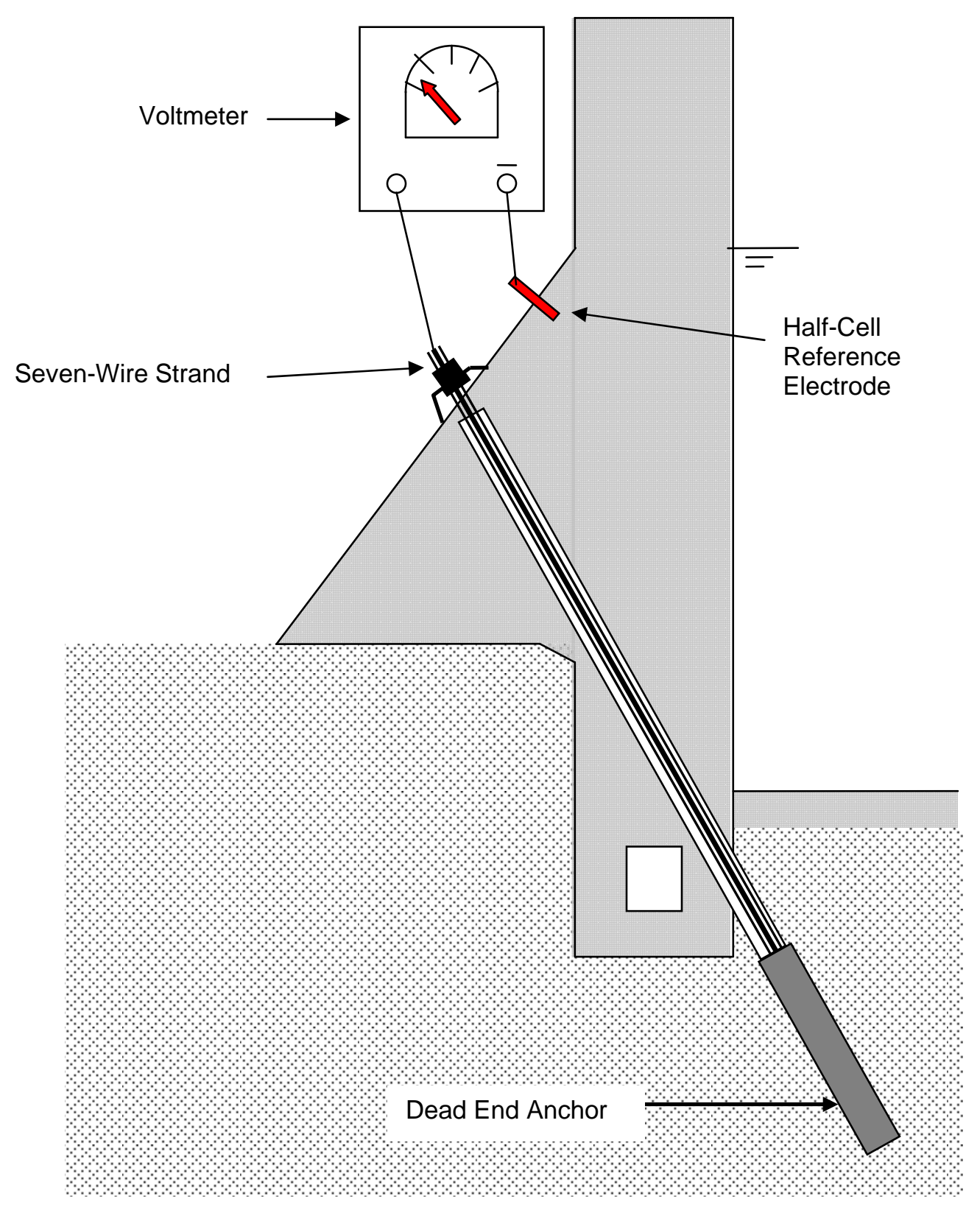

Figure 7-1. Half-cell potential measurement. 


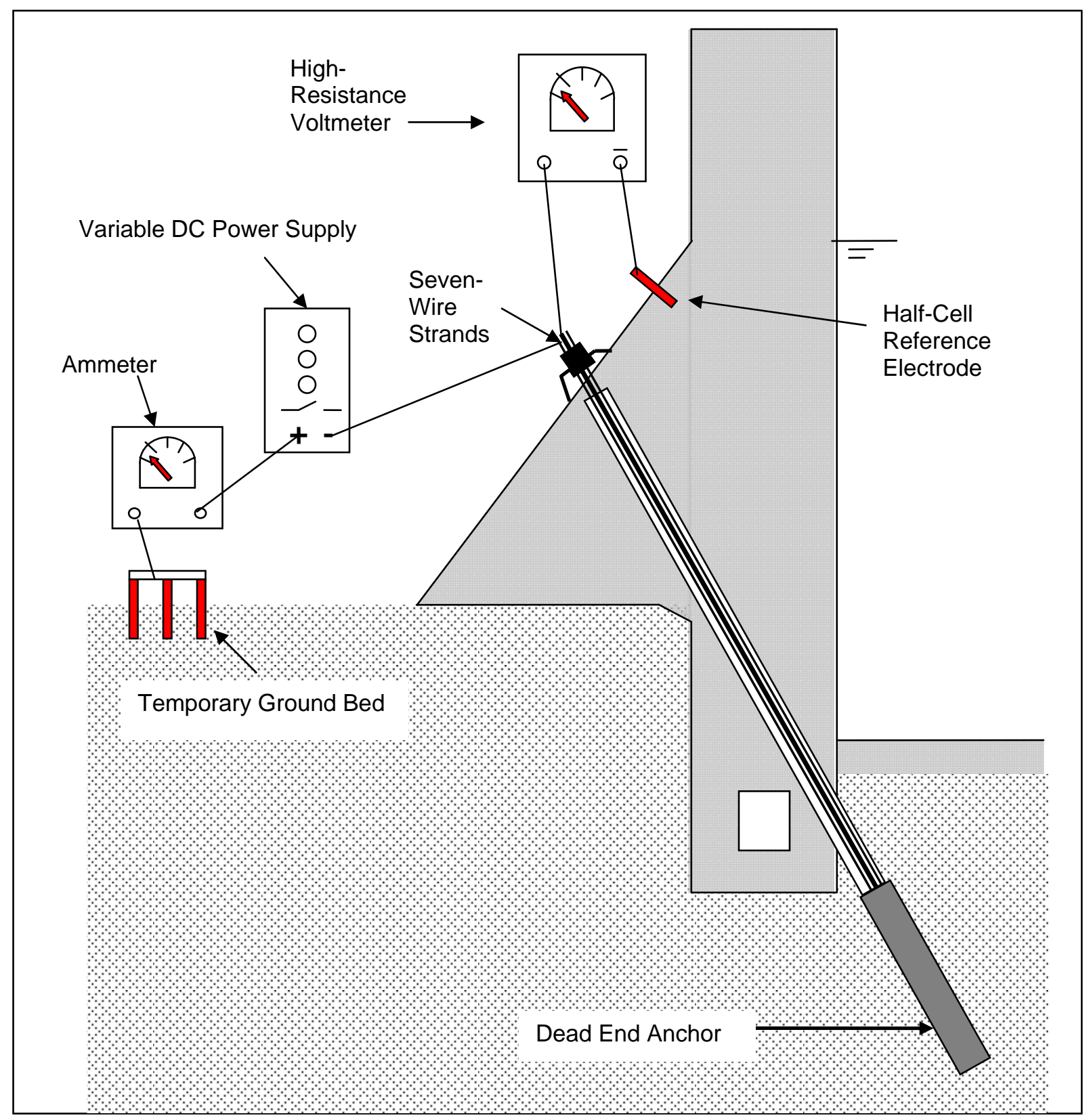

Figure 7-2. Polarization measurement. 


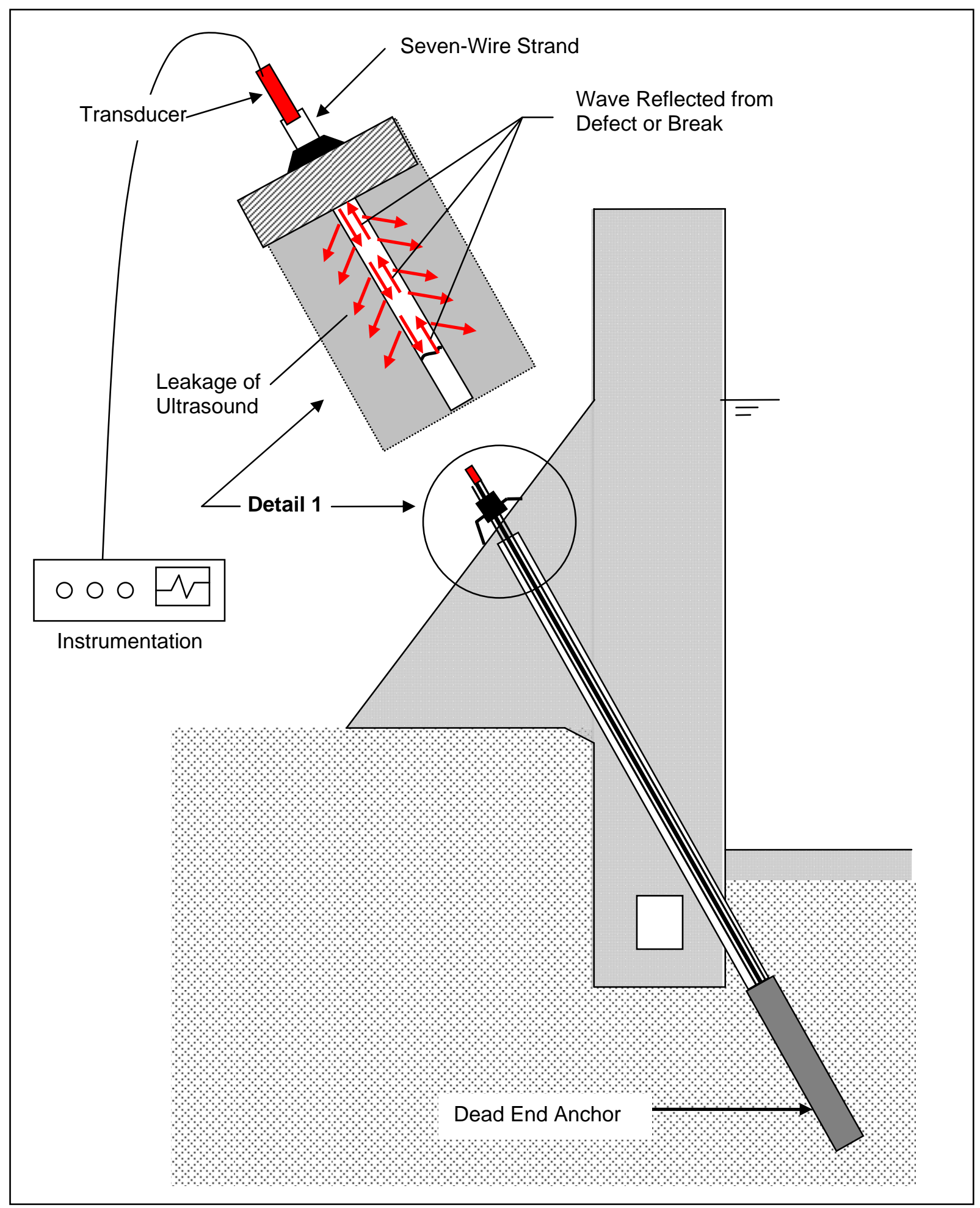

Figure 7-3. Ultrasonic guided waves. 


\section{ERDC Investigation of Post-Tensioned Failure}

\subsection{Pull test purpose}

Under the National Rock Anchor Research Program, Bruce and Wolfhope (2006) give the installation date and location of thousands of anchorages in the United States and Canada. Many of these installations predate modern corrosion protection methods and are therefore at an increased risk of corrosion-induced failure. An understanding of defect origination and progression and its significance, in terms of cable failure and load shedding, ultimately will help determine the requirements of an NDT system to capture and characterize relevant cable conditions. Toward this objective, tensile pull testing of seven-strand cables with defect variations are being performed. The first series of pull tests were conducted using an Instron 440,000-lb universal test machine (Figure 8-1). The o.6-in. diameter sevenstrand, post-tensioned cables and three-part wedge (Part No. 68 oo 0536) were acquired from DYWIDAG System International (DSI). Table 8-1 gives the key properties of the 0.6-in. diameter strand. In the first phase of this investigation, a small number of simple defects were created in the 84-in.long sections of cable. Discussed next are various aspects of naturally occurring and artificially created deterioration and defects.

\subsection{Overview of post-tensioning corrosion and defects}

Three main forms corrosion take place in post-tensioned cables: uniform, localized or pitting, and stress-induced. Hydrogen embrittlement has been considered as a separate type; however, it is now considered a variation of stress-induced corrosion (Fallis 2009). During uniform corrosion, the surface of the steel is attacked evenly and the thickness of a section is decreased uniformly. This generally occurs when unprotected steel is exposed to the environment. Darmawan and Stewart (2007) derive relationships between pit depths and cross-sectional loss. Further, they derive stress intensity factors for both stress corrosion cracking and brittle fracture. Stress intensity factors are discussed below. Other corrosion mechanisms that might be relevant to seven-strand, post-tensioned cables are crevice corrosion, fretting corrosion, and corrosion fatigue. Just as in the case of a pit or crack, a very localized, higher $\mathrm{pH}$ environment can result from the close contact of strands with adjoining strands, ducts, etc. This higher 


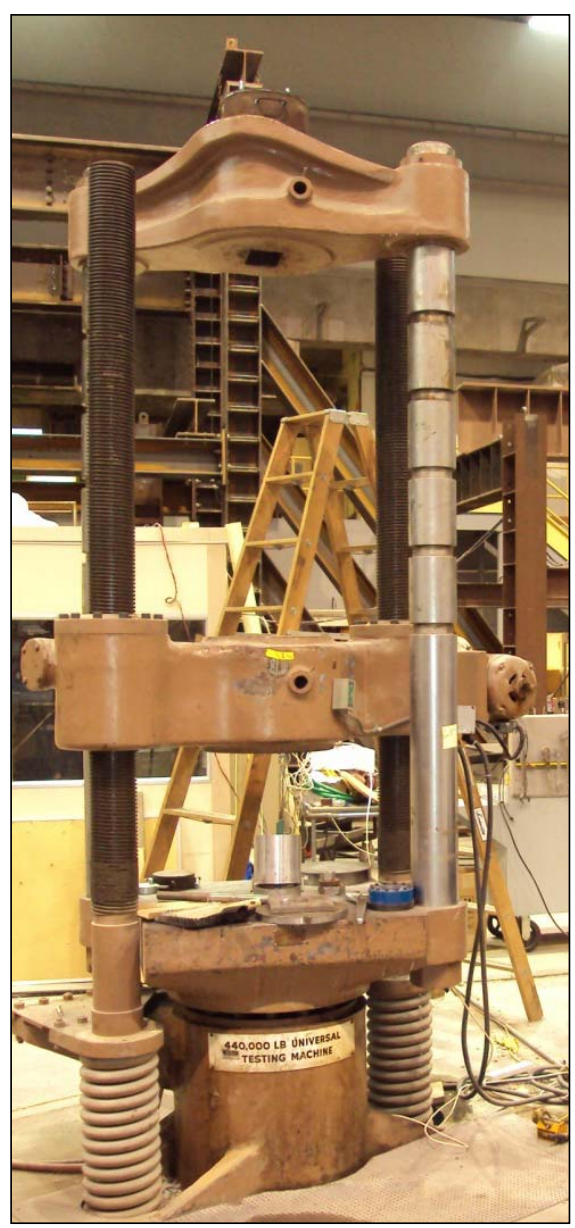

Figure 8-1. Machine used for cable pull test.

Table 8-1. Properties of high-strength cable.

\begin{tabular}{|l|l|}
\hline \multicolumn{2}{|c|}{ Mechanical Properties of Post-Tensioned Cable } \\
\hline Ultimate stress & $270 \mathrm{ksi}$ \\
\hline Modulus of elasticity & $28 \times 10^{6} \mathrm{psi}$ \\
\hline Ultimate strength & $60,800 \mathrm{lb}$ \\
\hline Ultimate elongation & $6.6 \%$ \\
\hline Nominal diameter (total) & $0.6 \mathrm{in}$. \\
\hline Single wire & $0.2 \mathrm{in}$. \\
\hline Steel area & $0.2157 \mathrm{in.} .^{2}$ \\
\hline Yield strength at 1\% elongation & $54,000 \mathrm{lb}$ \\
\hline Lay angle & $7-8^{\circ}$ \\
\hline Length difference (inner and outer) & $0.97 \%$ \\
\hline
\end{tabular}


$\mathrm{pH}$ environment is a catalyst for crevice corrosion (Proverbio and Bonaccorsi 2002). When contacting surfaces experience small displacements, the protective oxidative products that form around the steel are removed from the surfaces and a fretting corrosion can occur. Fretting corrosion also can be described as a material loss during which an actual corrosion product is not produced. Corrosion fatigue is fatigue in the presence of corrosion.

\subsection{Blunt defects such as lab saw cuts and stress concentration factors}

A cut made by a hacksaw blade is a blunt notch that is less influential, at the same depth, than sharp cracks such as the type occurring with stress corrosion cracking or fatigue. Because a sharp cut or crack ultimately will affect tensile strength, several properties can describe these. A stress concentration factor is one such property to describe the cuts made in the pull test. That factor is a number that raises stress locally due to factors such as holes or a change in cross section. In the latter case, the sharper the radius is at the cross-section change or the deeper the notch, the higher the stress concentration. An approximation for a shallow notch can be determined by:

$$
\mathrm{K} \tau=1+2 \tau r
$$

where $\tau$ is the depth of cut and $r$ is the radius of curvature of the notch. For this pull test, the radius is $0.015 \mathrm{in}$. and the two depths are 0.01 and $0.06 \mathrm{in}$. The resulting $K \tau$ factors using this approximation are 2.63 and 5.o.

\subsection{Sharp cracks and stress intensity factors}

The failures in the field potentially are precursored by sharp cracks as opposed to the blunt notches used in the pull test. Stress intensity factors are used to describe the fracture toughness in these situations. The stress intensity factor is a bit different from the stress concentration factor described above; it is an inherent property of the material that is tested and defined for various cracks or flaws. For cracks and flaws, the radius is small, approaching zero for sharp corners, and stress concentration factors become very high, approaching infinity. Used to calculate allowable stresses in this case were the measured stress intensity factor and equations of fracture mechanics. The stress intensity factor, $K$, has the form: 


$$
K=P * f a * a
$$

where $P$ is applied load, $a$ is crack length, and $f(a)$ is a geometry constant for a given crack length. The strength of a material in a corrosive environment is defined by the critical stress intensity factor for stress corrosion cracking (SCC) $\left(K_{1 s c c}\right)$. Testing by Segan et al. (1984) has shown the steel used here is susceptible to SCC and that the $K_{1 s c c}$ is 15 to 30 KSI(in.2). Based on this number and a working load of 6 kips, the crack needed to exceed $30 \mathrm{KSI} \sqrt{ }$ (in.) is about $0.01 \mathrm{in}$. (Segan et al. 1984). At this depth, the crack would undergo steady state growth in low $\mathrm{pH}$ environments, such as a crevice or corrosion pit. Darmawan and Stewart (2007) report an estimated $K_{1 s c c}$ threshold intensity factor of $39 \mathrm{ksi} \sqrt{ }$ (in.) and a $K_{1 c}$ for brittle fracture of $78 \mathrm{ksi} /$ (in.) based on the findings of several prior researchers. Laboratory and field findings discussed in that paper indicate stress corrosion cracking often is not the cause of failure, probably because the corrosion pit is not sharp enough for linear elastic fracture mechanics (LEFM) to apply. At the same time, they warn SCC cannot be ruled out because its likelihood is dependent on stress level, chemical environment, and mechanical and chemical properties. For grout-protected, prestressed strands, Darmawan and Stewart (2007) did not observe signs of SCC, crevice corrosion, or significant king wire corrosion. In their probabilistic model developed from accelerated corrosion testing that ignored corrosion edge effects, they found a $30 \%$ cross-sectional area loss could occur after only 20 years of a relatively low corrosion rate.

\subsection{Edge effects}

Based on conversations with DSI, a major supplier of post-tensioning hardware, it is common for failures to occur at or near the anchor wedge. This was observed in the field at John Day because many of the failed extruded king wires were 6 to 8 in. long, putting their failure points in the region of the wedge tip. A number of logical influences make this location a potential weak link:

1. The waterproof sleeve and grout must stop before the wedge so the wedge can bite into the cable. This leaves only the corrosion-inhibiting grease.

2. The wedge is a region of high stress and also has a high-stress differential.

3. Temperature, moisture, oxygen, galvanic potential, biological growths, etc., are generally worse in terms of corrosion potential at or near the wedge or trumpet area. 
4. The wedge itself initiates a surface defect that might contribute to crevice corrosion, chloride/phosphate buildup, or other failure mechanisms.

An apparent deficiency in both the Portland District-sponsored reports is, while the strands or cables were studied under tension and corrosion catalysts, the wedges and corrosion edge effects were part of the studies. The ASTM A370-12 Annex A7, which describes testing guidelines for multi-wire strands, gives the mechanisms for end fixation so failure occurs away from the gripping wedges and in the interior cable sections. These include such things as solder-potting the grip wedges or using a soft metal such as copper to more evenly distribute the tensile loading stress. The purpose is for the pull tests to evaluate only the cable strength. The authors of this report, on the other hand, are seeking to evaluate the system performance closer to how it acts in the field. With the exception of notch-induced failures at cable midspan and an occasional wire failure in proximity to it, all the failures observed here were at the wedge tips. Figure 8-2 illustrates the common failure observed at the bottom of the wedge. Notice the clear indentations in the cable from the wedge teeth. Figure 82a shows a wedge being taken apart where the strand failed just inside. Figure 8-2b shows the teeth of the three-part wedges from various perspectives, Figure 8-2c shows two wires broken just above the wedge tip. Figure 8-2d shows a number of strands with this consistent failure location and pattern.

\subsection{Variations in defects for pull testing}

To control the potentially large number of defect variable permutations in the initial pull testing, only a few variations were explored. All cables were pulled to total failure, meaning when possible all seven strands were broken. Two pristine wires were tested, and the rest were single cuts made to depths of 0.01 or 0.06 in., using a hacksaw on single strands. Cuts were made in either a perimeter wire or the king wires at either midspan of the 84-in. span or near the gripping wedge tip. Table 8-2 shows the varied parameter values for each test, shorthand graph labels, and the loads at the first and maximum breaks. Test 3 was not a saw cut, rather a smooth tapered reduction in a cross section around the perimeter of the wire. The table shows both the load at first break and the maximum load the cable attained. 


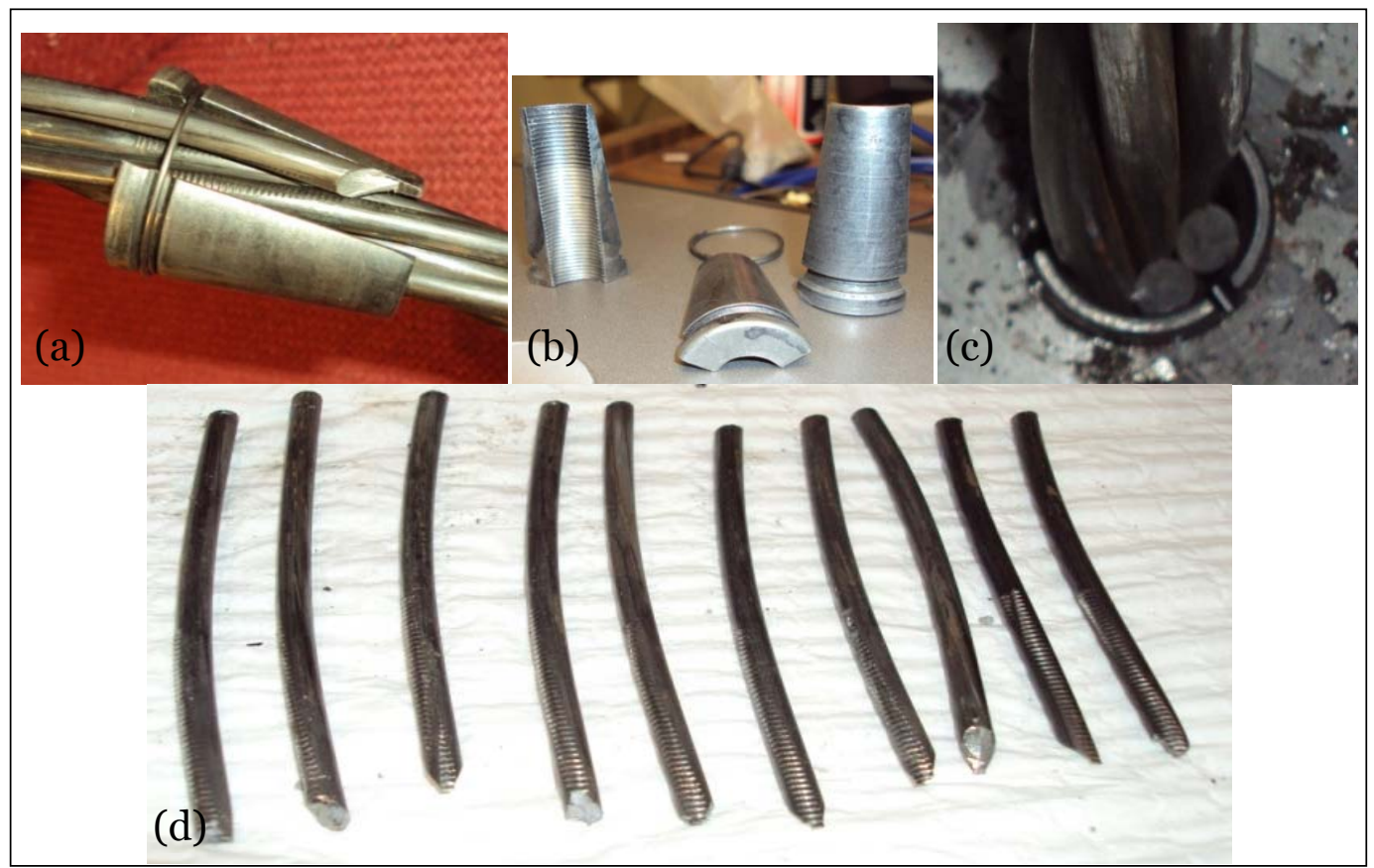

Figure 8-2. Common perimeter wire failure at wedge tip.

Table 8-2. Defect variations and ultimate strength of the first and maximum breaks.

\begin{tabular}{|l|l|l|l|l|l|l|}
\hline Test No. & Location & Depth & Wire & Max Load (lb) & Load (first break) & Graph Label * \\
\hline 2 & -- & --- & pristine & 58,006 & 58,006 & $\mathrm{p}$ \\
\hline 3 & - & --- & - & 52,970 & 51,698 & \\
\hline 4 & middle & 0.01 & perimeter & 48,867 & 47,769 & smp \\
\hline 5 & middle & 0.06 & perimeter & 50,120 & 33,557 & $\mathrm{dmp}$ \\
\hline 6 & middle & 0.01 & king & 55,905 & 55,905 & smk \\
\hline 7 & middle & 0.06 & king & 52,645 & 45,387 & $\mathrm{dmk}$ \\
\hline 8 & --- & --- & pristine & 56,770 & 56,770 & $\mathrm{p}$ \\
\hline 9 & at wedge & 0.06 & king & 51,187 & 51,187 & $\mathrm{dwk}$ \\
\hline 10 & at wedge & 0.01 & king & 55,792 & 55,792 & $\mathrm{swk}$ \\
\hline 11 & at wedge & 0.01 & perimeter & 53,144 & 52,666 & $\mathrm{swp}$ \\
\hline 12 & at wedge & 0.06 & perimeter & 52,954 & 36,690 & $\mathrm{dwp}$ \\
\hline
\end{tabular}

Label legend: location: W (at wedge), M (middle span); depth: S (shallow), D (deep); wire: P (perimeter), K (king).

\subsection{Notch vs. surface erosion}

Because failures in the field might be due to deterioration all the way around the wire surface (uniform corrosion), a conversion was made to allow comparison between notch depth area used in the pull test and an equivalent perimeter loss area. Figure 8-3 shows the relationship between a radial percentage of a saw-cut notch and the equivalent area from a radial percentage loss around the wire's entire perimeter. So, from the first point 
on the graph in Figure 8-3, a saw cut that is $10 \%$ of the radius is roughly equivalent to a $1 \%$ loss of radius all the way around the wire's perimeter. This 10\% radial cut is the 0.01-in. cut used in this experiment, with a remaining wire area of 0.031 in. ${ }^{2}$. The 0.06 -in. saw cut is a $60 \%$ reduction in radius, leaving 0.023 in. ${ }^{2}$ of cross section. As shown in Figure 8-3, this results in a stress equivalent of roughly a $13 \%$ loss of radius around the perimeter.

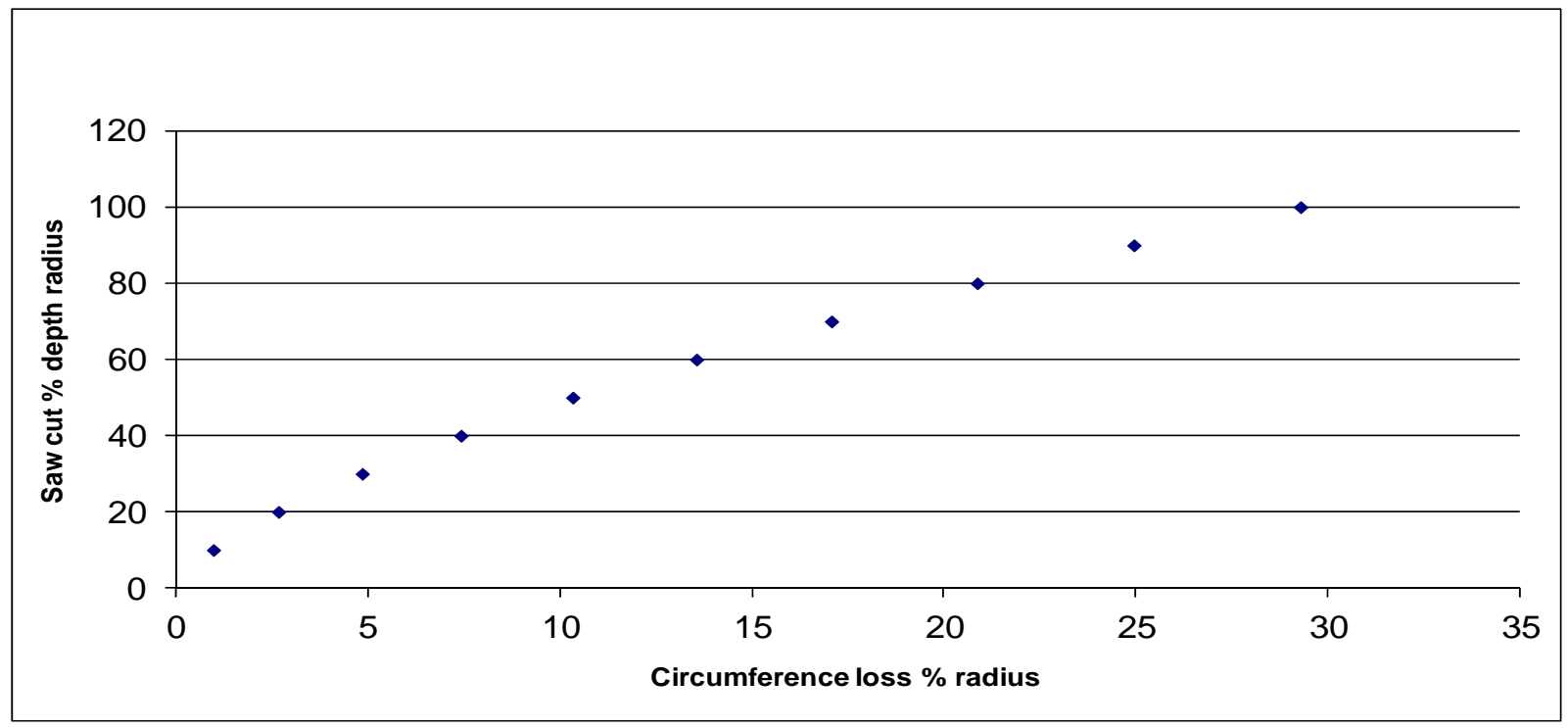

Figure 8-3. One-sided notch area vs. circumference loss.

\subsection{Failure data: Results and observations}

Figure 8-4 shows a load-vs.-displacement plot for the seven-strand cable evaluated in Test 10. All seven-strand breaks can be seen in this curve, as well as the relaxation in load and required displacement to re-tension the cable. Only a few of the strand breaks of the 60 to 70 observed exhibited necking at the failure. Most failures appeared to be brittle, and the failures at the wedge showed signs of shearing.

Brittle failure or low ductility is common in high-strength steels. In addition to load-vs.-displacement curves, stress-vs.-displacement curves were created by dividing by the area of the remaining strands. Figure 8-5 shows the stress-strain curve for the same test depicted in Figure 8-4. The entire load and stress data sets for the 10 pull tests are in Appendix A. 


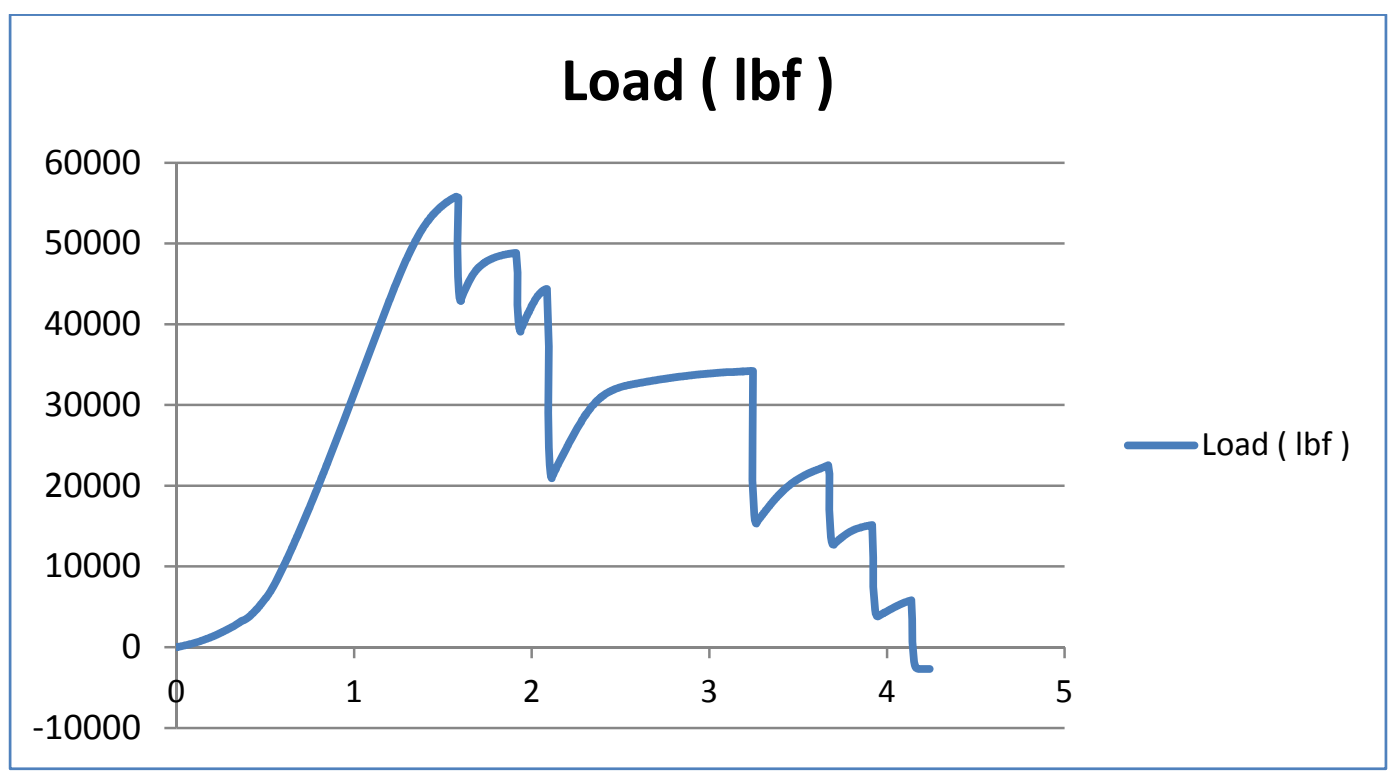

Figure 8-4. Typical seven-strand load-vs.-displacement curve for swk (Test 10).

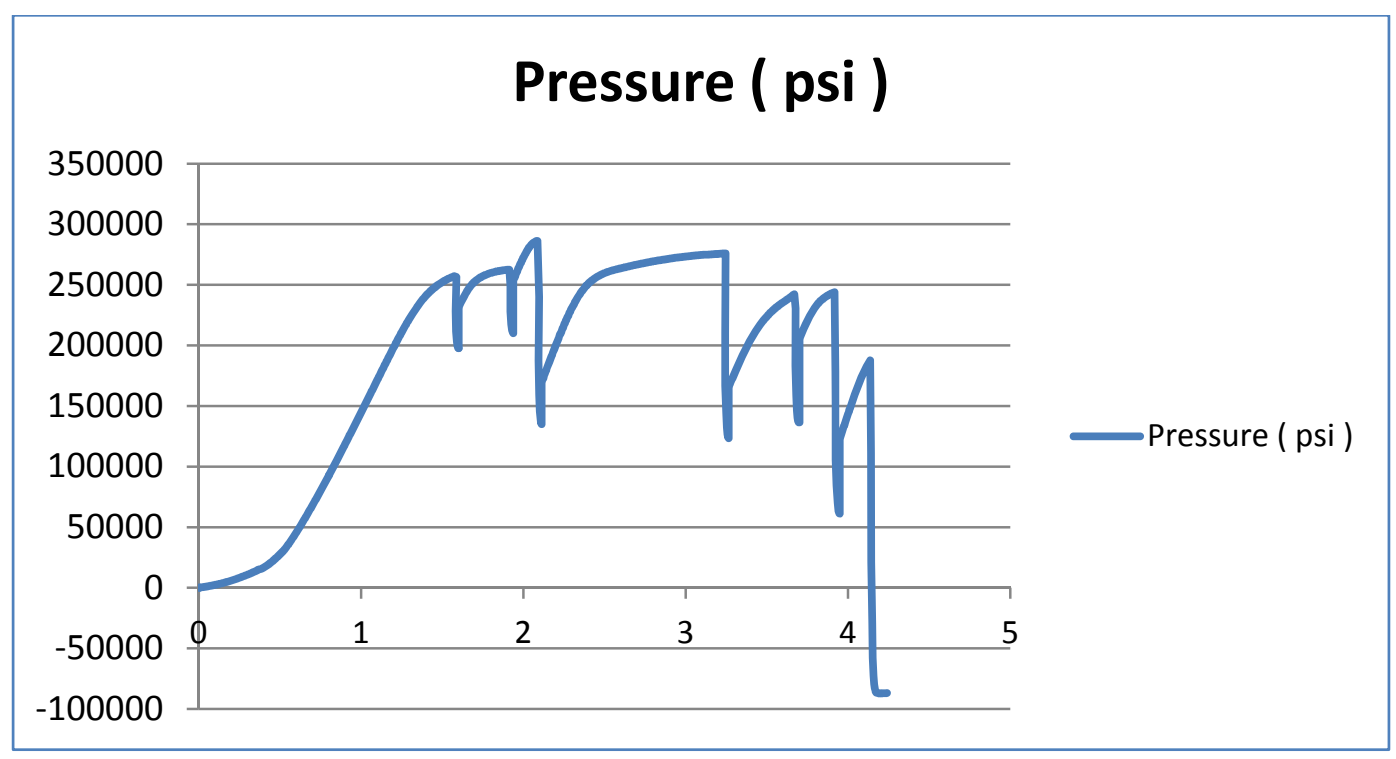

Figure 8-5. Stress for swk (Test 10) determined by changing cross-sectional area as strands fail.

Figure 8-6 graphs the percent reduction in tensile strength at the first break (data in Table 8-2). This graph captures the relevant strength influences of the various defects in terms of the first break.

Some things about the varied parameter were observed. A notch in the perimeter wire had a greater influence than a notch of the same depth in the king wire, in terms of the first strand failure. This difference was an additional 17 to $22 \%$ reduction in ultimate strength. Likewise, a notch at midspan had slightly more impact than the same notch near the wedge 


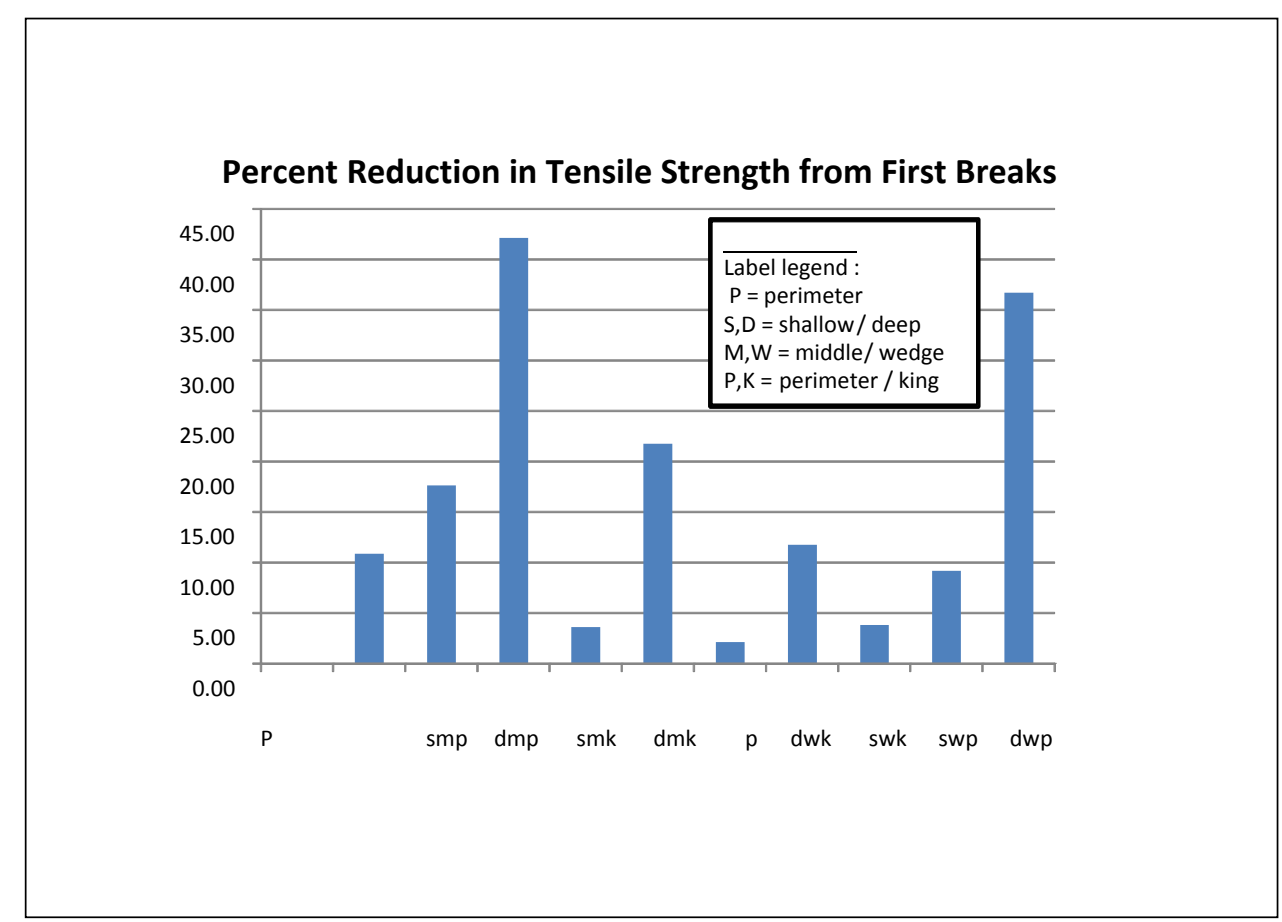

Figure 8-6. Tensile strength from a notch at various locations, depth, and wires.

(4 to 5\% strength reduction). Failure of the king wire away from the wedge (due to an imposed defect) causes the outer wires to fail in the same location. Failure of the first strand generally sheds 10 to $20 \%$ of the load. Another observation from the laboratory testing to date is that subsequent wire failures tend to cause the next outer adjacent wire to fail. This failure has more to do with tension on the strand than the presence of the strand because the subsequent failures commonly alternate between top- and bottom-loading wedges. This is true probably due to rotational shear forces building around the missing strand. The scalloped and angled fracture surfaces near the wedge breaks indicate a brittle shear fracture mode. Scalea et al. (2003) determined the axial load on the king wire was only $1 \%$ larger than the axial load on the perimeter wires. They also determined analytically that the bending and twisting forces in the helical wires could be neglected. It might be that this is true for strand sections away from the wedge and less true as the resistance imposed by the wedge is approached.

Simultaneous strand failure (i.e., failure of more than one strand at a time) occurred only for the cases for which there was cable symmetry, such as for the pristine wires. Integration was used to compare the area under the loading curve across the studied set of defects. While the contrast was small, the damaged king wires did result in a lowered performance of the strand as all the individual wires continued to fail. At John Day and similar sites 
where one anchor head is used to load multiple strands, individual wire displacement (i.e., loading) is not possible. Even if individual strands could be re-tensioned, there is a high probability corrosion would not allow physical separation of the wedge and its receiver. Cornforth Consultants (2009) warns any field tensioning, even for the purposes of assessment, carries an intrinsic risk of failing wires that are at reduced capacity due to corrosion.

\subsection{High-resolution fracture surfaces}

Fracture surfaces were imaged using scanning electron microscopy (SEM) and optical microscopy (OM). SEM imaging was performed using an FEI Nova NanoSEM 630 field-emission scanning electron microscope. The instrument was operated at an accelerating voltage of $15 \mathrm{kV}$, in secondary electron mode. The specimens were sputter-coated with gold $(\sim 20 \mathrm{~nm}$ thickness) to minimize charging issues during SEM imaging. OM images were obtained using a Zeiss SteREO Discovery.V12 stereo microscopy, with no additional sample preparation. The cup/cone failure, shown full scale in Figure 8-7 (a, b) and in high resolution in 8-7c, shows typical fracture for pearlitic (mixture of ferrite, $\mathrm{BCC} \mathrm{Fe}$, and cementite, $\mathrm{Fe}_{3} \mathrm{C}$ ) pre/poststressing steels in which small zones of ductile fracture exist but large cleavage planes that form cracks where the longitudinally oriented grains begin to exfoliate and separate.

A shear failure is shown in Figure 8-8 (a, b, c). It can be difficult to see shear fracture surfaces in pearlitic steels because the grain sizes are so small (nanoscale). It is clear that the failure surface is much smoother, though, compared to the cup/cone failure (Figure 8-7), which is typical for shear failures. This failure surface also is at $\sim 45^{\circ}$ (Figure 8-8a, b), which indicates shear mode of failure.

Figure 8-9 shows the failure of the notched sample. The rough area on the right in Figure 8-9c is where the fracture occurred. On the right in Figure 8-9a is the cut (notched) surface. There is a transition between the notch and the fracture surface, from the smooth face on the left in Figure 8-9c and the rough area on the right in that same figure, where the fracture occurred. Observed were some zones of ductile failure and many cleavage faces adjacent to the notch (appearing as stair steps randomly distributed near the interface). 


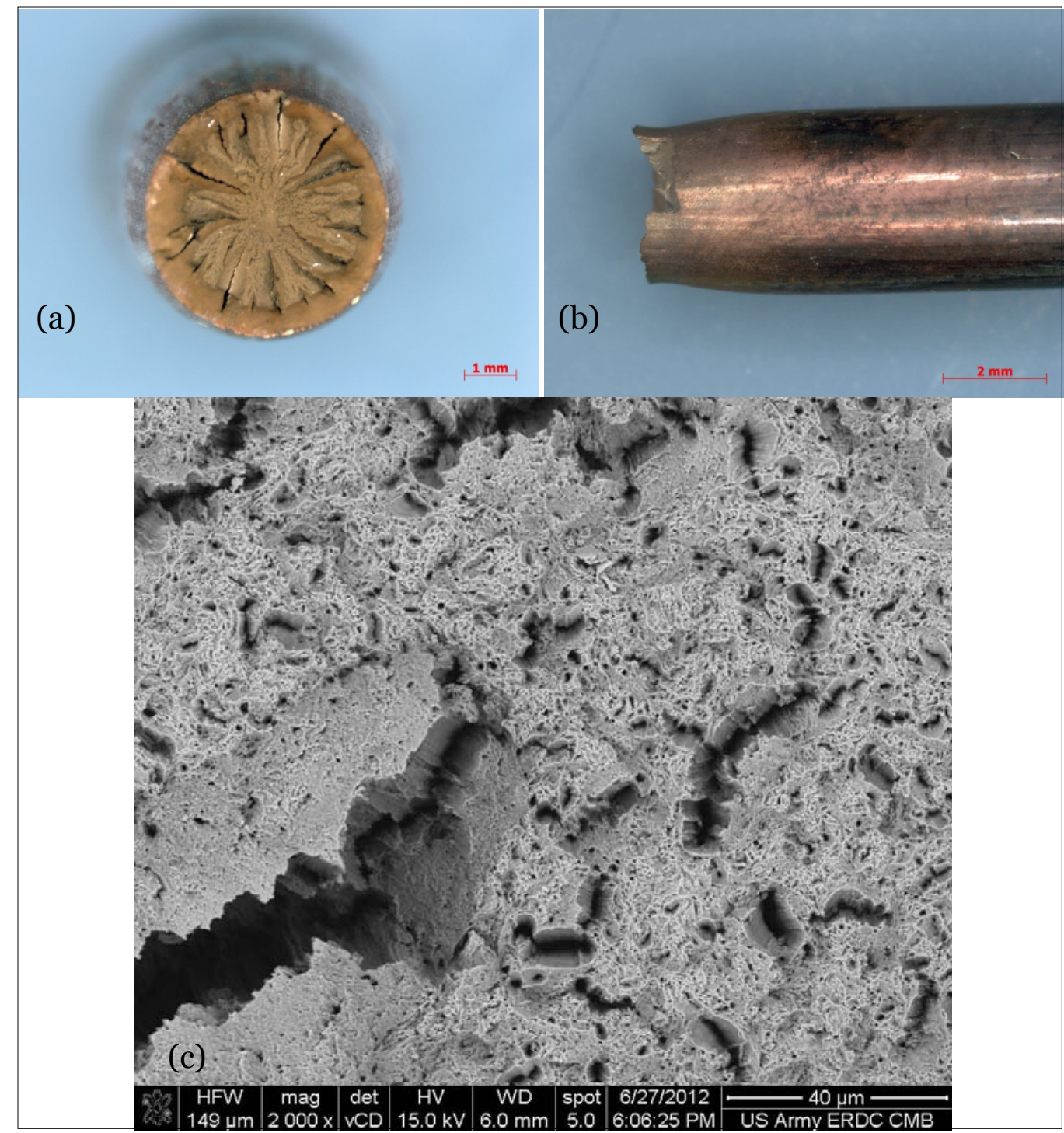

Figure 8-7. Images of (a) cup failure and (b) cone failure with (c) high resolution.

\subsection{Correlation of laboratory and field observations of exposed ends}

Recent pull tests have indicated that the small (1/16 to $1 / 8$ in.) vertically displaced wires, as seen from the top of the loading head in both the field and lab, most often appear to be a result of that specific single wire failing. Figure 8-10 shows the (a) surface past the wedge (b) in the smooth condition (c) and with a displaced king wire (d) and perimeter wires. The king wire is the center wire, and perimeter wires are the outside wires. Cornforth Consultants (2009) compared observed failure with calculated remaining strands and estimated that observation of the displaced end captures all but about 7 to $8 \%$ of the failures. So far, lab testing has been performed on ungrouted sections of cable and, in these tests, it was common for a cable to fail without resulting in any visual clue in terms of strand displacement 


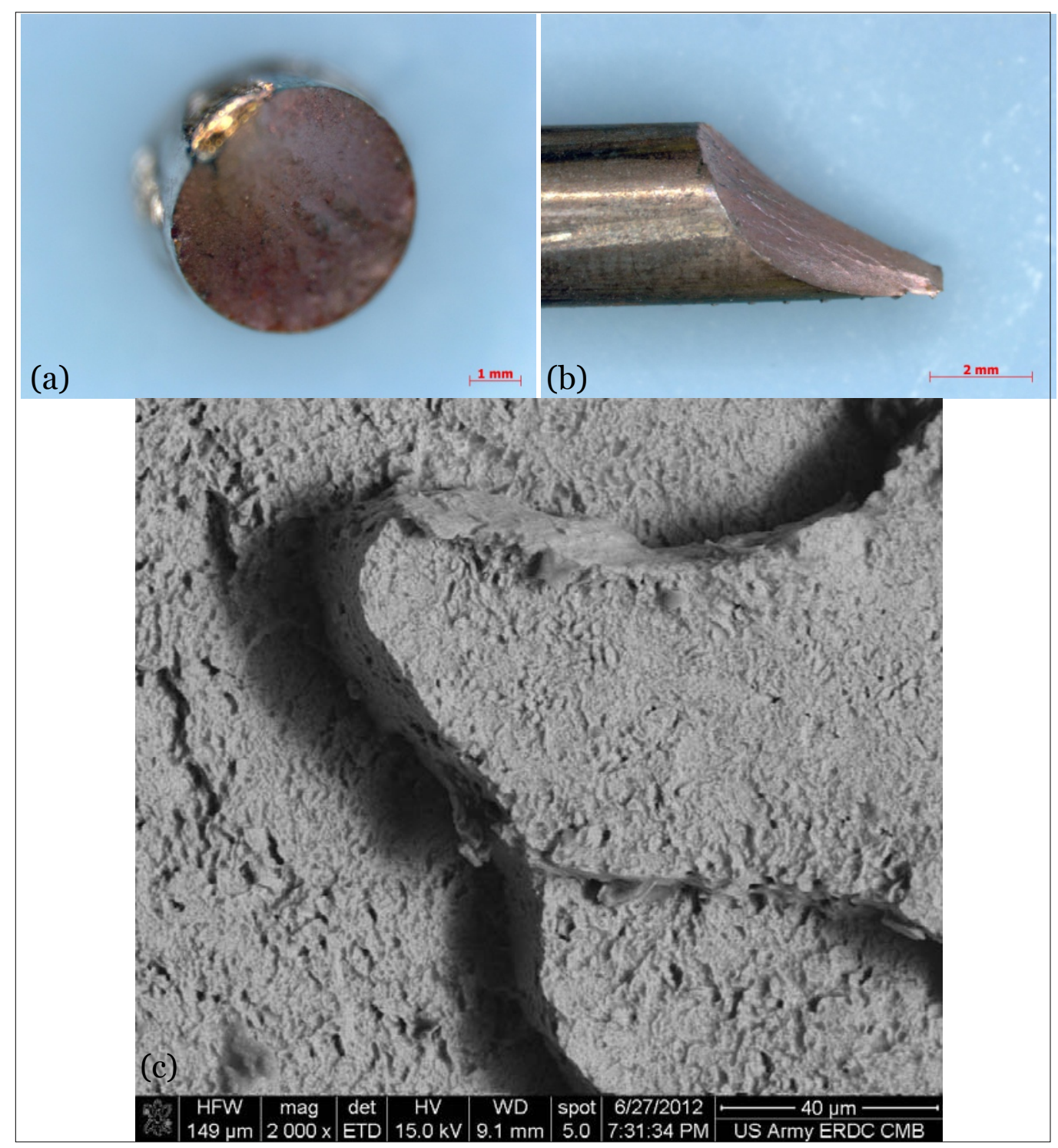

Figure 8-8. Images of shear failure: (a) section view, (b) side view, and (c) high-resolution view.

beyond the wedge. The shorter sections of cable would store less potential energy. This issue, along with the lack of a confining grout, might explain the difference between end displacement observed in the laboratory and observations made in the field. It was common in these initial laboratory pull tests for a failed strand to unwind itself. Typically, a strand will fail near the tip of the wedge and, as a result, will unwind itself at the other end with a 6- to 10-in. bend radius being the norm. Figure 8-11 shows the unwound cable in the universal testing machine. It was unclear if the presence of a confining "plastic" grout, such as at John Day, would force the energy back up to the wedge and result in more displacement beyond the wedge. 


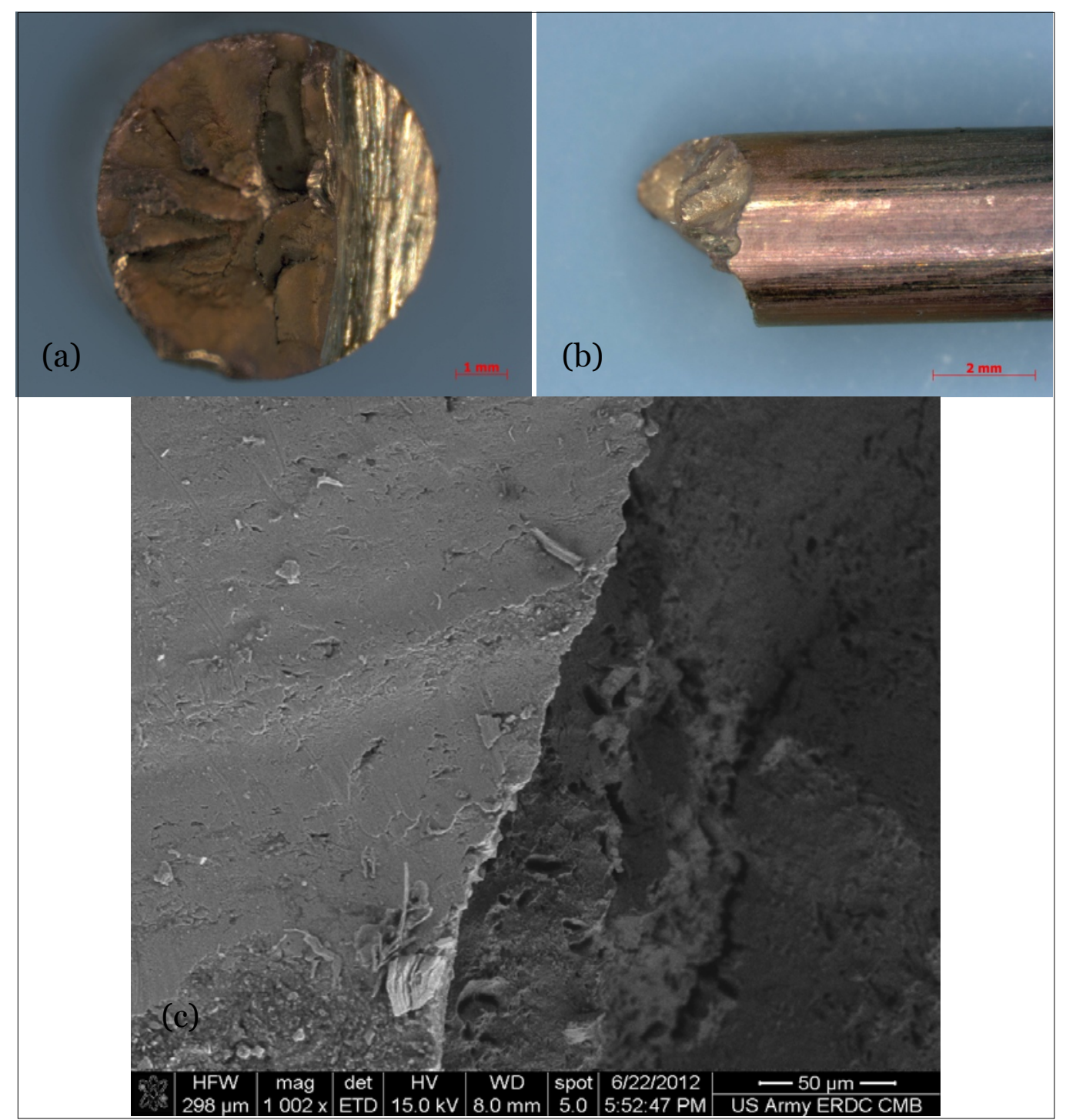

Figure 8-9. Failure images from a notched sample: (a) section view, (b) side view, and (c) high-resolution view. 

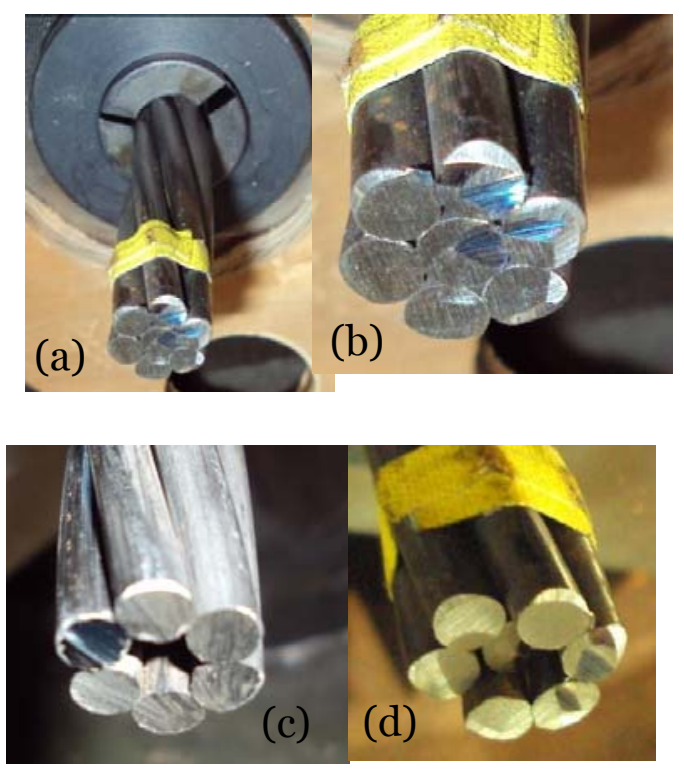

Figure 8-10. Displacement past the wedge seen in pull testing.

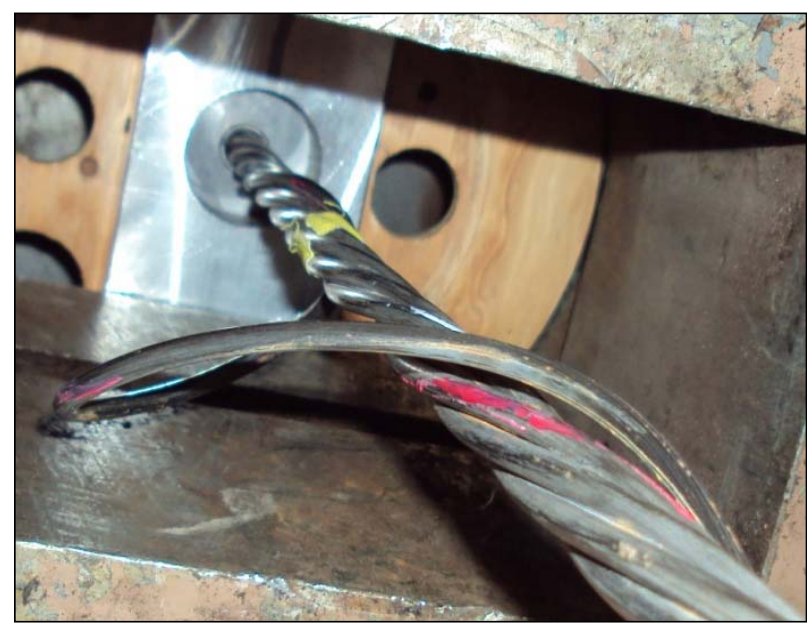

Figure 8-11. Cable unwinding due to energy release after failure. 


\section{Candidate NDT Technologies}

Chapter 8 makes it clear that relatively small defects can have significant influence on cable strength. The accessibility limitations mean practical system deployment can be accomplished only by working at the single exposed end of the cables. Most desired is a system that is capable of detecting failed strands, characterizing the wire's remaining cross sections (from either cracks or surface corrosion), and ascertaining strand load. While a number of technologies have been developed, ultrasonic guided waves most likely can perform these actions (Nato and Warncke 2008). A fall-back technology might be corrosion-potential monitoring because it provides some qualitative feedback regarding ongoing potentials. Nato and Warncke (2008) includes an extensive literature review performed in 2008 for the Pennsylvania Department of Transportation and provides a detailed review and current state of the science in this area.

\subsection{Ultrasonic guided waves}

Unlike conventional ultrasonic inspection, guided waves allow for highresolution defect detection and characterization at great distances from the applied transducer(s). These methods are well developed for a number of commercial needs including underground and/or coated pipes and rods.

When inspection frequencies are high enough (e.g., when the ultrasonic wavelength is $1 / 10$ the cross-sectional thickness or diameter), the propagation velocities can be treated like an ultrasonic wave propagating in a bulk material with no boundary influence (Rose 1999). At these frequencies, however, ultrasonic propagation characteristics such as attenuation, scatter, and inspection volume typically are poorly suited to detection of flaws at long distances.

In general, waveguide structures such as plates, rods, pipes, and even more arbitrarily shaped extrusions such as railroad tracks, greatly affect the propagation characteristics of practical or usable ultrasonic frequencies. Together, the cross sections, material properties, and surrounding materials affect how the various propagation modes will perform at different frequencies. The cause of this frequency-based variation in behavior is due to the reflection, refraction, and mode conversion occurring perpetually at the material interfaces (Rose 1999). 
Graphs called dispersion curves are used to describe the various phase and group velocity changes that occur with respect to a changing frequency or frequency-diameter product. Dispersion being described here is a waveguide effect and not an intrinsic material property, as seen in some nonlinear materials.

Phase velocity is the velocity of a phase point, and is used in the development of tuned transducers and in the derivation of the group velocity curves. Group velocity is the actual movement speed of a wave packet down the length of the waveguide and is used in determining distances to downrange reflectors such as defects or ends.

These modes and frequencies have in-plane and out-of-plane displacement characteristics that affect attenuation and cross-sectional sensitivity and often are exploited either to minimize propagation losses or control sensitivity at various cross-sectional positions. For example, for a pipe structure, a mode might be selected that minimizes the effect of fluid loading from a material present within the pipe. Likewise, for an attenuative surrounding material such as grease or concrete, a mode might be selected that minimizes out-of-plane surface displacement and, hence, reduces signal loss. Energy velocity is group velocity curves where attenuation calculations have been included (Beard et al. 2003).

When determining an inspection mode and frequency, it also is beneficial to select a point of maximum energy velocity to limit the effects of dispersion and to reduce the risk of other modes complicating the detection of the received signal. Propagation modes can be either symmetric or antisymmetric in nature for compressional and shear wave propagation. The compressional or longitudinal energy is characterized by particle displacements that are parallel to the direction of propagation.

In bulk material inspection, the compressional wave will travel almost twice as fast as the shear wave energy. The shear wave or transverse wave is characterized by particle motion perpendicular to the direction of wave propagation.

In general, shear waves exist only in solids and are not carried in fluids. Some grease has limited capacity in carrying shear waves. Because the viscosity of some grease will vary greatly with seasonal temperature 
changes, this is a parameter space that will be explored under controlled laboratory conditions.

In a rod-like structure, the shear wave particle displacements can be either in the radial direction (transverse shear) or parallel to the surface (horizontal shear or torsional). These two shear modes represent two very different guided wave propagation modes.

In general with guided wave inspection, the horizontal shear or torsional mode is usually the more desirable. This is because it is composed primarily of in-plane displacement. There is very little mode conversion and, therefore, this propagation mode tends to be non-dispersive and less attenuated by surrounding media. It has been described as capable of slithering under clamps and other attenuative-type bulkheads. The ability to place a torsional wave transducer around the perimeter of the test piece helps minimize the downrange sensitivity variations that can occur in torsional wave inspection.

For pipe structures, the total focusing method and flexural torsional focusing (Sun et al. 2005) can help equalize and, therefore, improve downrange flaw detection. Until or unless a clear performer is determined, both the torsional and longitudinal wave modes will be considered for inspection.

In conventional ultrasonic pulse echo testing of low-attenuation bulk materials (i.e., non-waveguide-type structures), a short-duration pulse or burst is typically the optimum inspection signal. The short-duration, low-Q pulse has benefits in terms of spatial resolution, focusing, and near-field detection. However, because short pulses are intrinsically broadband, they tend to excite a wider range of frequencies in guided wave testing and, therefore, stimulate more than just a single mode of propagation. Beard et al. (2003) address this issue for the center strand of a grouted o.6-in.diameter post-tensioned cable, to determine 20 cycles would allow stimulation of only the desired $\mathrm{L}(0,8)$ at $4.76 \mathrm{MHz}$. In general, this pulse count determination must balance attenuation, mode stimulation, and near-field flaw detection for the specific mode and frequency selected.

\subsection{Guided wave transducers}

Acoustical energy can be stimulated in a steel cable or rod by a variety of means, all having intrinsic differences. Table 9-1 illustrates this point. 
Investigators for seven-strand steel cable typically have used either a magnetorestrictive transducer around the strand or a small footprint piezoceramic operating in longitudinal mode. Other transducer concepts such as the torsional microtransducer exist (Friend et al. 2002). Likewise, some clamped-on transducers such as those described for pipe testing by Kwon et al. (2010) have specialized cross sections that help facilitate single-mode generation.

The piezoelectrics offer simplicity and higher power, and the magnetorestrictives offer better mode control and contactless measurement. The removal of transducer contact is a benefit when applying nonlinear methods because it removes the nonlinearity caused by the transducer and test specimen surfaces. Both of these transducer technologies are used in guided wave testing and research.

Table 9-1. Guided wave transducer types and characteristics.

\begin{tabular}{|l|l|l|l|}
\hline & Mechanical & Piezoelectric & Magnetorestrictive \\
\hline Applied Frequency & Low & Medium to high & Medium to high \\
\hline Mode Conversion & High & Med & Low \\
\hline Surface Contact & Yes & Yes & Yes or No \\
\hline Bandwidth & Wide & Narrow or wide & Narrow or wide \\
\hline Power/Efficiency & High & High & Low \\
\hline
\end{tabular}

\subsection{Nonguided wave response}

Guided waves are described by their dispersion characteristics, which are a function of frequency and waveguide dimension. If the acoustical wave is very short (high frequency) or very long (low frequency) with respect to the waveguide dimensions, its propagation generally is non-dispersive. Very high frequencies usually suffer from increased attenuation and scattering, and very low frequencies usually lack temporal and spatial resolution. Low frequencies, however, are used for cable tension assessment in structures such as cable-stay bridges and will be discussed here. If a tight posttensioned rod or cable is plucked inside the region between its two fixation points, its response primarily will be a very low-frequency one. There are two vibration modes, and their associated harmonics drive the response of the modes. The first, which is more significant in the case of a rod than for a cable, is the cantilever vibration mode. This mode is analogous to a tuning fork, where the material stiffness and its cross section provide the restoring force. When accessibility is limited to a point beyond the tensioning head, as 
typically is the case in post-tensioned structures, the response becomes significantly more complex. Specifically, the free end of the cantilever acts as an input and output filter, making it difficult if not impossible to stimulate and receive the fundamental mode of vibration. If the taut section is not in free air or is restrained by the presence of, or contact with, a solid surface, the received vibrations will be affected further by the location of that contact point or the properties of the damping material.

\subsection{Acoustical guided waves in seven-strand cables}

Plates, pipes, and rods are examples of simple guided wave geometries. The seven-strand, post-tensioned cable is composed of a center straight wire called the king wire, which is wrapped in one direction by six perimeter wires. The effective length difference between the inner and outer wires is $0.76 \%$ longer due to their helical pitch of 17 times the o.6-in. diameter (Scalea et al. 2003). Several important papers on guided waves in sevenstrand, post-tensioned cables have been found. Some of these investigations focus on acoustical injection and reception on the king wire, which greatly simplify simulation and modeling. Others have, experimentally and through simulations, looked at the more complex seven-strand structures in terms of dispersion and other acoustical properties. Bartoli et al. (2007) use a semianalytical finite element (SAFE) code and experimental measurements to show group velocity propagation of the longitudinal and flexural modes for core, peripheral, and total strand in both the loaded and unloaded conditions. The rotation of the peripheral wire and the loading of the strand both complicate the experimental dispersion curves. When going from a noload to a loaded condition, the cable changes from behaving like seven distinct acoustical waveguides to taking on the form of a coupled, more complex waveguide. Bartoli et al. (2003) also looks at interwire acoustical leakage and the influence of load on anchorages. One common focus is load determination on existing seven-strand, post-tensioning systems. Scalea et al. (2003) and Chaki and Bourse (2009b) put the king wire tensile load approximately 1 and $9 \%$ higher, respectively, than the perimeter wires. Various acoustical alternatives for load determination have been explored in the literature. These are the acoustoelastic effect, which exploits stressinduced variations in compressional and shear wave speeds, and waveguide effects such as a developed notch frequency or the interwire coupling, both of which are proportional to the applied tension. 


\subsection{Acoustoelasticity in cables}

Chen et al. (1998) and Chen and Wissawapaisal (2001) applied conventional piezoelectric transducers in a through-transmission mode (both ends of cable accessible). These investigations focused only on assessment using the king wire. To explore acoustoelastic measurement, Washer (2001), Kwun and Bartels (1998), and Kwun and Teller (1994) employed magnetorestrictive sensors for guided wave transduction in seven strands. Scalea et al. (2003) integrated the acoustoelastic equations and the guided wave relations for thin rods to derive an expression for the acoustoelastic factor in terms of loaded and unloaded group velocities. The 2003 paper also gives the construction details of the magnetorestrictive transducer used: a 320 $\mathrm{kHz}$ center frequency, based on the findings of Washer (2001). The authors go on to show the group velocity changes in the core and peripheral wires generally track each other past loads at $20 \%$ ultimate tensile strength. Chaki and Bourse (2009a) also note a nonlinearity of the seven-strand cable's acoustoelastic constant at loads below $32 \%$ ultimate strength. Based on nominal working loads between 36.5 and $45 \%$ ultimate tensile strength, previous researchers have suggested the method should be useful for expected field service loads. Acoustoelasticity has an intrinsically low sensitivity effect and, as such, presents significant challenges in obtaining reliable performance in the presence of unknown and varying field conditions. Changes in unbounded cable length, steel properties, temperature, and cable dispersion characteristics all complicate field application of this method.

\subsection{Notch frequency and other waveguide effects}

Kwun and Bartels (1998) first investigated the presence of a load-dependent notch frequency, which in laboratory settings has been used successfully to ascertain cable load. In addition to this notch frequency increasing with load, large dispersion was observed on both sides of a notch in a manner similar to the behavior near a cutoff frequency. Several possibilities for this effect have been explored and ruled out because they don't match the numerical observations of the notch existing at 75 to $105 \mathrm{kHz}$. The exact source of this notch is unknown, but a number of researchers have observed its presence and demonstrated how its $\log$ function is linearly proportional to tension.

As the load increases, the cable's waveguide properties change from parallel single-strand to single. This confirms the need to perform NDT 
system development under at least partial loads. Bartoli et al. (2011) found interwire acoustical leakage and load-based losses at the anchorage might be used to determine the load condition of the strand. They found the best transducer layout was excitation on a peripheral wire with reception on the king wire in the 400 to $500 \mathrm{kHz}$ frequency range. Looking at a steel and aluminum composite wire rope, Mijarez et al. (2012) analytically and experimentally looked at mode coupling between adjacent strands. They say interwire coupling caused by radial displacements plays an important role in the excitation not only of longitudinal modes, but also the flexural modes. Interwire coupling could be a simple stress determination method at the anchor, if developed for a pitch-catch configuration from the exposed free end and if time gated to the proper length loss influences in the grout and grease could be minimized.

\subsection{Defect detection}

In terms of commercial development, guided wave technology for pipe-type inspections has progressed further. Pipes tend to be coated or buried with limited surface accessibility, and they experience defects ranging from earthquake-induced stress, pressure fatigue, and corrosion. Transducerfocusing methods used for guided wave and nonlinear acoustics for small pipes have carry-over application for post-tensioned steel rods and cables.

A finite amount of guided wave research has been done for defect detection and characterization in seven-strand, post-tensioned cables. If the research is further refined to include grout, grease, single-sided transduction, and other field boundary conditions, the literature is quite limited. On an elemental level, the wires in the strands are individual rod-type waveguides. As load is increased, the dispersive nature becomes more affected by the helical outer wire, laying at roughly $8 \%$. Defect detection in guided wave application involves either detection of a gradual loss of cross section, such as corrosive sectional loss, or an abrupt and possibly small perpendicular crack. Corrosive sectional loss using guided waves has been commercialized for anchor rod testing. Guided Wave Analysis LLC produces a hardware unit that uses magnetorestrictive transducers to detect underground corrosion loss along the anchor rod's length. This product is the result of efforts of the South West Research Institute in Texas. Sharma and Mukherjee (2010) describe accelerated corrosion testing of rods and using guided waves tuned for high cross-sectional sensitivity. For chloride-type defects with caustic pitting and surface distortion, the decrease in surface profile sensitivity increases the sensitivity to local bar topography (Sharma and Mukherjee 
2010). For a 1-in. bar, they selected a high point on the $\mathrm{L}(0,7)$ mode at 1 $\mathrm{MHz}$ with core sensitivity to pick up notch-like defects. They also selected a high surface interface sensitive mode such as the L(0,1)'s low attenuation point around $100 \mathrm{kHz}$ to detect progressive debonding between grout and steel due to corrosion. He et al. (2006) performed similar guided wave measurements for rock-bolt debonding localization and characterization at distances up to $10 \mathrm{ft}$.

Because multiple researchers have shown that the waveguide effects of the seven-strand cable and, hence, the dispersion behavior changes with load, it is important that system evaluation be performed on at least a partially loaded strand. Using a magnetorestictive transducer for the entire strand, Scalea et al. (2003) received a $32 \%$ loss in transmitted signal due to a $7 \%$ reduction in cross section (saw cut). This demonstrated the perimeter or helical wires will carry a portion of the total measured acoustical wave at $320 \mathrm{kHz}$ that is 3.7 times larger in amplitude than that of the core. This indicates good defect sensitivity in the peripheral wires. In terms of bounding media, the core wire is more controlled because it is encircled by the peripheral wires and, in modern applications, encircled by anticorrosive, wax-like interstitial filler. Scalea et al. (2003) also demonstrate the detection of peripheral wire damage in the anchor and the fracture of a king wire. They conclude the guided wave approach can detect defects developing in strands. Toward addressing guided wave penetration, Scalea et al. (2003) state a signal loss of $90 \%$ for the $320 \mathrm{kHz}$ waveform propagating $30 \mathrm{ft}$. This number will worsen when anticorrosive grease is present. It is likely that a less dispersive propagation mode with lower attenuation will be needed if ultrasonic inspection is to use a backwall reflection. Laguerre et al. (2000) draw the same conclusion in their experimental work with magnetorestrictive generation and receiver. They note significant signal loss above $100 \mathrm{kHz}$ and a lowered dispersion level below $50 \mathrm{kHz}$. In this frequency range, they were able to clearly identify failed strands at the distances investigated (between 6 and 25 in.). Beard et al. (2003) describe mode and frequency selection for a seven-strand tendon. While their statement regarding the seven-strand cable being individual waveguides in the field (i.e. under stress) conflicts with other research, they lay out selection criteria based on attenuation, dispersion, and crosssectional sensitivity. Because they discount the L $(0,1)$ mode as being low frequency (approximately $35 \mathrm{o} \mathrm{kHz}$ ) and likely to propagate in the grouting duct as a whole, they end up choosing the higher frequency of the $\mathrm{L}(0,8)$ mode, which is around $4.76 \mathrm{MHz}$. Using disperse modeling software, they 
show the in-plane and out-of-plane displacements as a function of radial position. This helps show relative cross-sectional sensitivity and expected losses into the surrounding material. $\mathrm{L}(0,8)$ pulse echo measurements were made on inner and outer wires in a grouted strand scenario. These tests showed a much higher attenuation rate in the peripheral wire, due to its surface coupling with the grout, than the center wire. Also, as additional slower mode echos showed in the king wire, it was speculated by Beard et al. (2003) that these additional modes might have been attenuated by the grout in the peripheral wire. Lastly, they address the issue of curvature and show, even for slight curvatures, disruptions occur in the low-leakage propagation points. They also point to the need for further investigation in this area. Studies such as those by Yang and Yi (2011) of grouted anchor rods indicate higher frequency modes with less leakage loss typically are desired for backwall echo detection and lower frequency modes are better served to explore material interface conditions, such as the presence of delaminations or corrosion.

When defects exist in the form of closed cracks, such as certain phases of fatigue or stress corrosion cracking, they might require more specialized ultrasonic inspection methods. Those such as time-of-flight diffraction or nonlinear acoustical methods have been developed to improve or simplify closed crack detection. Intrinsic nonlinearities such as the anchoring wedge and the wire-to-wire contact present challenges that are best resolved with careful integration of guided wave with nonlinear methods. Nonlinear methods use a variety of measurement schemes for crack detection and characterization by analysis of nonlinear effects on harmonics and modulation parameters. A limited amount of research exists on integration of the guided wave methods for remote measurement with nonlinear methods for detection of closed-type defects. Ekimov et al. (1999) demonstrated detection of simulated microcracks by modulating a high-frequency torsional wave with a low-frequency longitudinal impact. The authors demonstrated new selection criteria from the phase and group velocity curves that also allow for determination of nonlinear harmonic parameters. Pruell et al. (2009) showed careful selection of modes so the first and second harmonic used in nonlinear analysis meet the common selection criteria for dispersion (high velocity, low attenuation), as well as synchronization for nonlinear harmonic analysis. Harmonic synchronization is particularly important in shorter duration pulses and is optimized by matching the first and second harmonics' phase velocities and their group velocities. The phase velocity helps improve cumulative growth, particularly important in 
shorter pulse trains, and the group velocity requirement helps assure the second harmonic energy stays within the same wave packet. Pruell et al. (2009) go on to demonstrate successful nonlinear guided wave application for detection of fatigue damage in aluminum plates. Balasubramaniam (2011) covers in detail second harmonic analysis methods for assessment of damage in metals.

\subsection{Preliminary ERDC measurements of seven-strand cable}

Under no-load conditions, longitudinal waveguide frequencies of 351 and $441 \mathrm{kHz}$ have been identified in experiments at ERDC to be unloaded, lowloss modes with low surface loss, where an echo was detectable through $210 \mathrm{ft}$ of cable length, though it was joined to itself in a coiled configuration (Figure 9-1). Measurement was made using $500 \mathrm{kHz}$ Panametrics transducers and the RITEC Advanced Measurement System. Further testing will be needed for conclusion, but the mode used here, according to published dispersion curves (Chaki and Bourse 2009b), is likely L(0,2). Additional transducers have been acquired to explore higher order modes and coupling to specific wires.

The candidate NDT technologies discussed in this chapter are being studied further as part of this ongoing research and development effort. 
(a)

(b)

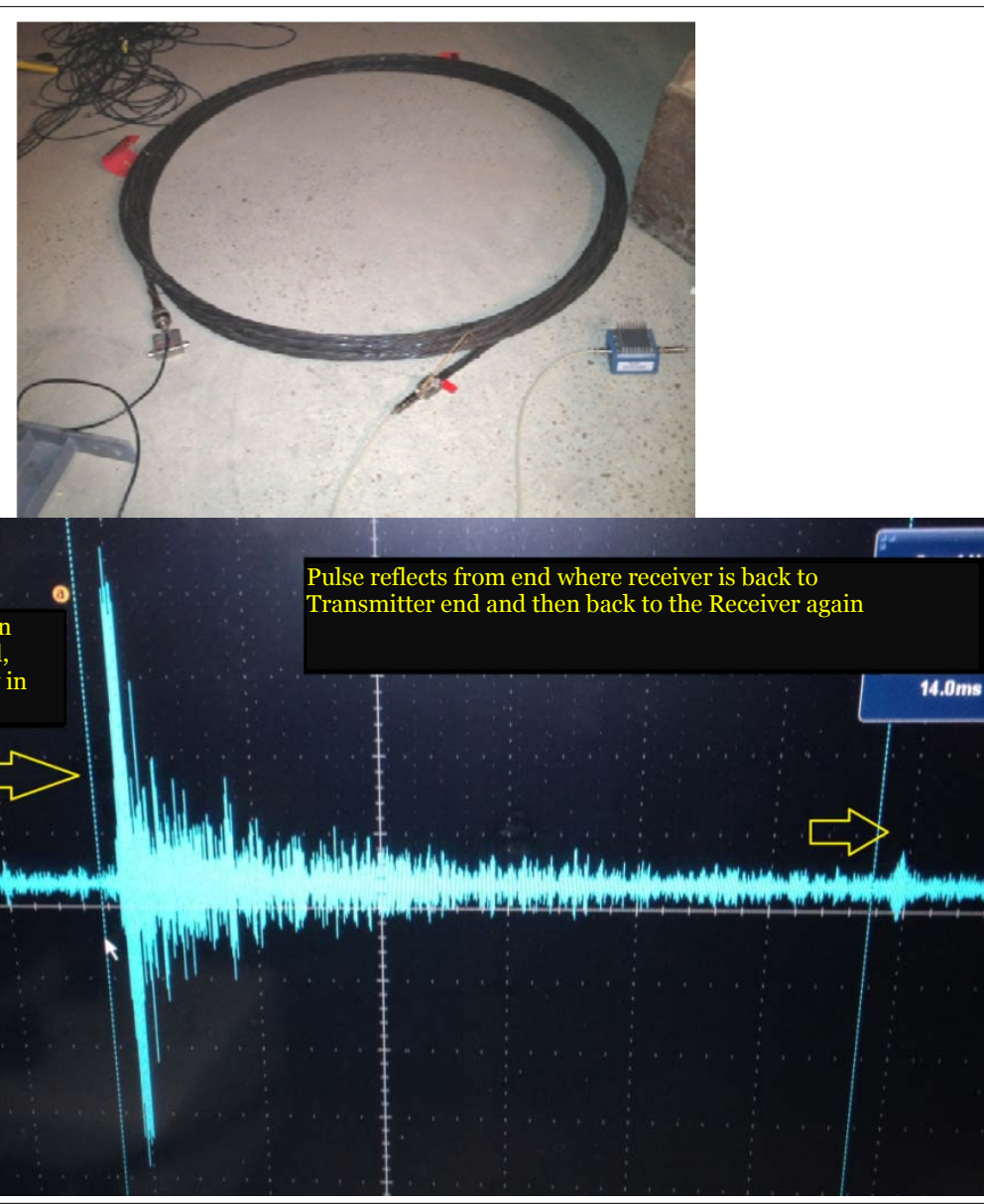

Figure 9-1. (a) Coiled cable with transmitter and receiver on each end; (b) measurement's first peak is through transmission and the second is through echo. 


\section{Multistrand Test Bed}

To apply tension and accelerate the corrosion of multistrand cables, a test bed was constructed at ERDC. It is $15 \mathrm{ft}$ long and can support six single strands enclosed within six individual, 1.25-in. PVC tubes and two fivestrand assemblies enclosed within 3-in. PVC tubes (Figure 10-1a, b). The initial design is shown in Figure 10-2.

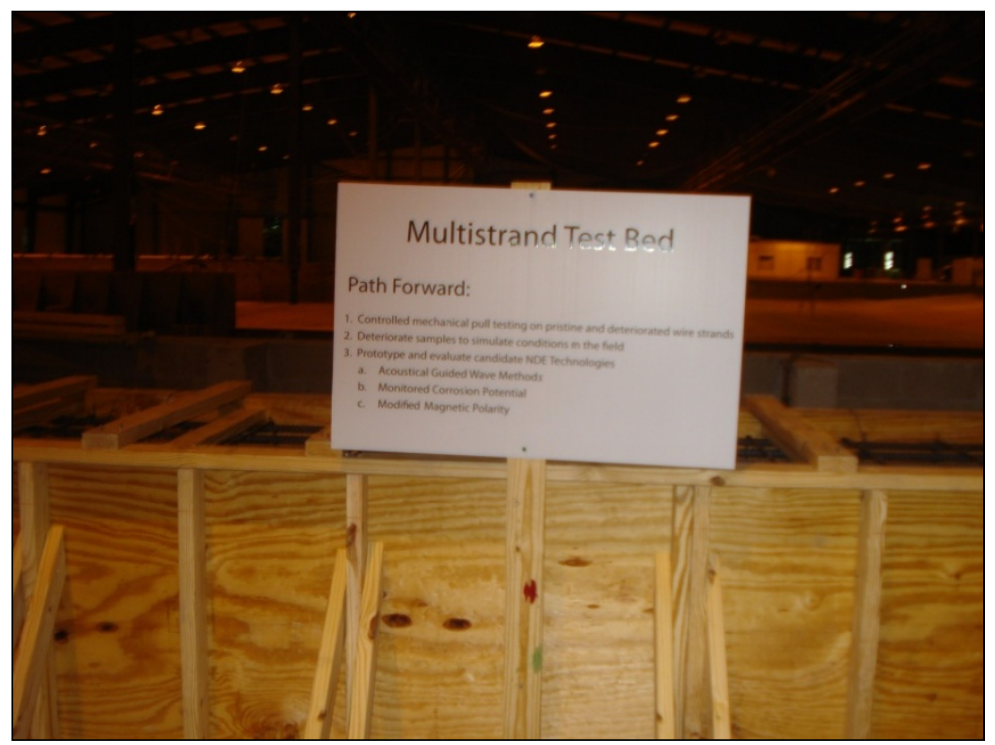

Figure 10-1a. Side view of framing for test bed.

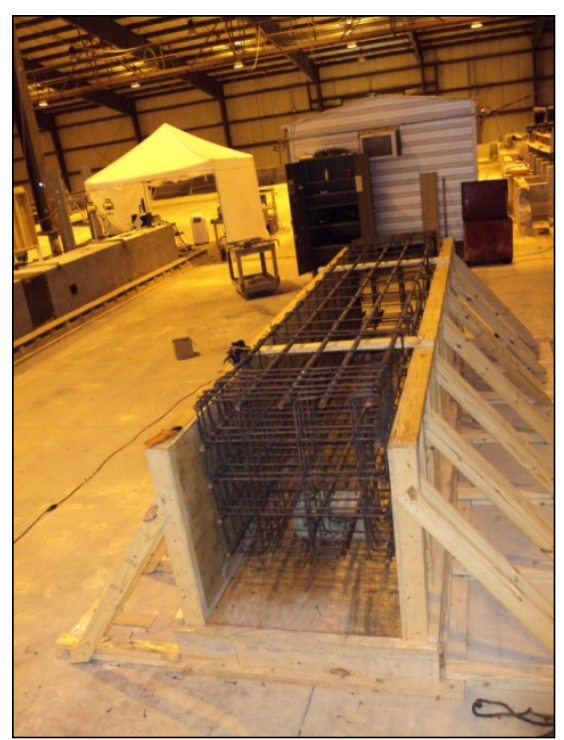

Figure 10-1b. End view of test bed with reinforcement rebar. 


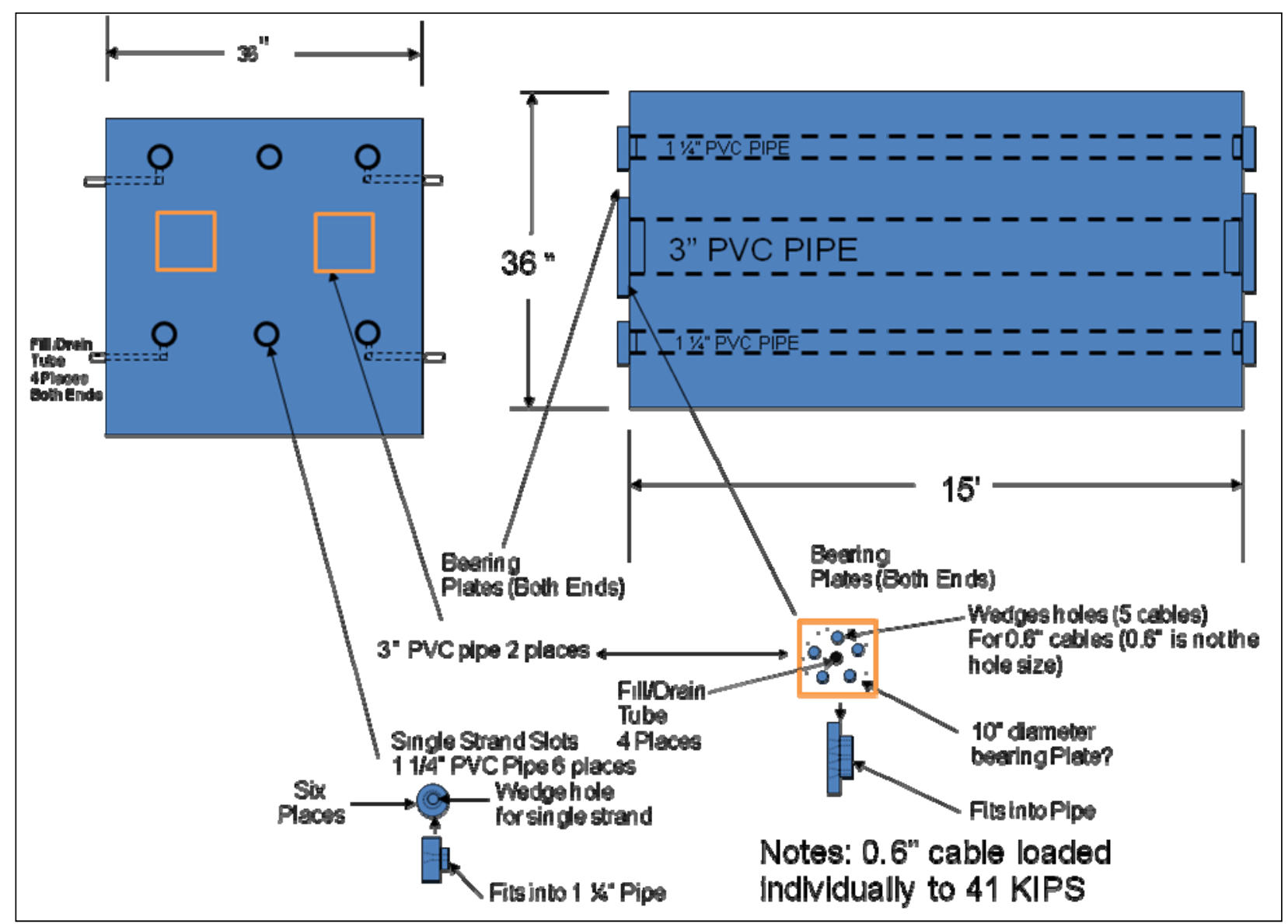

Figure 10-2. Test bed design with strand support hardware shown.

The test bed will enable engineers to stress individual strands using a hydraulic ram-stressing machine (Figure 10-3a, b) up to their load-bearing capability, while being exposed to corrosive fluids by introducing those fluids directly into the tubes. Test ports are arranged on each of the larger tubes, one-third of the way down the length of the test bed. These provide the engineer with access to the cable within the test bed and enable him to sense the cable's condition.

\subsection{Signature fixture}

A fixture has been developed that simulates the actual anchor head, except on a much smaller scale (Figure 10-4a, b). The fixture is being used to research the signature of an acoustical signal as it passes through the anchor head and to determine if an acoustical signal passing through the anchor wedges can detect slight losses within the wire strand crosssectional area. 

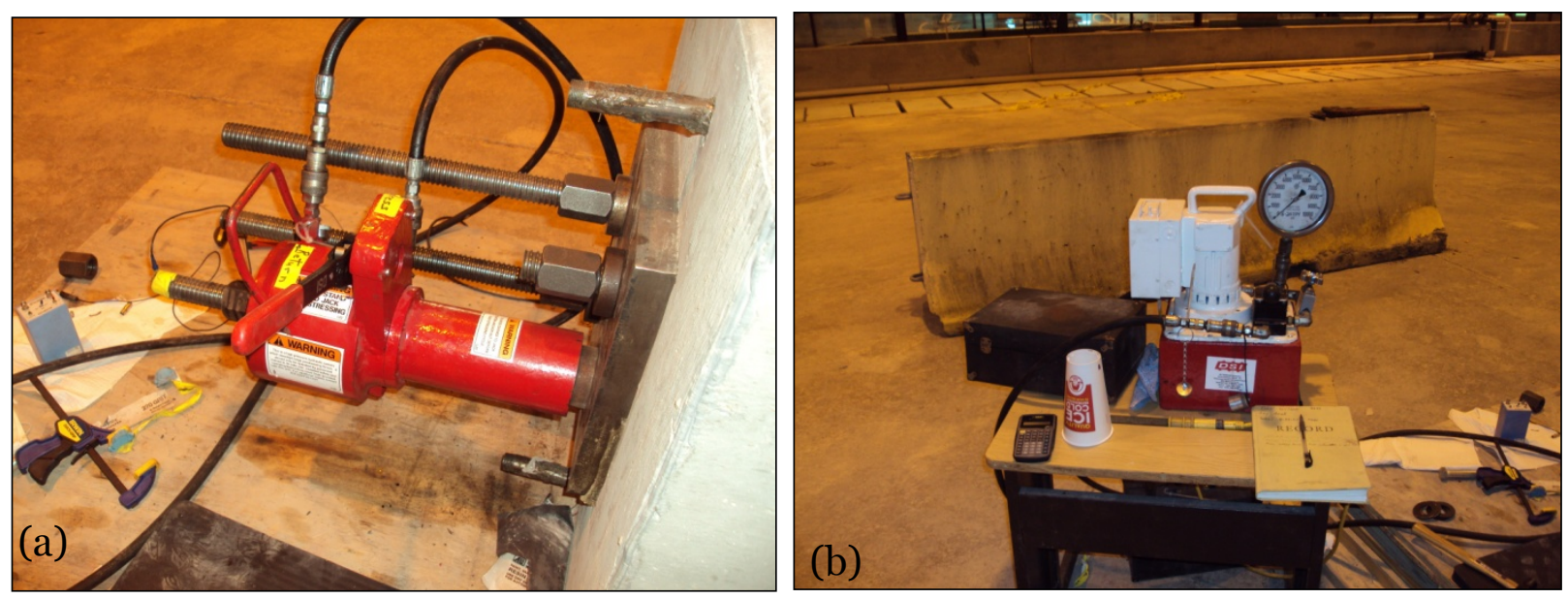

Figure 10-3. Stressing tool similar to the multistrand one.

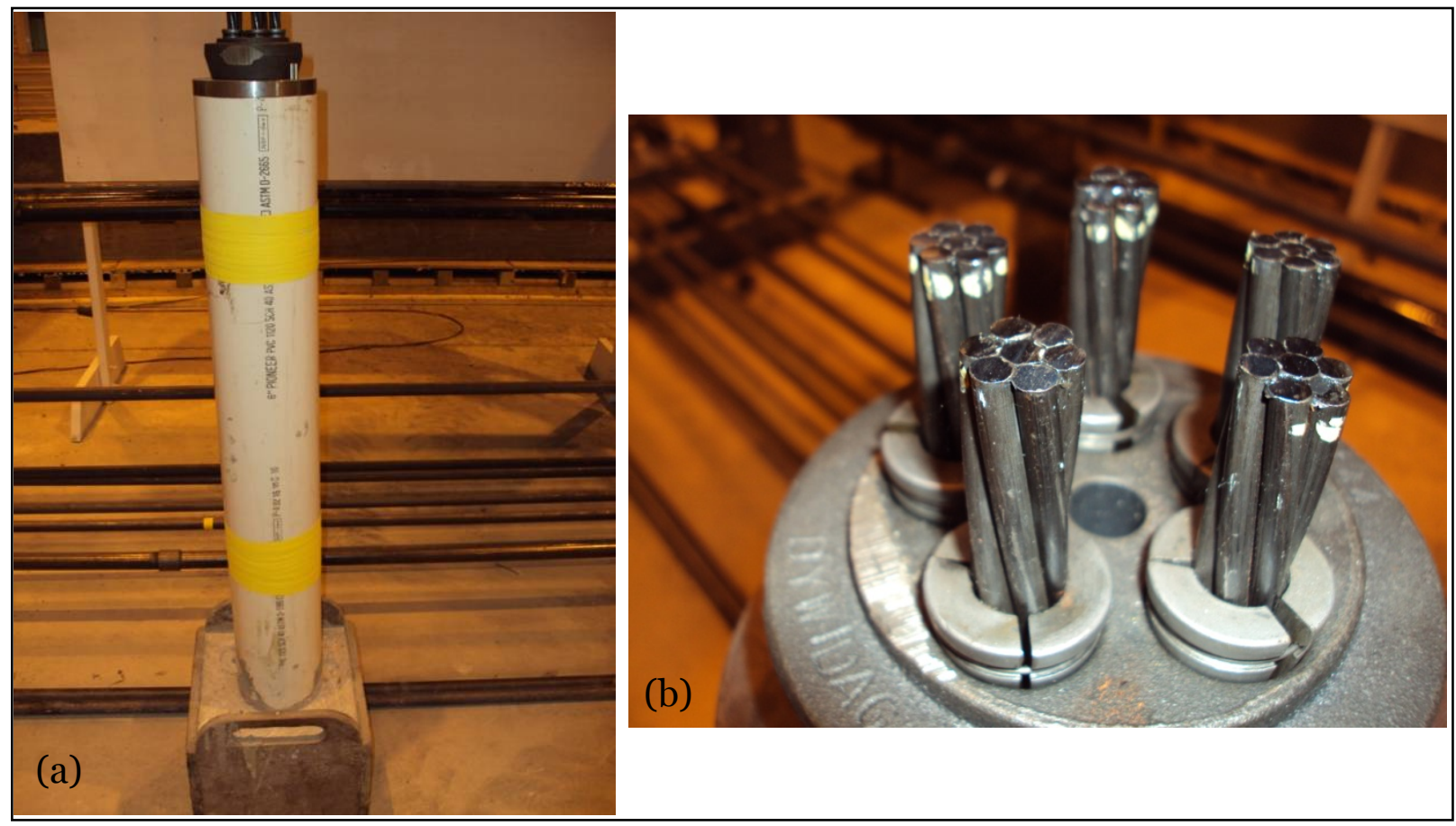

Figure 10-4. Acoustical signature fixture.

Multistrand anchorages and wires will be evaluated in this test bed facility during the next phase of this research effort. 


\section{References}

American Concrete Institute (ACI). 1985. Corrosion of metals in concrete. ACI Committee 222.

American Concrete Institute (ACI). 2001. Corrosion of pre-stressing steels. ACI Committee 222.

American Concrete Institute (ACI). 2007a. Causes, evaluation, and repair of cracks in concrete structures. ACI Committee 224, Report 224.1R-07.

American Concrete Institute (ACI). 2007b. Report on thermal and volume change effects on cracking of mass concrete. ACI Committee 207, Report 207.2R-07.

American Concrete Institute (ACI). 2011. Guide to design and construction practices to mitigate corrosion of reinforcement in concrete structures. ACI Committee 222.

Azizinamini, A., J. Saeed, and A. J. Yakel. 2007. Nondestructive testing for concrete bridges using residual magnetic flux leakage method. Transportation Research Board Annual Meeting.

Balasubramaniam, K. 2011. Understanding of material state and its degradation using non-linear ultrasound (NLU) approaches. Submitted to AOARD, AFOSR Tokyo, Japan.

Bartoli, I., A. Marzani, F. L. di Scalea, P. Rizzo, E. Viola, E. Sorrivi, R. Phillips. 2007. SAFE modeling of waves for the structural health monitoring of prestressing tendons. In, Health monitoring of structural and biological systems.

Bartoli, I., S. Salamone, R. Phillips, F. L. di Scalea, and C. Sikorsky. 2011. Use of interwire ultrasonic leakage to quantify loss of prestress in multiwire tendons. American Society of Civil Engineers Journal of Engineering Mechanics 137(5):324-333.

Beard, M. D., M. J. S. Lowe, and P. Cawley. 2003. Ultrasonic guided waves for inspection of grouted tendons and bolts. American Society of Civil Engineers Journal of Materials in Civil Engineering 15(3):212-218.

Bertolini, L., B. Elsner, P. Pedeferri, and R. Polder. 2004. Corrosion of steel in concrete. Wiley-VCH Verlag GmbH \& Co.

BRITE/EURAM. 1995. The residual service life of reinforced concrete structures. Technical Report BRUE-CT92-0591.

Bruce, D. A., and J. S. Wolfhope. 2006. Rock anchors for dams: National research project: The (semi) final results of the Phase I study. In Proceedings, Annual Conference of the Association of State Dam Safety Officials (Dam Safety 2006), 10-14 September, Boston.

Castel, A., D. Coronelli, N. A. Vu, and R. Francois. 2011. Structural response of corroded, unbonded post-tensioned beams. American Society of Civil Engineers Journal of Structural Engineering 137(7). 
Chaki, S., and G. Bourse. 2009a. Stress level measurement in prestressed steel strands using acoustoelastic effect. Experimental Mechanics 49:673-681.

Chaki, S., and G. Bourse. 2009b. Guided ultrasonic waves for non-destructive monitoring of the stress levels in prestressed steel strands. Ultrasonics 49:162-171.

Chen, H. L., Y. He, and H. V. GangaRao. 1998. Measurement of prestress force in the rods of stressed timber bridges using stress waves. Materials Evaluation, August.

Chen, H. L., and K. Wissawapaisal. 2001. Measurement of tensile forces in a seven-wire prestressing strand using stress waves. American Society of Civil Engineers Journal of Engineering Mechanics 127(6):599-606.

Ciolko, A. T., and H. Tabatabai. 1999. Nondestructive methods for condition evaluation of prestressing steel strands in concrete bridges. Final Report, Phase I: Technology Review, Transportation Research Board National Research Council, NCHRP Project 10-52, NCHRP Web Document 23 (Project 10-53).

Clear, K. C. 1989. Measuring rate of corrosion of steel in field concrete structures. Transportation Research Record: Journal of the Transportation Research Board, No. 1211.

Cooper, T. R. 2005. Improving the durability of post-tensioned bridges. Transportation Research Board Annual Meeting.

Cornforth Consultants. 2009. Anchor inspection and lift-off testing, John Day Dam Navigation Lock, Contract 6 W9127N-07-D-0001, Task Order 6. Unpublished Letter Report to Portland District, US Army Corps of Engineers.

Darmawan, M. S. 2010. Probabilistic assessment of pitting corrosion effect on flexural strength of partially prestressed concrete structures in a chloride environment. Journal of Civil Engineering and Architecture 4(2).

Darmawan, M. S., and M. G. Stewart. 2007. Effect of pitting corrosion on capacity of prestressing wires. Magazine of Concrete Research 59(2):131-139.

Dickson, T. J., H. Tabatabal, and D. A. Whiting. 1993. Corrosion assessment of a 34-yearold precast post-tensioned concrete girder. Precast/Prestressed Concrete Institute Journal, November-December.

Ebeling, R. M., R. C. Patev, and R. L. Mosher. 1996. Case histories of earth pressureinduced cracking of locks. Technical Report ITL-96-9. Vicksburg, MS: US Army Engineer Waterways Experiment Station.

Ebeling, R. M., R. C. Patev, and G. A. Riveros. 2001. Smeared and discrete crack evaluations of a lock exhibiting earth pressure-induced cracking. ERDC/ITL TR-01-7. Vicksburg, MS: US Army Engineer Research and Development Center.

Ebeling, R. M., M. C. Fong, J. L. Wibowo, and A. Chase. 2012. Fragility analysis of a concrete gravity dam embedded in rock and its system response curve computed by the analytical program GDLAD_Foundation. ERDC TR-12-4. Vicksburg, MS: US Army Engineer Research and Development Center. 
Ebeling, R. M., R. W. Haskins, D. H. Scofield, J. E. Hite, and R. W. Strom. 2012. Posttensioned multistrand anchorage capacity deterioration due to corrosion: John Day Lock Project. ERDC/CHL CHETN-IX-28. Vicksburg, MS: US Army Engineer Research and Development Center, http://chl.erdc.usace.army.mil/chetn.

Ekimov, A. E., I. N. Didenkulov, and V. V. Kazakov. 1999. Modulation of torsional waves in a rod with a crack. Journal of Acoustical Society of America 106(3):1289.

Fallis, G., and T. O. Arnesen. 2009. Corrosion evaluation and cable break detection for post-tensioned and prestressed cables. Structural Congress Papers, ASCE SEI2009.

Francois, R., A. Castel, and V. Thierry. 2006. A finite macro-element for corroded reinforced concrete. Materials and Structures 39:571-584.

Friend, J. R., K. Nakamura, and S. Ueha. 2002. A novel torsional microtransducer using bulk PZT. In Proceedings, Institute of Electrical and Electronics Engineers Ultrasonics Symposium, 8-11 October, Munich.

Gucunski, N., F. Romero, S. Kruschwitz, R. Feldmann, A. Abu-Hawash, and M. Dunn. 2010. Multiple complementary nondestructive evaluation technologies for condition assessment of concrete bridge decks. Transportation Research Record: Journal of the Transportation Research Board, No. 2201.

Harris, D., S. Hong, and S. A. Newbolds. 2010. Practical evaluation of bridge deck reinforcement corrosion using ground penetrating radar, half cell, and sounding. Transportation Research Board Annual Meeting.

He, C., J. K. Van Velsor, C. M. Lee, and J. L. Rose. 2006. Health monitoring of rock bolts using ultrasonic guided waves. American Institute of Physics Review of Quantitative Nondestructive Evaluation 25:195.

Headquarters, US Army Corps of Engineers (HQUSACE). 2005. Stability analysis of concrete structures. EM 1110-2-2100. Washington, DC.

Heslin, G., D. A. Bruce, G. S. Littlejohn, and T. Westover. 2009. Performance of aging post-tensioned rock anchors in dams. In Proceedings, ASDSO Northeast Regional Conference, 14-16 June, State College, PA.

Jaeger, B. J., M. J. Sansalone, and R. W. Poston. 1996. Detecting voids in grouted tendon ducts of post-tensioned concrete structures using the impact-echo method. American Concrete Institute Structural Journal, July-August.

Kwon E. K., J. W. Kim, and Y. Y. Kim. 2010. Method to suppress higher modes of the guided torsional wave for sending the non-dispersive mode through a pipe. In Proceedings, Institute of Electrical and Electronics Engineers International Ultrasonics Symposium, 11-14 October, San Diego.

Kwun, H., and K. A. Bartels. 1998. Magnetorestrictive sensor technology and its applications. Ultrasonics 36(1-5):171-178.

Kwun, H., and C. M. Teller. 1994. Detection of fractured wires in steel cables using magnetostrictive sensors. Materials Evaluation, April. 
Laguerre, L., J. Christian, M. Brissaud. 200o. Generation and detection of elastic waves with magnetoelastic device for the nondestructive evaluation of steel cables and bars. In Proceedings, $15^{\text {th }}$ World Conference on Nondestructive Testing, 15-21 October, Roma, Italy.

Li, J., L. Aki, R. Hunsperger, W. Liu, M. Chajes, and E. Kunz. 2005. Time-domain reflectometry to detect voids in post-tensioning ducts. Transportation Research Record: Journal of the Transportation Research Board, CD 11-S.

Lyer, S., A. J. Schokker, and S. K. Sinha. 2003. Ultrasonic c-span imaging - Preliminary evaluation for corrosion and void detection in post-tensioned tendons. Transportation Research Record: Journal of the Transportation Reasearch Board, No. 1827, Paper No. 03-2667.

MacDougal, C., and M. F. Bartlett. 2005. Mechanical model for unbonded seven-wire tendon with symmetric wire breaks. American Society of Civil Engineers Journal of Engineering Mechanics, December.

Mijarez, R., R. Orlando, and A. Baltazar. 2012. Experiments and modeling of guided wave propagation in multiple-wire cable. In Proceedings, $18^{\text {th }}$ World Conference on Nondestructive Testing, 16-2o April, Durban, South Africa.

Minchin, R. E., J. Baciak, and A. Haghighat. 2007. Identification and demonstration of a technology adaptable to locating water in post-tensioned bridge tendons. Transportation Research Board Annual Meeting.

Mosher, R. L., T. L. Bevins, and B. D. Neeley. 1991. Structural evaluation of Eisenhower and Snell Locks, Saint Lawrence Seaway, Massena, New York. Technical Report ITL-91-4. Vicksburg, MS: US Army Engineer Waterways Experiment Station.

National Cooperative Highway Research Program (NCHRP). 1999. Nondestructive methods for condition evaluation of pre-stressing steel strands in concrete bridges. Final report, Phase I: Technology review, March 1999. NCHRP Web Document 23 (Project 10-53).

National Cooperative Highway Research Program (NCHRP). 2002. Recommended practice for evaluation of metal tensioned systems in geotechnical applications. NCHRP Report 477.

Nato, C., and J. Warncke. 2008. Inspection methods and techniques to determine nonvisible corrosion of prestressing strands in concrete bridge components. Pennsylvania Department of Transportation, ATLSS Report No. 08-06.

Nierlich, H., and D. A. Bruce. 1997. A review of the Post-Tensioning Institute's revised recommendations for prestressed rock and soil anchors. In Ground anchorages and anchored structures, ed. G. S. Littlejohn, 522-530. Proceedings of Institution of Civil Engineers International Conference, 20-21 March, London.

Nurnberger, U. 2002. Corrosion induced failures of prestressing steel. Otto-Graf Journal 13 .

Phares, B. M., G. A. Washer, and M. E. Moore. 1999. FHWA's Nondestructive Evaluation Validation Center - A national treasure. Transportation Research Record: Journal of the Transportation Research Board, No. 1680, Paper No. 99-1020. 
Podolny, W. 1985. The cause of cracking in post-tensioned concrete box girder bridges and retrofit procedures. Precast/Prestressed Concrete Institute Journal, MarchApril.

Podolny, W. 1992. Corrosion of pre-stressing steels and its mitigation. Precast/Prestressed Concrete Institute Journal, September-October

Post-Tensioning Institute (PTI). 1980. Recommendations for pre-stressed rock and soil anchors, $1^{\text {st }}$ edition, $1^{\text {st }}$ printing. Phoenix, Arizona.

Post-Tensioning Institute (PTI). 1986. Recommendations for pre-stressed rock and soil anchors, $2^{\text {nd }}$ edition, $1^{\text {st }}$ printing. Phoenix, Arizona.

Post-Tensioning Institute (PTI). 1996. Recommendations for pre-stressed rock and soil anchors, $3^{\text {rd }}$ edition, $1^{\text {st }}$ printing. Phoenix, Arizona.

Post-Tensioning Institute (PTI). 2004. Recommendations for pre-stressed rock and soil anchors, $4^{\text {th }}$ edition, $1^{\text {st }}$ printing. Phoenix, Arizona.

Post-Tensioning Institute (PTI). 1999. Post-tensioning manual, $5^{\text {th }}$ edition, $4^{\text {th }}$ printing . Phoenix, Arizona.

Precast/Prestressed Concrete Institute (PCI). 1974. Tentative recommendations for prestressed rock and soil anchors, $1^{\text {st }}$ printing. Phoenix, Arizona.

Proverbio, E., and L. M. Bonaccorsi. 2002. Failure of pre-stressing steel induced by crevice corrosion in pre-stressed concrete structures. 9DBMC Paper 026.

Pruell, C., J. Y. Kim, J. Qu, and L. Jacobs. 2009. Evaluation of fatigue damage using nonlinear guided waves. Smart Materials and Structures 18:1-8.

Roberge, P. R. 2008. Corrosion engineering principles and practice. Columbus, $\mathrm{OH}$ : McGraw-Hill.

Rose, J. L. 1999. Ultrasonic waves in solid media. New York: Cambridge University Press.

Sabatini, P. L., D. G. Pass, and R. C. Bachus. 1999. Ground anchors and anchored systems. Geotechnical Engineering Circular No. 4, FHWA-SA-99-015. Washington, DC: Federal Highway Administration.

Salamone, S., I. Bartoli, and R. Phillips. 2011. Health monitoring of prestressing tendons in post-tensioned concrete bridges. Transportation Research Board Annual Meeting.

Scalea, F., P. Rizzo, and F. Seible. 2003. Stress measurement and defect detection in steel strands by guided stress waves. American Society of Civil Engineers Journal of Materials in Civil Engineering, May-June.

Schupack, M. 1978. A survey of the durability of post-tensioning tendons. American Concrete Institute Structural Journal 75(10).

Schupack, M. 1991. Corrosion protection for unbonded tendons. Concrete International 13(2). 
Schupack, M. 1994a. Durability study of a 35-year-old post-tensioned bridge. Concrete International 16(2).

Schupack, M. 1994b. Studies of the Bissell Bridge post-tensioning tendons after 35 years. Concrete International 16(3).

Schupack, M. 1994c. Unbonded tendons - Evolution and performance. Concrete International 16(12).

Schupack, M., and M. G. Suarez. 1982. Some recent corrosion embitterment failures of prestressing systems in the United States. Precast/Prestressed Concrete Institute Journal, March April.

Segan, E. G., D. Socie, and D. Morrow. 1984. Assessment of the stress corrosion cracking of post-tensioned tendons at the John Day Lock. CERL-TR-M-349. Champaign, IL: US Army Construction Engineering Research Laboratory.

Sharma, S., and A. Mukherjee. 2010. Longitudinal guided waves for monitoring chloride corrosion in reinforcing bars in concrete. Structural Health Monitoring 9(6).

Strom, R. W., and R. M. Ebeling. 2002. Methods used in tieback wall design and construction to prevent local anchor failure, progressive anchorage failure, and ground mass stability failure. ERDC/ITL TR-01-11. Vicksburg, MS: US Army Engineer Research and Development Center.

Sun, Z., L. Zhang, and J. Rose. 2005. Flexural torsional guided wave mechanics and focusing in pipe. American Society of Mechanical Engineers Journal of Pressure Vessel Technology 127:471.

Tinkey, Y., and L. C. Olsen. 2006. Non-destructive evaluation method for determination of internal grout conditions inside bridge post-tensioning ducts using rolling stress waves for continuous scanning. Transportation Research Record, Final Report, Highway IDEA Project 102.

Tinkey, Y., and L. D. Olsen. 2007. Sensitivity studies of grout defects in post-tensioned bridge ducts using impact echo scanning method. Transportation Research Record: Journal of the Transportation Research Board, No. 2028.

Tinkey, Y., and L. D. Olsen. 2008. Applications and limitations of impact echo scanning for void detection in post-tensioned bridge ducts. Transportation Research Record: Journal of the Transportation Research Board, No. 2070.

US Army Corps of Engineers (USACE). 1982. Supplement No. 2 to Design Memorandum No. 48 (section NPDEN-GS-L, 82-C-140). Portland OR: Northern Pacific Divison, USACE.

Venugopalan, S. 2008. Corrosion evaluation of post-tensioned tendons in a box girder bridge. Paper IBSMCo8-035. Siva Corrosion Services, Inc.

Vu, N. A., A. Castel, and R. Francois. 2009. Effect of stress corrosion cracking on stressstrain response of steel wires used in prestressed concrete beams. Corrosion Science 51(6). 
Washer, G. A. 2001. The acoustoelastic effect in prestressing tendons. PhD diss., The Johns Hopkins Univ.

Weber, R. A. 2010. Corrosion testing of anchor assemblies used at Delaware Lake Spillway. Unpublished CERL Letter Report. Champaign, IL: US Army Engineer Research and Development Center.

Woodtli, J., and R. Kieselbach. 2000. Damage due to hydrogen embrittlement and stress corrosion cracking. Engineering Failure Analysis 7(6):427-450.

Wouters, J. P., K. Kesner, and R. W. Poston. 1999. Tendon corrosion in precast segmental bridges. Transportation Research Record: Journal of the Transportation Research Board, No. 1654, Paper No. 99-1155.

Yang, H., and L. Yi. 2011. Inspected simulation of port anchor metal rods ultrasonic guided wave based on dispersion characteristic. Institute of Electrical and Electronics Engineers (978-1-4244-9698-3/11). 


\section{Appendix A: Pull Test Data}

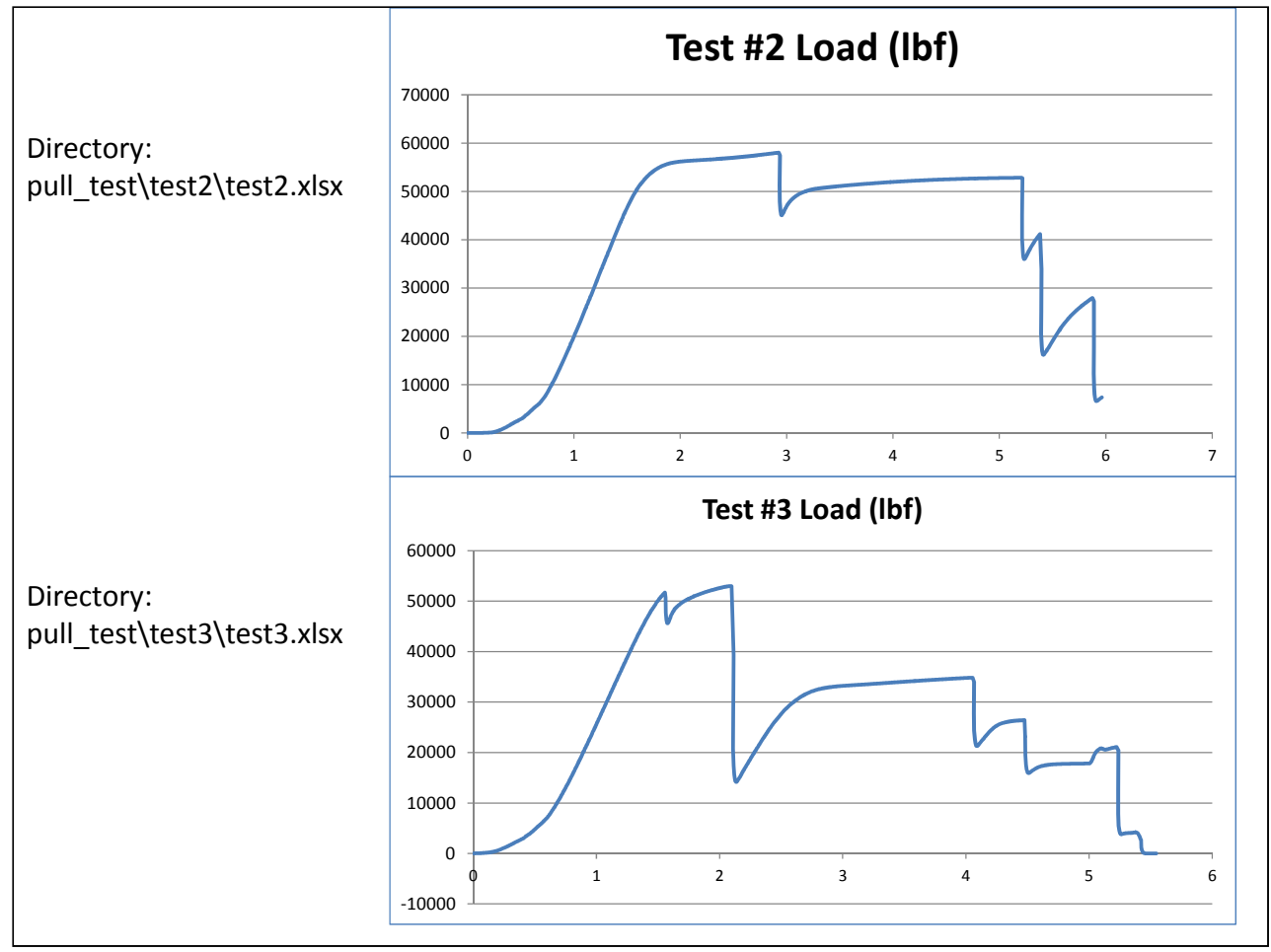

Figure A-1. Pull Tests 2 and 3. 


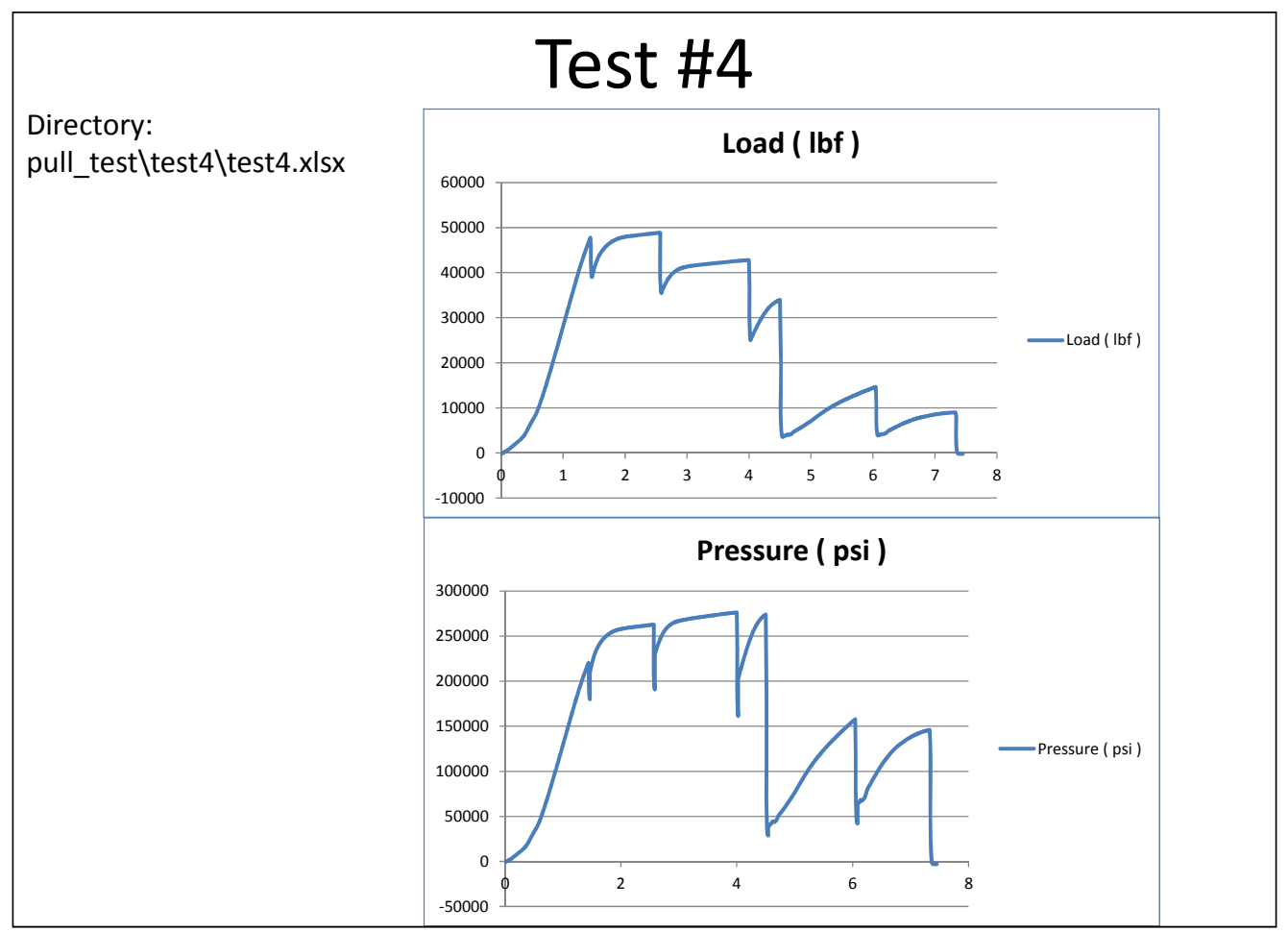

Figure A-2. Pull Test 4.

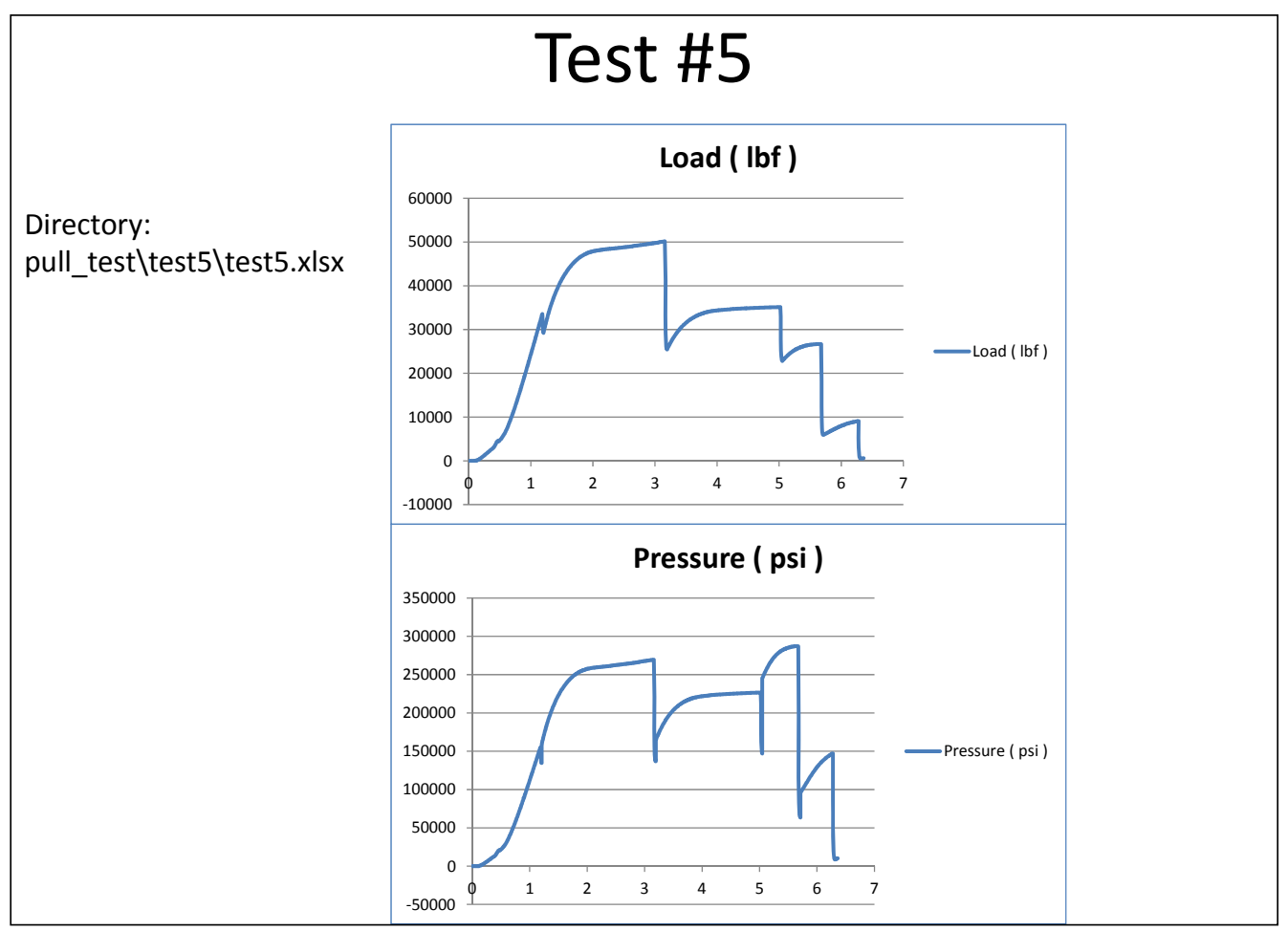

Figure A-3. Pull Test 5. 


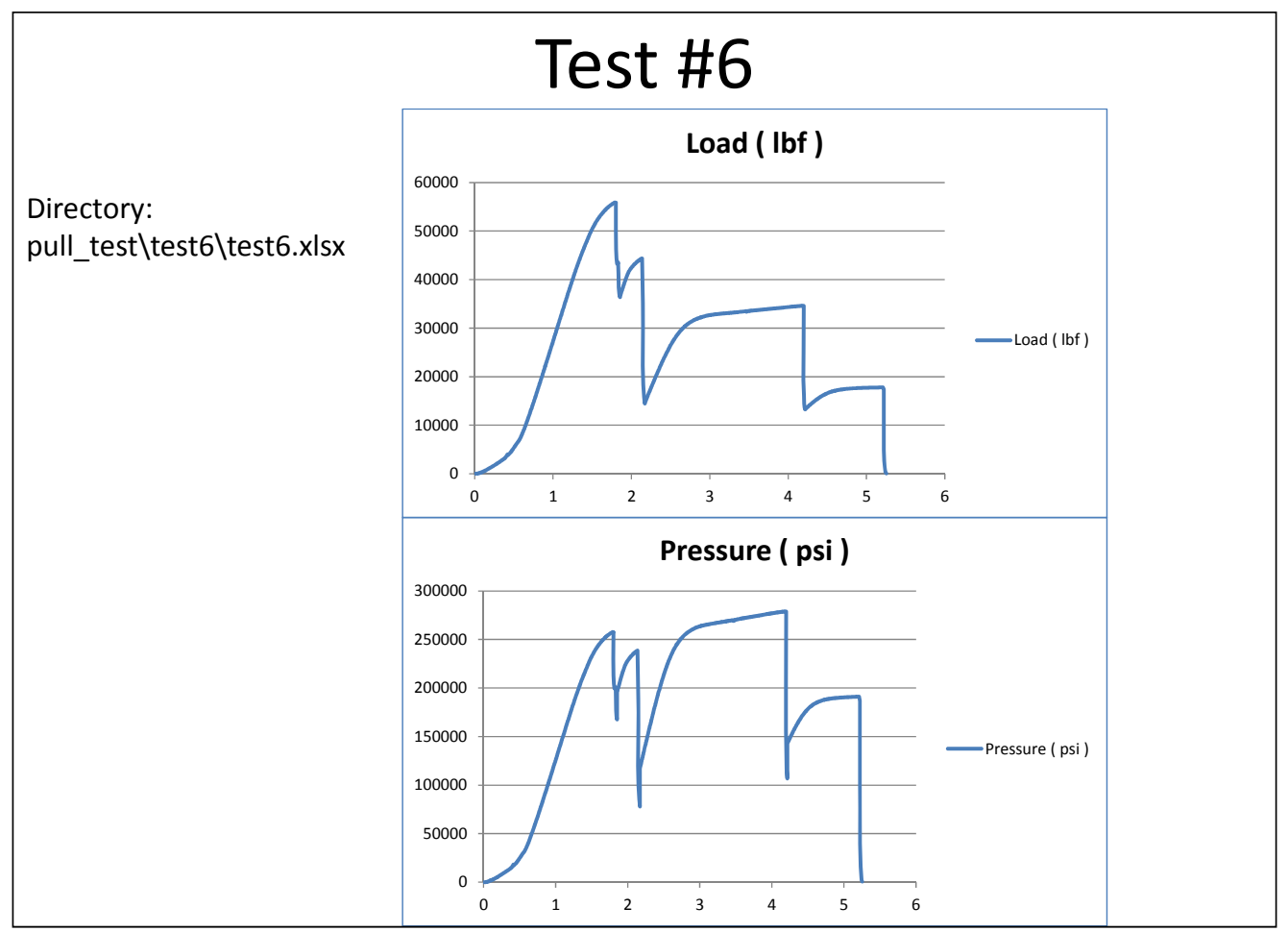

Figure A-4. Pull Test 6.

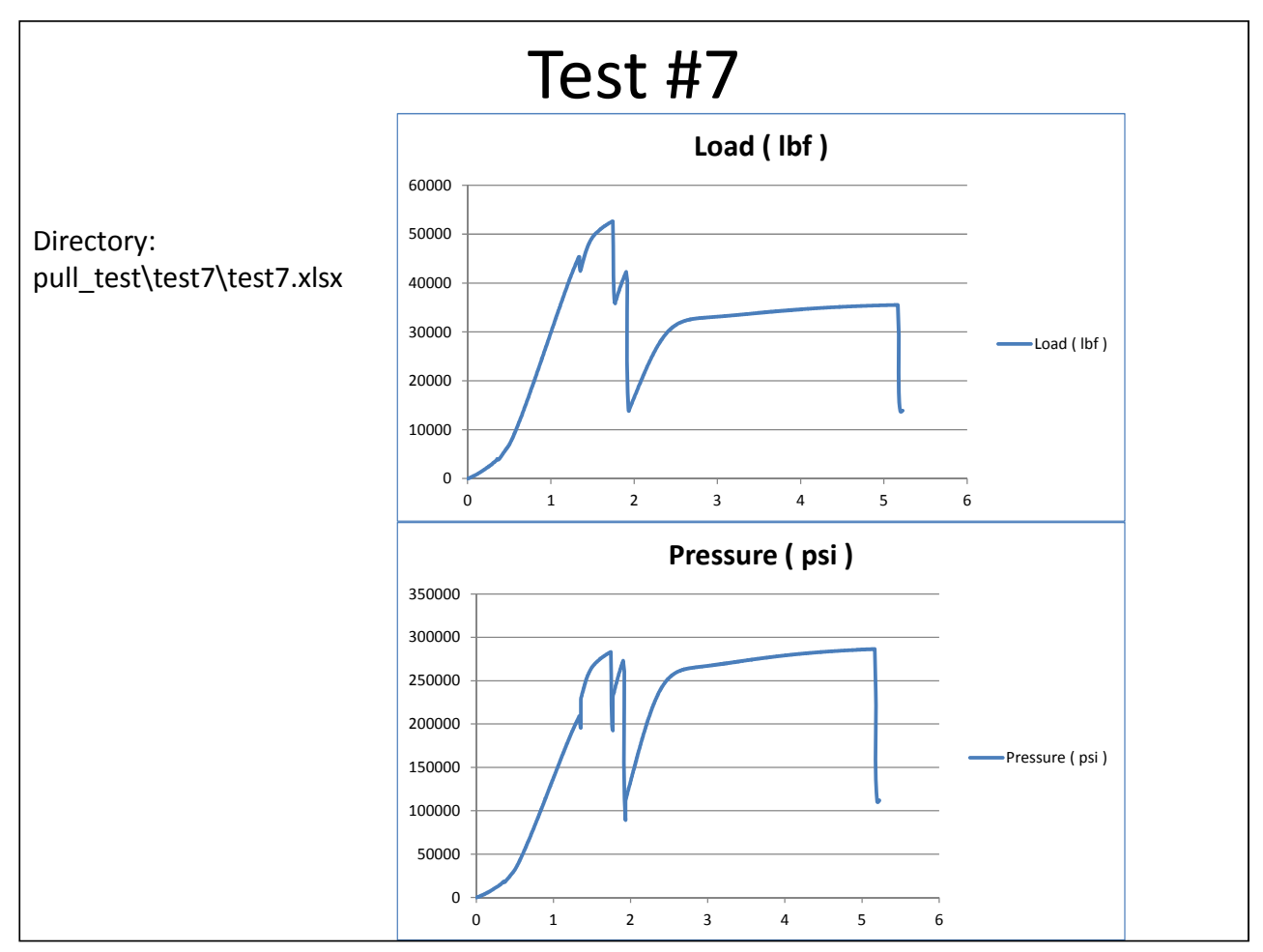

Figure A-5. Pull Test 7. 


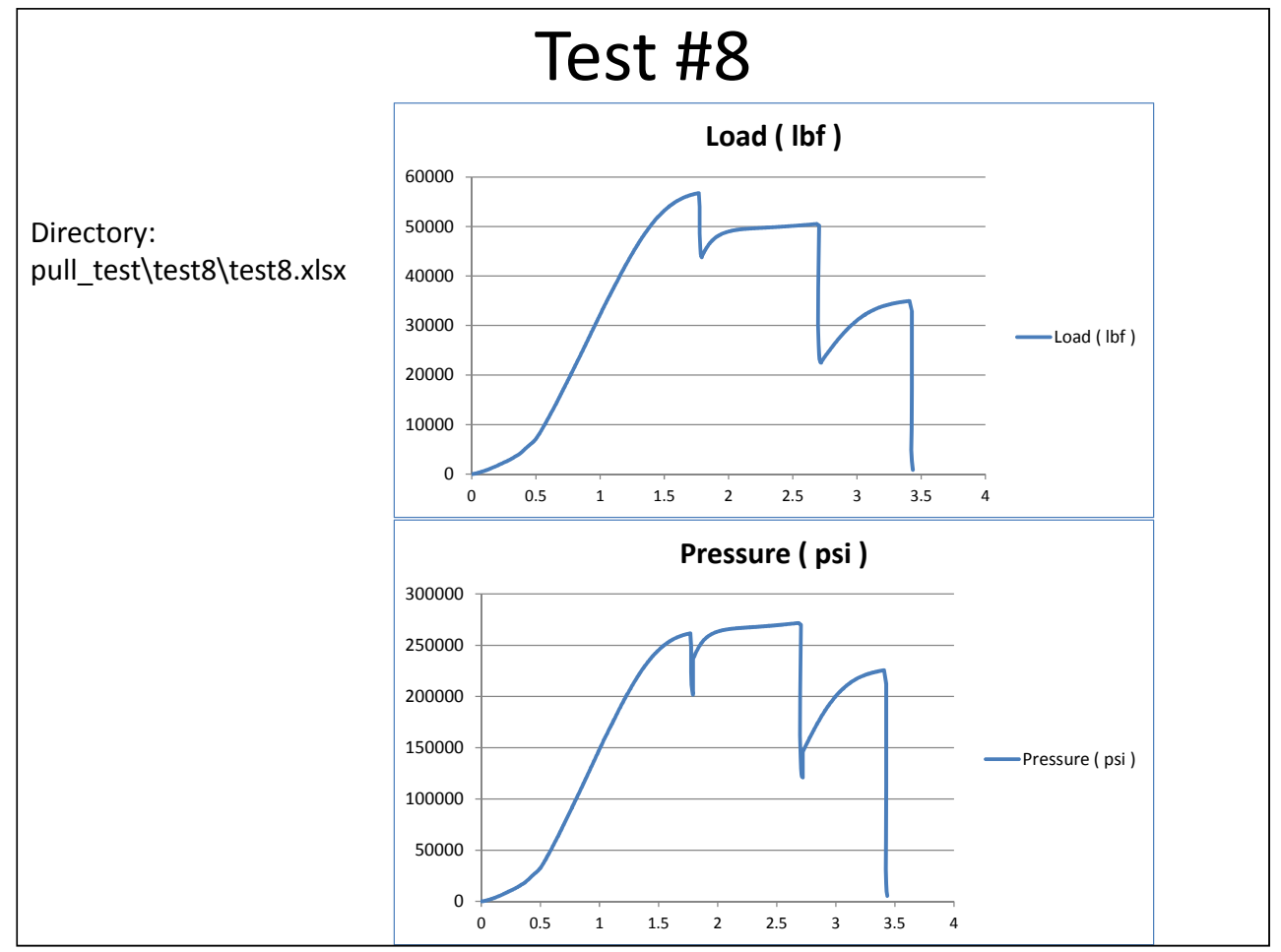

Figure A-6. Pull Test 8.

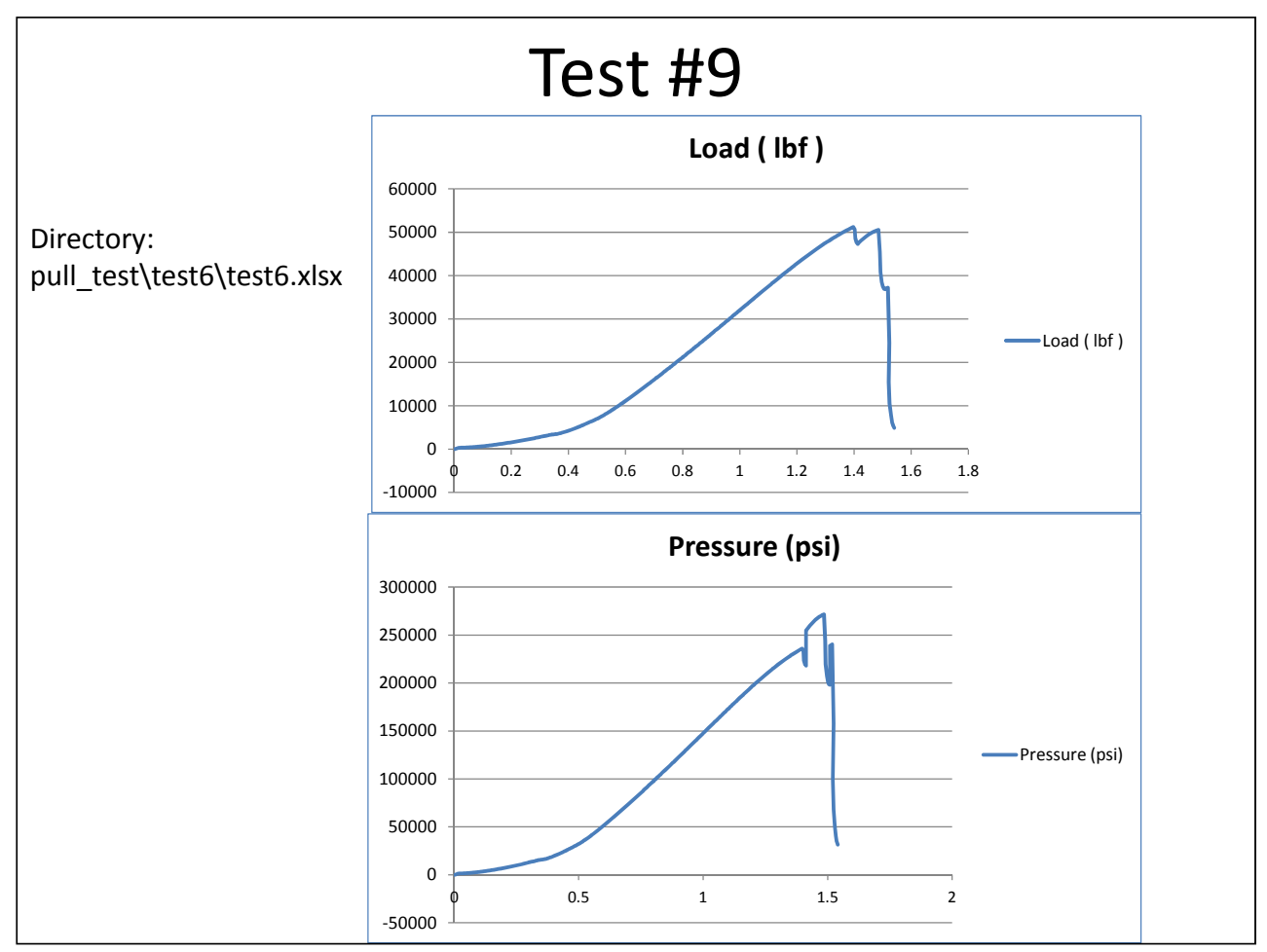

Figure A-7. Pull Test 9. 


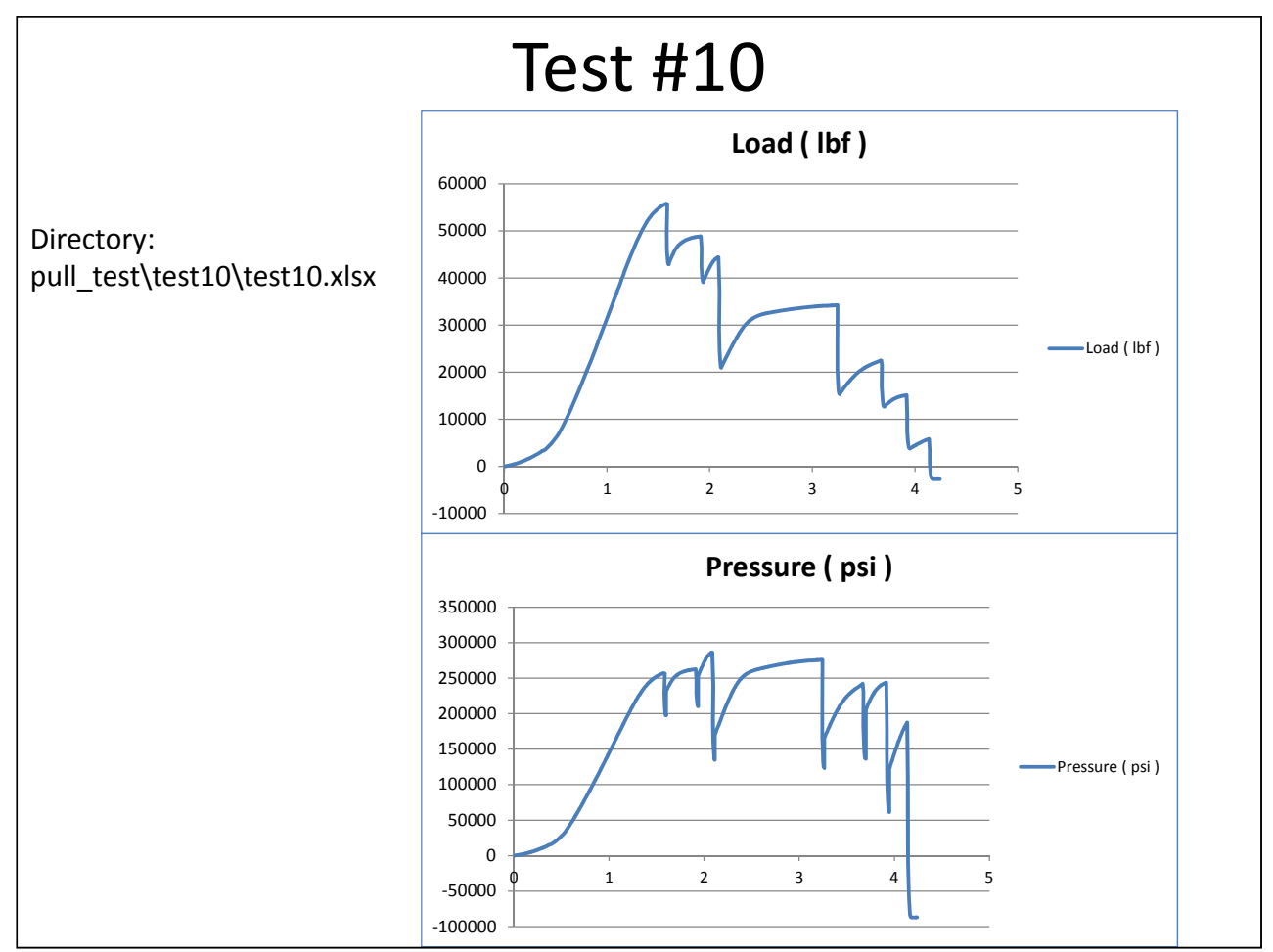

Figure A-8. Pull Test 10.

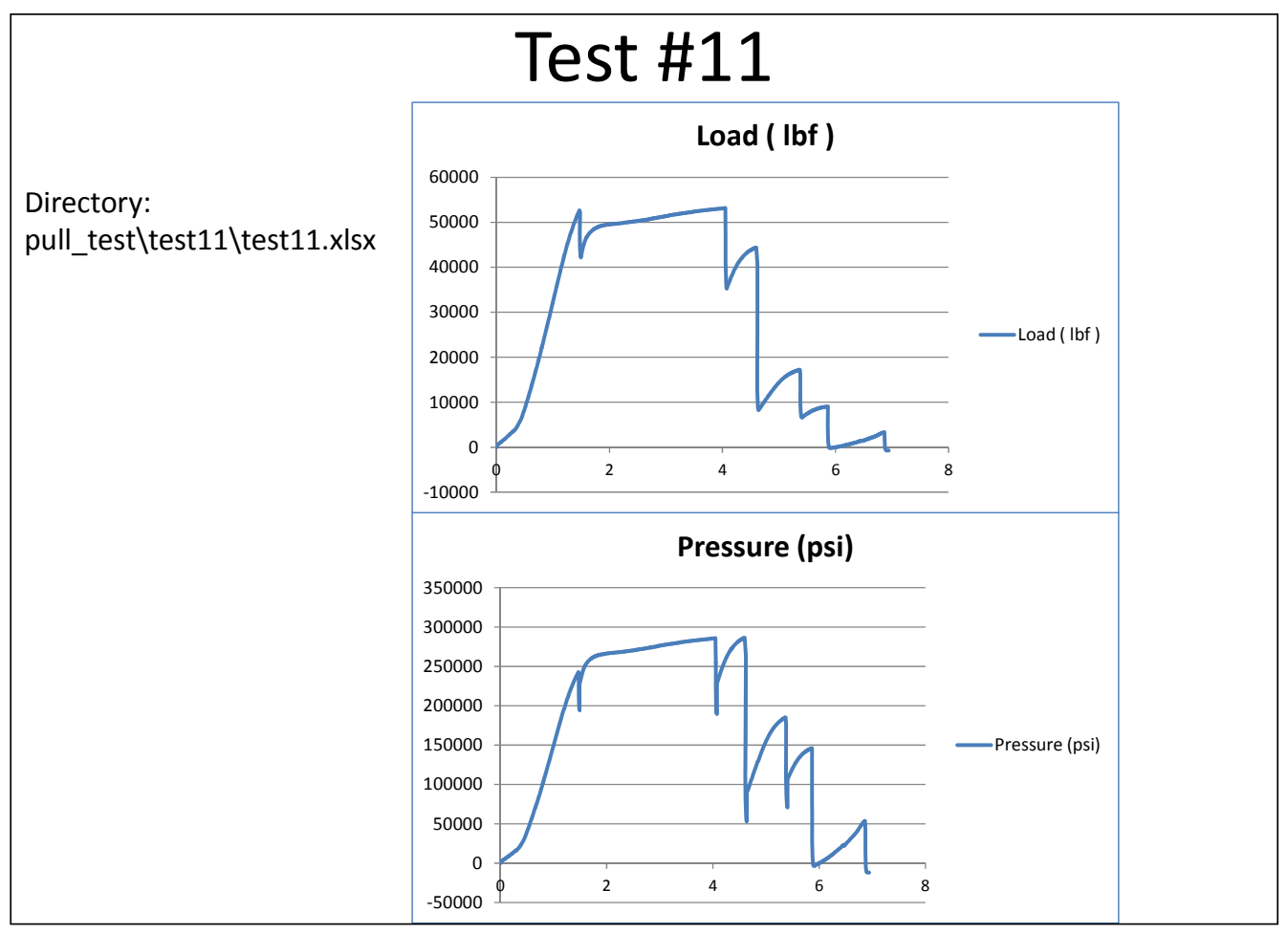

Figure A-9. Pull Test 11. 


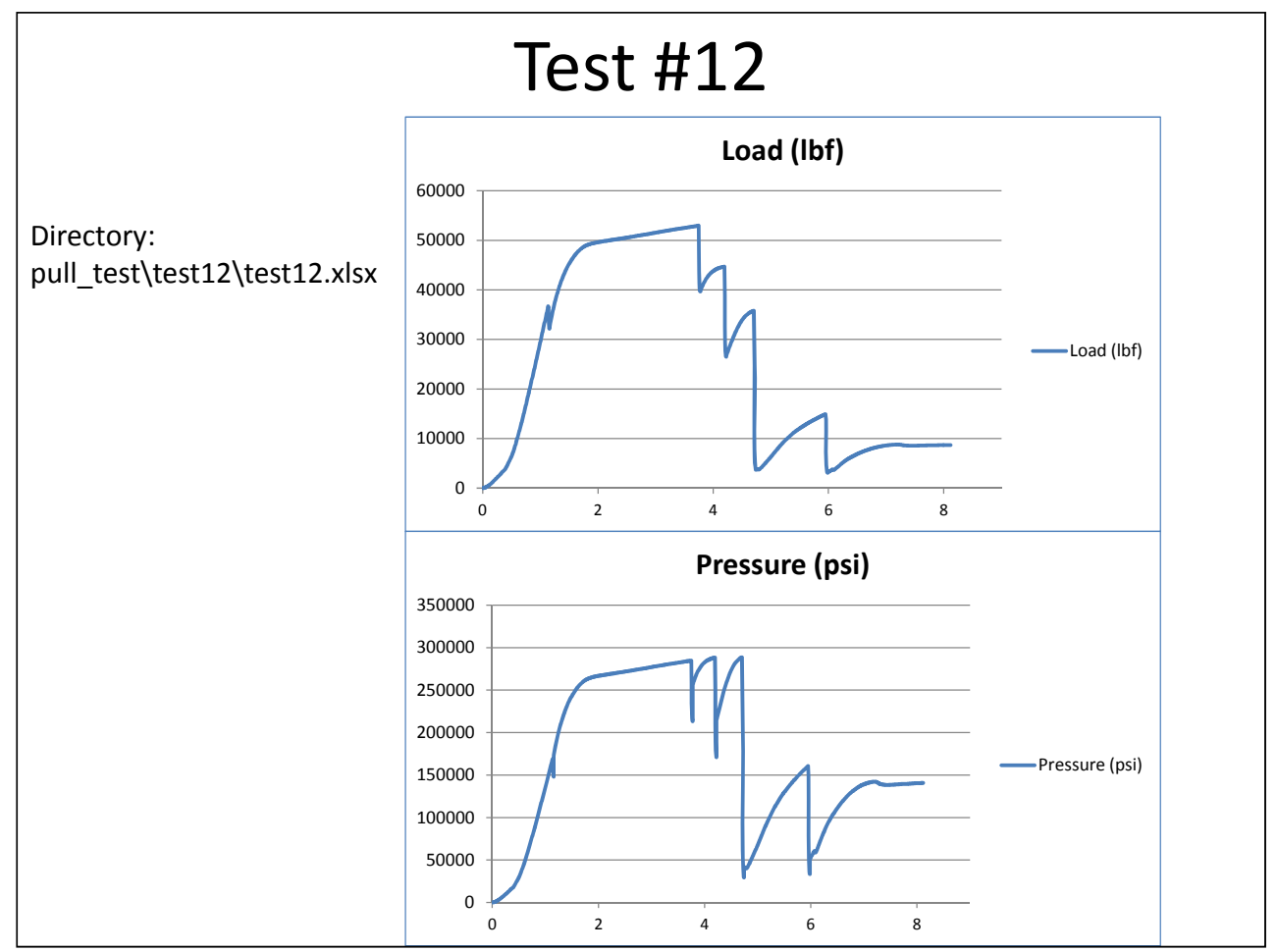

Figure A-10. Pull Test 12.

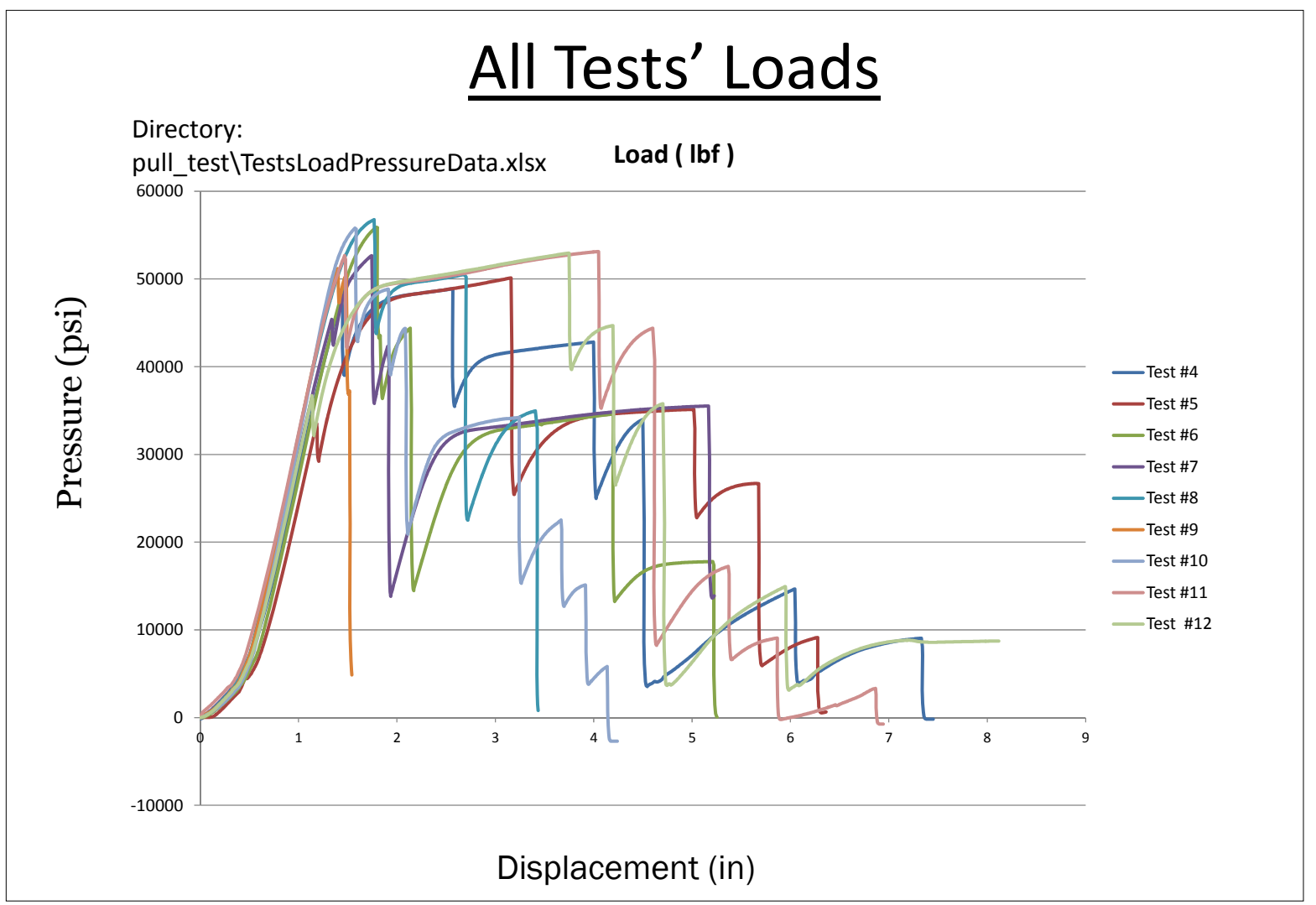

Figure A-11. Results for Pull Tests 4-12. 


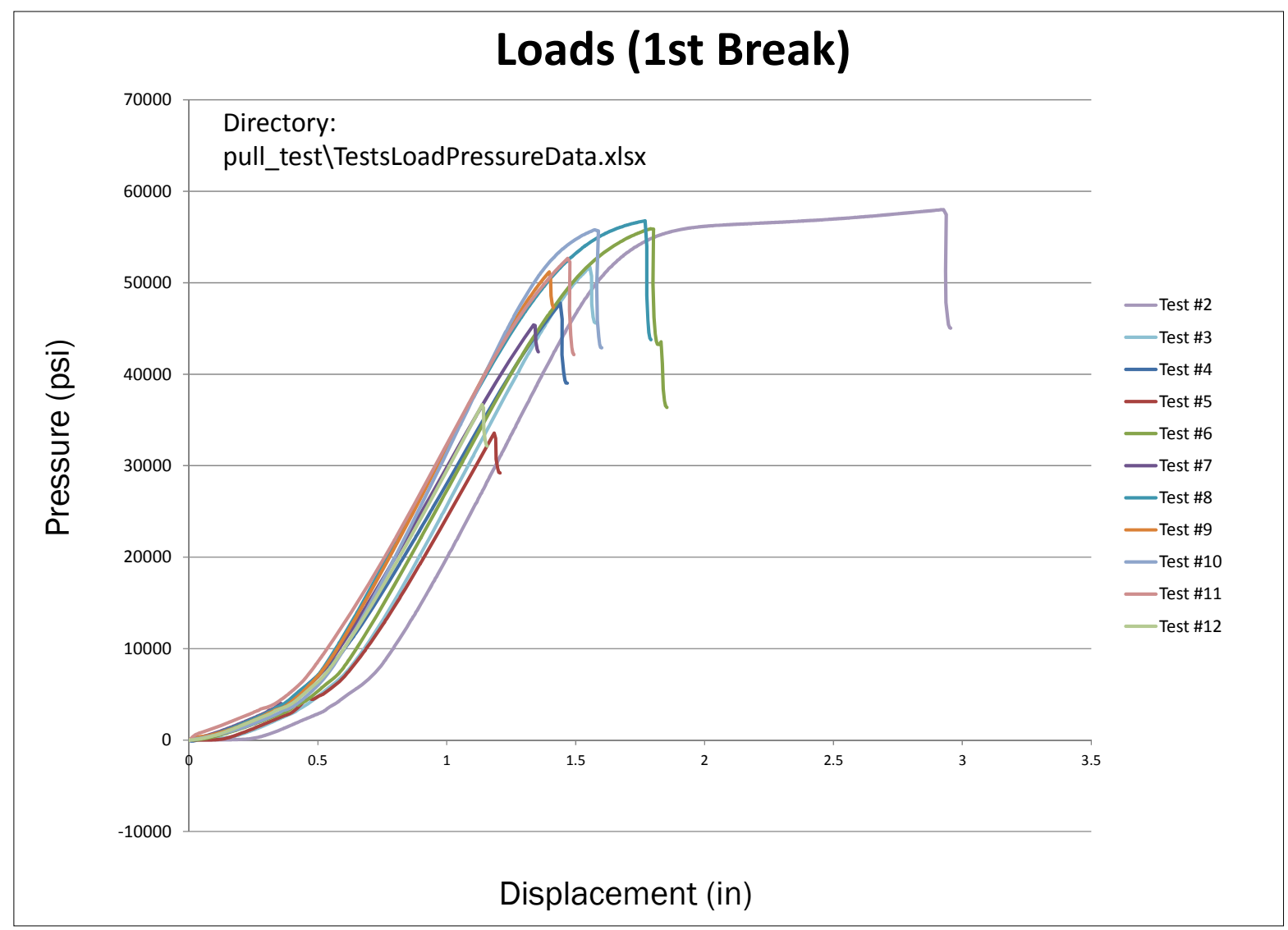

Figure A-12. Pressure vs. deflection pull test results to first wire break (Tests 2-12). 


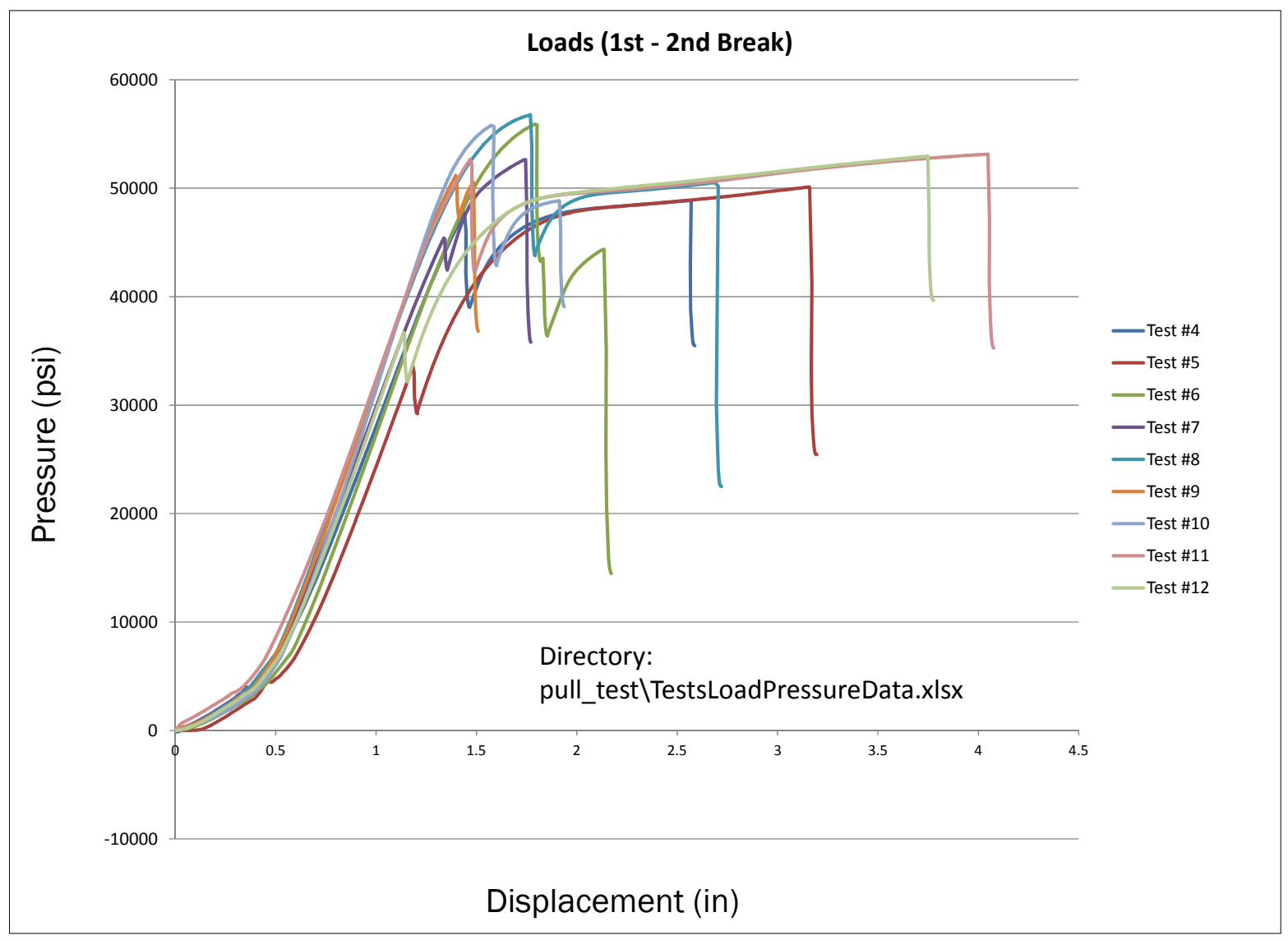

Figure A-13. Pressure vs. deflection pull test results to second wire break (Tests 4-12). 


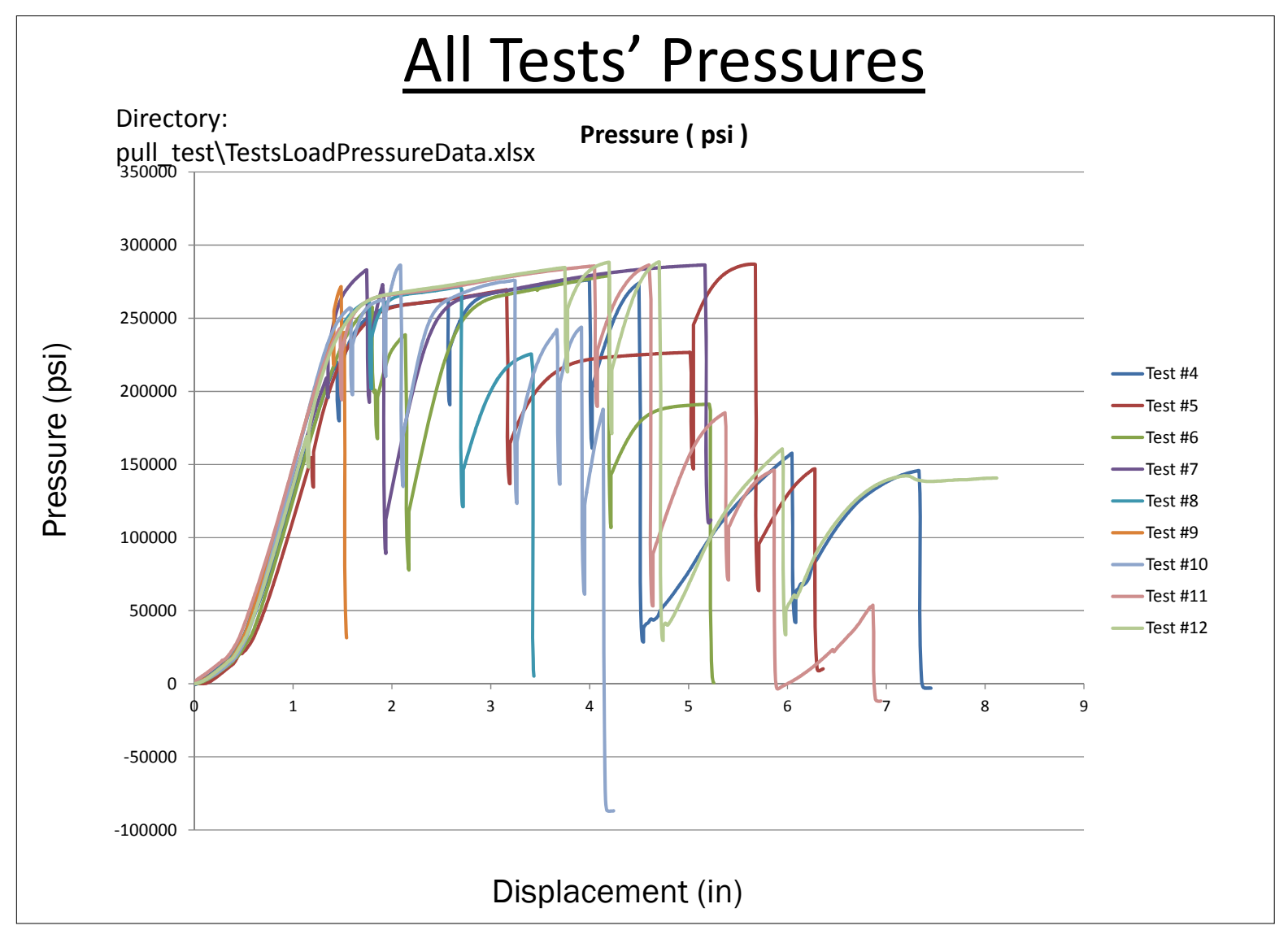

Figure A-14. Pressure vs. deflection pull test results (Tests 4-12). 


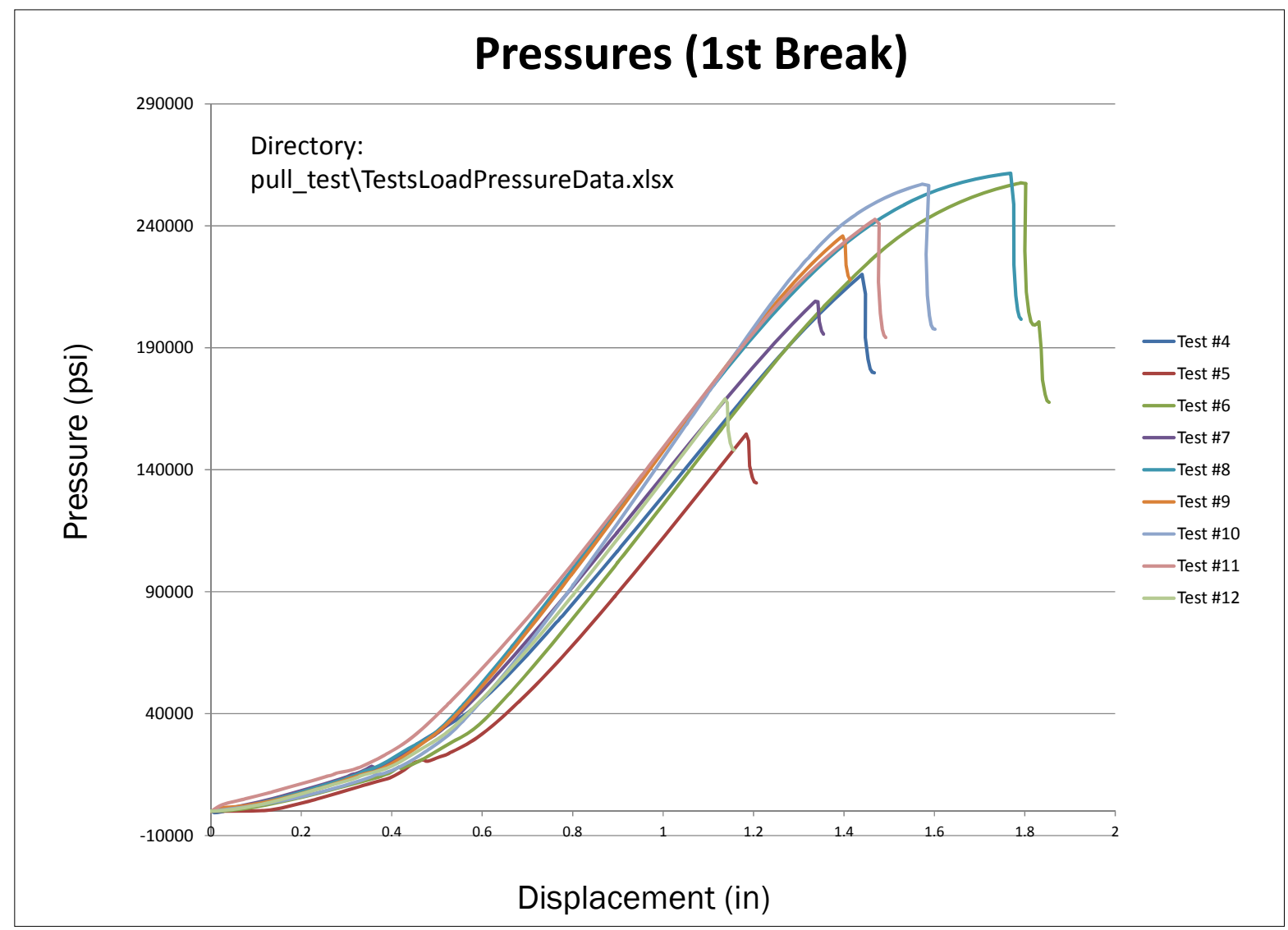

Figure A-15. Pressure vs. deflection pull test results to first wire break (Tests 4-12). 


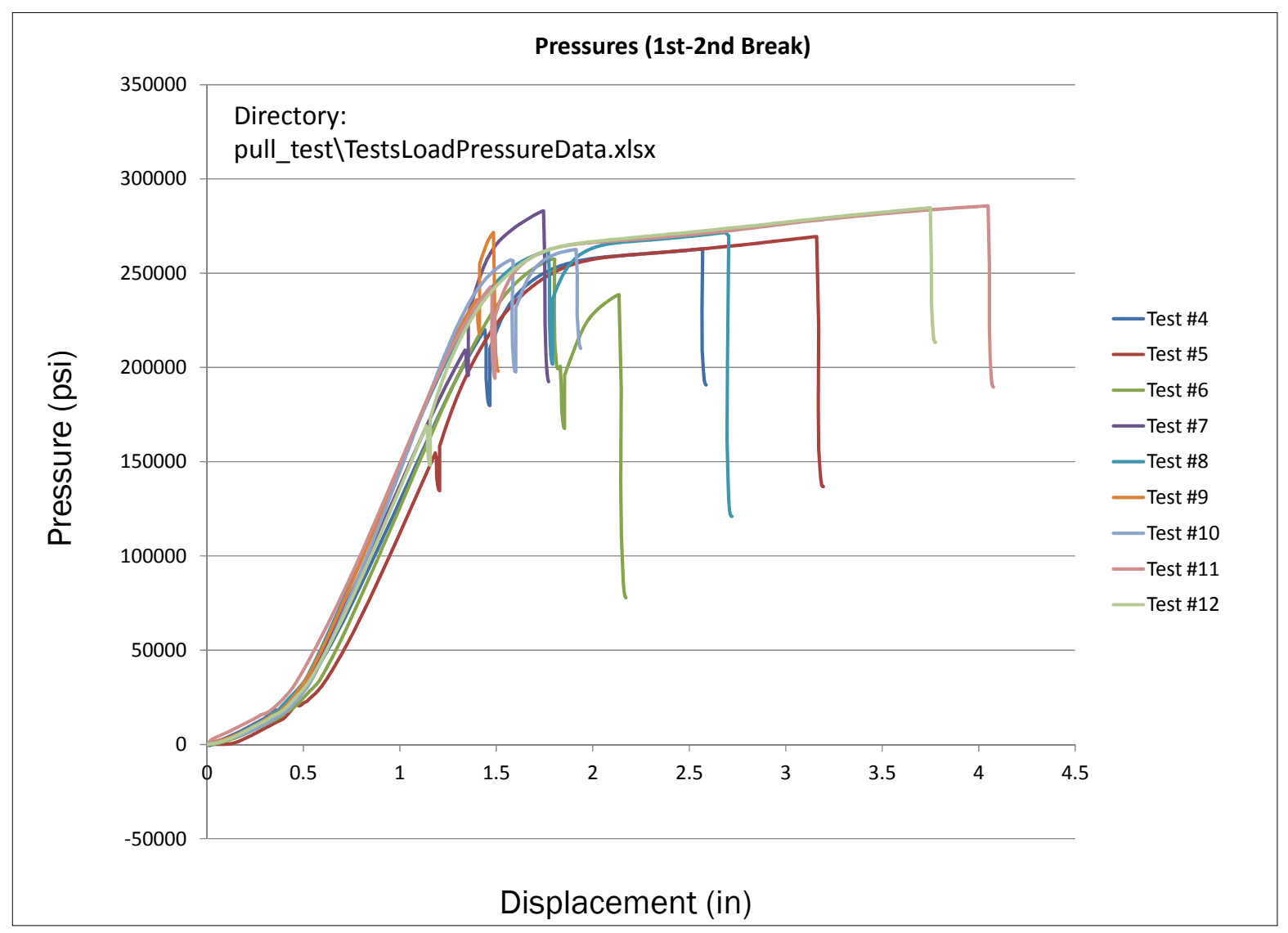

Figure A-16. Pressure VS. deflection pull test results to second wire break (Tests 4-12). 


\section{Appendix B: Literature Search of Methods Suitable for Use in Predicting Corrosion Damage and Progression}

A literature search was conducted to determine methods suitable for use in predicting corrosion damage and progression at Corps projects. The search provided valuable insight to:

1. Corrosion processes relative to metals embedded in concrete;

2. Mitigation of corrosion of metals in concrete;

3. Performance of structures subjected to corrosive environments;

4. NDT methods useful in the detection of corrosion damage to metals in concrete;

5. Analytical methods for evaluating corrosion damage.

Corrosion processes are described in: ACI $(1985,2001)$, Bertolini et al. (2004), Roberge (2008), Vu et al. (2009), and Woodtli and Kiesekbach (2000).

Corrosion mitigation measures are identified in: ACI (2011), Cooper (2005), PCI (1974), and PTI (1980, 1986, 1996, 1999, and 2004).

The performance of structures in corrosive environments are described in: Castel et al. (2011), Nurnberger (2002), Podolny (1985), Schupack and Suarez (1982), Schupack (1978, 1994a, b, c), Venugopalan (2008), and Wouters et al. (1999).

Descriptions of the various nondestructive methods available for assessing corrosion damage in structures can be found in: Azizinamini et al. (2007), Ciolko and Tabatabai (1999), Gucunski et al. (2010), Nato and Warncke (2008), Salamone et al. (2011), and Phares et al. (1999).

Information on specific NDT techniques can be found in: Harris et al. (2010), Jaeger et al. (1996), Li et al. (2005), Lyer et al. (2003), Minchin et al. (2007), and Tinkey and Olsen (2006, 2007, 2008). 
Information on the use of analytical methods for assessing the detrimental effects of corrosion damage on structures can be found in Francois et al. (2006) and for assessing the effects of broken wires in MacDougal and Bartlett (2005). 


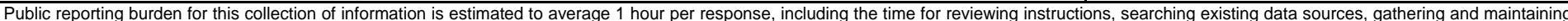

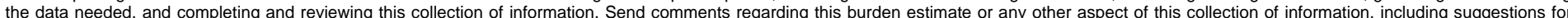

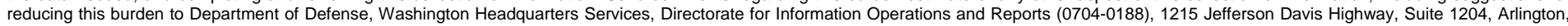

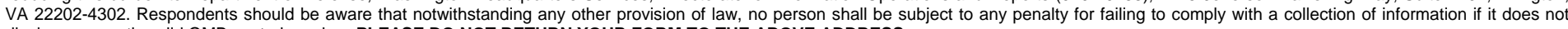
display a currently valid OMB control number. PLEASE DO NOT RETURN YOUR FORM TO THE ABOVE ADDRESS.
1. REPORT DATE (DD-MM-YYYY) 2. REPORT TYPE
July 2013 Final
3. DATES COVERED (From - To)

\section{TITLE AND SUBTITLE}

Assessing Corrosion Damage and Corrosion Progression in Multistrand Anchor Systems in Use at Corps Projects

\section{5a. CONTRACT NUMBER}

5b. GRANT NUMBER

5c. PROGRAM ELEMENT NUMBER

\section{AUTHOR(S)}

Robert M. Ebeling, Richard W. Haskins, James A. Evans, John E. Hite Jr., and Ralph W. Strom

5d. PROJECT NUMBER

5e. TASK NUMBER

5f. WORK UNIT NUMBER

\section{PERFORMING ORGANIZATION NAME(S) AND ADDRESS(ES)}

Information Technology Laboratory

US Army Engineer Research and Development Center

8. PERFORMING ORGANIZATION REPORT NUMBER

3909 Halls Ferry Road

Vicksburg, MS 39180-6199

9. SPONSORING I MONITORING AGENCY NAME(S) AND ADDRESS(ES)

10. SPONSOR/MONITOR'S ACRONYM(S)

Headquarters, US Army Corps of Engineers

HQUSACE

441 G. Street, NW

Washington, DC 20314-1000

11. SPONSOR/MONITOR'S REPORT NUMBER(S)

\section{DISTRIBUTION / AVAILABILITY STATEMENT}

Approved for public release; distribution is unlimited.

\section{SUPPLEMENTARY NOTES}

\section{ABSTRACT}

Stressed steel tendons have been used to strengthen hydraulic structures and to improve their serviceability and stability. Over the past three decades, the US Army Corps of Engineers has worked to upgrade its projects by installing high-capacity, post-tensioned foundation anchors. The goal has been to achieve structural stability for Corps hydraulic concrete structures and/or to remediate cracked concrete monoliths. Substantial improvements to protect multistrand anchor systems from corrosion have been made since they were first used at Corps projects more the 50 years ago. Corrosion of older multistrand units is of concern.

Researchers at the US Army Engineer Research and Development Center (ERDC) are looking to develop engineering procedures to estimate the current state of load-carrying capacity of the ground anchorage, to estimate remaining life of the tendon, and to establish the deterioration of anchorage capacity (with time) so costly replacement of ground anchorage can be delayed until absolutely needed. Analytical, laboratory, and field-testing efforts will be used to develop a methodology and analytical models. Probabilistic procedures will be used to quantify uncertainties for the primary variables and will be carried into the analytical model. Procedures to extend the life of deteriorating multistrand tendons also will be investigated.

A review of Corps projects using multistrand anchors and a literature review of corrosion of the anchors are summarized in this report. Also included are the history and performance of the multistrand anchors at the John Day Navigation Lock (Columbia River, Portland District), along with post-installation lift-off test results. A summary of a review of nondestructive testing (NDT) to identify defects in the anchors is part of this report, too.

\begin{tabular}{|c|c|c|c|c|c|}
\hline 15. SUBJECT TERMS & \multicolumn{2}{|c|}{ John Day Lock } & \multicolumn{2}{|c|}{ Nondestructive inspection (NDI) } & Test bed \\
\hline Corrosion & \multicolumn{2}{|c|}{ Multistrand anchor systems } & \multicolumn{2}{|c|}{ Post-tensioned foundation anchors } & Wire pull tests \\
\hline Guided wave & \multicolumn{2}{|c|}{ Nondestructive testing (NDT) } & \multicolumn{2}{|c|}{ Seven-strand wires } & \\
\hline \multicolumn{3}{|c|}{ 16. SECURITY CLASSIFICATION OF: } & \multirow[t]{3}{*}{$\begin{array}{l}\text { 17. LIMITATION } \\
\text { OF ABSTRACT }\end{array}$} & \multirow[t]{2}{*}{$\begin{array}{l}\text { 18. NUMBER } \\
\text { OF PAGES }\end{array}$} & $\begin{array}{l}\text { 19a. NAME OF RESPONSIBLE } \\
\text { PERSON: Robert E. Ebeling }\end{array}$ \\
\hline a. REPORT & b. ABSTRACT & c. THIS PAGE & & & 19b. TELEPHONE NUMBER (include \\
\hline Unclassified & Unclassified & Unclassified & & 104 & \\
\hline
\end{tabular}

